\title{
THE PRIMORDIAL CRANIUM OF THE CAT
}

\author{
ROBERT J. TERRY \\ Department of Anatomy, Washington University Medical School \\ THIRTY FIGURES (TWELVE PLATES)
}

\section{CONTENTS}

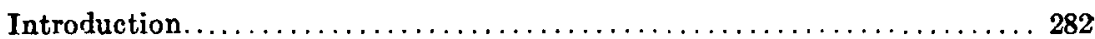

Material and methods....................................... 285

Part I. Observations.................................... 287

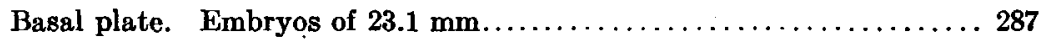

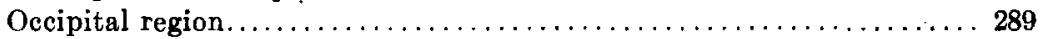

Atlas and epistropheus................................ 293

Basal plate and occipital region in smaller embryos .............. 294

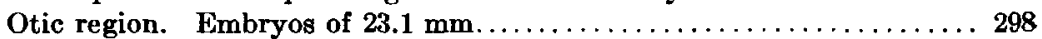

Pars canalicularis. Outer form . . . . . . . . . . . . . . . . . . . . 299

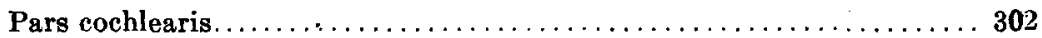

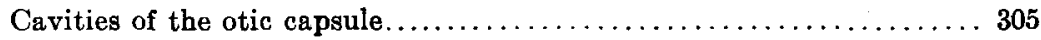

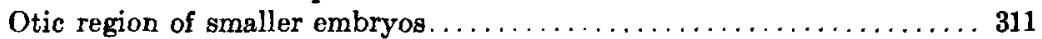

Nerves in the otic region................................... 314

Blood vessels in the otic region.......................... 316

Orbito-temporal region in embryos of $23.1 \mathrm{~mm} \ldots \ldots \ldots \ldots \ldots \ldots \ldots 317$

Orbito-temporal region in smaller embryos.................... 325

Ethmoidal region in embryos of $23.1 \mathrm{~mm} \ldots \ldots \ldots \ldots \ldots \ldots \ldots \ldots \ldots$

Ethmoidal region of smaller embryos..................... 340

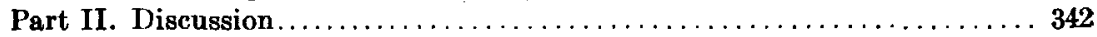

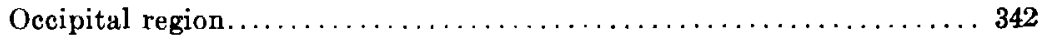

Basal plate................................. 342

Atlas............................................ 351

Occipito-atlantal articulation............................ 353

Plane of the foramen magnum.......................... 354

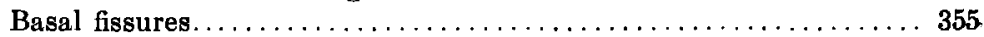

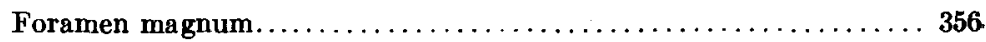

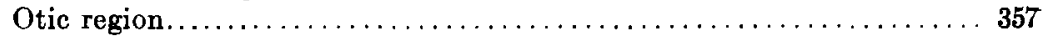

Position of the otic capsules......................... 357

Origin of the cartilaginous otic capsule.................. 359

Foramina acustica and meatus acusticus internus........... 363

Foramen perilymphaticum........................... 364

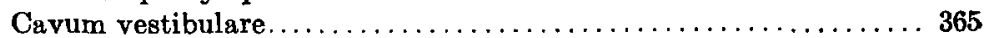

Lamina parietalis and tectum posterius................... 366

Facial and acustic nerves............................ 369

281

JOURNAL OF MOAPHOLOGY, YOL. 29, NO. 8

SEPTEMB ER, 1917 
Orbito-temporal region. $\ldots \ldots \ldots \ldots \ldots \ldots \ldots \ldots \ldots \ldots \ldots \ldots \ldots \ldots \ldots \ldots$

Hypophyseal cartilage........................ 370

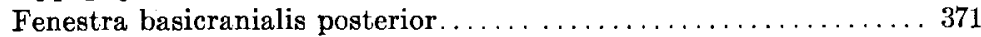

Crista transversa and dorsum sellae. . . . . . . . . . . . 371

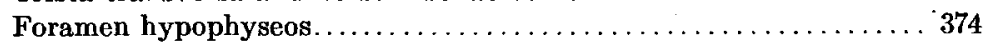

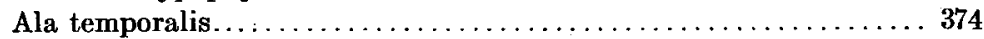

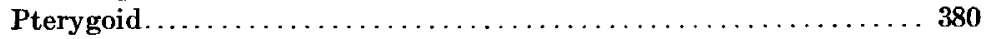

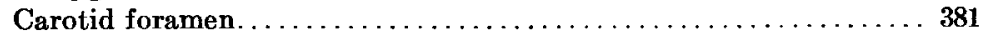

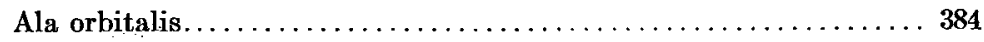

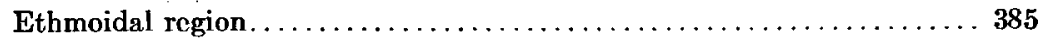

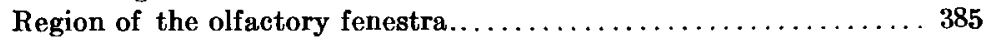

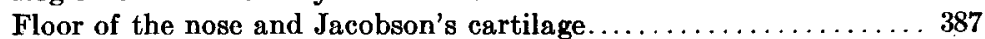

Tectum nasi................................... 390

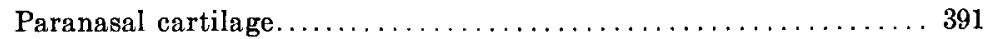

Lamina antorbitalis. . . . . . . . . . . . . . . . . . . . . . . 394

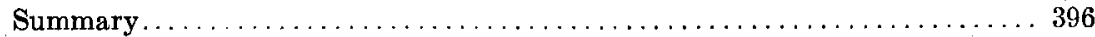

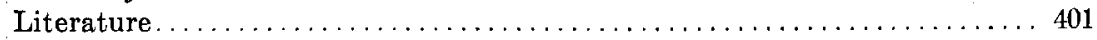

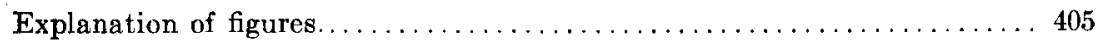

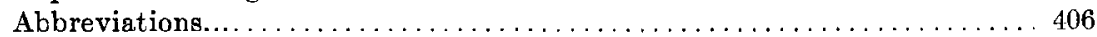

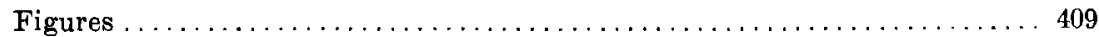

\section{INTRODUCTION}

Studies of the primordial cranium of mammals have in most instances dealt with but a single stage, and offer, therefore, almost no data on developmental processes. Moreover, there seems to be a tendency, unfortunately, to pursue the study after this manner and so to continue limiting inquiry to the methods of comparative, descriptive anatomy. This criticism cannot be made of investigation of the crania of the ichthyopsida. It has been rather the rule than the exception for research in this group to include as complete a survey of developmental processes as the technique of the time permitted; that is, the studies proceeded toward the solution of cranial problems by comparative embryological methods. No doubt, certain physical conditions have in the one case been an obstacle to embryological work. The difficulty of securing material in control and of sufficient amount, and the great extent to which the investigation of even a few stages leads one, are factors which have determined in no small degree the methods and results of research on the crania of higher forms. However, these difficulties are not serious and should not stand in the way of gaining for the mam- 
malian cranium that knowledge of its development which is so much desired.

For the study of problems of the mammalian primordial cranium, the domestic cat offers material possessing certain advantages. In general, the processes of chondrification proceed sufficiently slowly to permit of easy determination of the origin of parts and of subsequent study of their individual histories. Also, the cat among the domestic mammals has remained standardized to a degree not exceeded, if equalled, by any other, and is on this account of value for anatomical study. Yet, notwithstanding these points in its favor, the house cat has not been utilized for cranial study to the extent that might be anticipated. There is at the present time no paper on the development of the cranium as a whole and no extensive description of a single stage in the course of its development. Not even Parker described the primordial cranium of the domestic cat. The only investigation which attempts to deal with the whole chondrocranium is that by Decker in which brief accounts of two rather advanced stages are presented. Wincza's communication discusses a number of questions, for the solution of which cat material has been employed, but it does not include all regions of the cranium. This valuable paper is available to a relatively small number of investigators since it was published in the Polish language.

What has been said in regard to cat for the study of the whole chondrocranium does not apply in the case of investigations of special problems, although even in the latter case this material has been used to a more limited extent than might be expected. Of the cranial regions usually recognized, the occipital in cat has received less attention than have the others. The otic region is represented by a number of papers concerned for the most part with late embryonic stages and adult conditions. Among these, the publications of Spence, Bondy, van Kampen, and Denker have been consulted in the present work. Wincza's paper deals especially with the ala temporalis and carotid foramen; an article by Arai includes the cat in a study of the craniopharyngeal canal, and a paper by Williams deals 
with the notochord in its later history. In the ethmoidal region interest has been centered upon the skeletal structure of the floor of the nose. Harvey, Broom, and Zuckerkandl have each contributed valuable descriptions of the cartilaginous framework about Jacobson's organ and the incisive ducts in cat.

In the present paper the monographs on the anatomy of cat by Strauss-Durckheim, Wilder and Gage, Jayne, and Reighard have been very helpful, as have those works of a more general scope, but including the cat, by Chauveau, Paul Martin, and Weber. Finally should be mentioned those studies, in which cat has offered the material, of head structures other than the cranium which are inseparably connected with the problems of the skeleton, many of which have aided the present investigation. Among these are, specially, Retzius' researches on the ear; Göppert and Corning on the ocular muscles; Peter, Born and Seydel on the nose; Froriep and van Wijhe on the occipitospinal nerves.

This paper is concerned with some of the problems of cranial development in mammals, the chondrocranium (exclusive of the visceral skeleton) in cat serving as the material for study. It was the intention to give the descriptive portions of the several cranial regions, as far as possible equal treatment, but to limit the discussion to a few problems upon which some light was thrown by the structure and development of the cranium in the particular form under consideration. The occipital region was looked to with keen interest as an unworked field for observation, and for any evidence of those processes revealed by Weiss, Gaupp, and Weigner in mammals which indicate a close resemblance to, if not an actual repetition of the steps in the development of the atlas. As stated above, the work on the otic region, hitherto, treats of late embryonic and adult conditions. In the present paper, attention has been directed mainly to conditions of early development, such as the origin of the cartilaginous otic capsule, the comparison of the embryonic vestibule with that of reptiles and the theoretical questions concerned with the development of the cochlear skeleton. Consideration of questions relating to the development and signifi- 
cance of the ala temporalis and to the formation of the hypophyseal skeleton forms the main part of the study of orbitotemporal region. Concerning the origin and early history of the ethmoidal skeleton of mammals comparatively little is known, whereas, on the contrary, a great literature exists on the development of the nasal conchae, floor of the nose and nasal sinuses. Cat material was found favorable for the investigation of many early processes of ethmoidal development, and to a discussion of these, practically the whole of the section on the ethmoidal region has been devoted.

\section{MATERIAL AND METHODS}

The present study starts with a cat embryo of $23.1 \mathrm{~mm}$., series no. 466 of the Harvard Embryological Collection. From this, a model of the chondrocranium was reconstructed by students of the Harvard Medical School under the direction of the author while a teaching fellow in histology in that institution. ${ }^{1}$ The model, enlarged thirty-three times, includes, in addition to the chondrocranium, the ossifications, main bloodvessels and nerves. It is an example of care and industry and as such has been on the one hand invaluable as material for study and on the other a reminder of the enthusiasm and earnest effort of those students, then in their first year of medical study, Messrs. G. D. Cutler, I. Gerber and R. D. Leonard, who responded to the suggestion to undertake the labors of cranial reconstruction.

Through the kindness of the late Professor Minot and Professor F. T. Lewis, the model, together with the following series of cat embryos from the collection at the Harvard Medical School, was placed at my disposal in St. Louis.

\footnotetext{
1 The model was reconstructed in 1907 . The present investigation was undertaken in St. Louis several years later but on account of interruptions its progress was delayed. I take this opportunity to acknowledge the many courtesies of Prof. J. S. Kingsley and the staff of the Marine Biological Laboratory at South Harpswell, Maine, where during the summer of 1915 it was my privilege
} to work. 

Cat $9.7 \mathrm{~mm}$., frontal,
Series 448
Cat $10.6 \mathrm{~mm}$., frontal, Series 476
Cat $12.0 \mathrm{~mm}$., frontal, Series 404
Cat $12.0 \mathrm{~mm}$., horizontal of head, Series 403
Cat $12.0 \mathrm{~mm}$., sagittal,
Series 400
Cat $17.0 \mathrm{~mm}$. , sagittal,
Series 492

I am indebted also to Professor Huntington for the use of series of cat embryos of the following stages, from the collection at the College of Physicians and Surgeons, Columbia University.
Cat $10 \mathrm{~mm}$. , Series 500
Cat $11 \mathrm{~mm}$., Series 473
Cat $12 \mathrm{~mm}$., Series 263
Cat $13 \mathrm{~mm}$., Series 262

From the collection in the Department of Anatomy of Washington University the following were studied:

$\begin{array}{lr}\text { Cat } 12 \mathrm{~mm} ., \text { frontal, } & \text { Series } 50 \\ \text { Cat } 12 \mathrm{~mm} ., & \text { transverse, Series } 52 \\ \text { Cat } 15 \mathrm{~mm} ., & \text { transverse, Series } 56 \\ \text { Cat } 17 \mathrm{~mm} ., & \text { Series } 80 \\ \text { Cat } 17 \mathrm{~mm} ., \text { sagittal, } & \text { Series } 81 \\ \text { Cat } 17 \mathrm{~mm} ., \text { transverse, Series } 82\end{array}$

Several special reconstructions were made of complex regions. One is of the left otic capsule of the $23.1 \mathrm{~mm}$. embryo; a second represents the course and relations of the facial nerve in the same specimen; a third, the eye-ball and its muscles in relation to the chondrocranium; a fourth the cranial relations of the notochord. The atlas and epistropheus were included in the main model. The base of the cranium in the region of the carotid artery was reconstructed from a $12 \mathrm{~mm}$. embryo; from the same a reconstruction of the hypophyseal cartilage was made. The nasal capsule and nasal sac have been modeled from an embryo of $17 \mathrm{~mm}$.

The study of all stages of the chondrocranium was facilitated by a collection of preparations made by the van Wijhe ('02) 
method. These are of great value for studies of the cartilaginous skeleton, especially when used in comparison with the sections. Cat embryos were fixed in formalin, stained with methylene blue, decolorized, cleared and preserved in liquid Canada balsam. The last procedure, which departs slightly from van Wijhe's final treatment, is of much advantage in permitting the free handling and turning of the specimen so that it may be easily observed from every aspect. The following stages were prepared and studied: Cat embryos of $10 \mathrm{~mm} ., 12 \mathrm{~mm} ., 15 \mathrm{~mm}$., $17 \mathrm{~mm}$., $20 \mathrm{~mm}$., $24 \mathrm{~mm}$., $30 \mathrm{~mm}$., and $35 \mathrm{~mm}$.

As stated above, the present paper centers upon a particular stage, with which earlier and later stages have been compared. In accordance with this method the structures of each region of the chondrocranium as found in the stage of $23.1 \mathrm{~mm}$., that is, the stage of the model, are first described, then younger stages are considered.

\section{PART I. OBSERVATIONS}

Basal plate.-Embryos of $23.1 \mathrm{~mm}$.

The term basal plate is used here to designate that portion of the floor of the chondrocranium corresponding in cephalocaudal extent with the cranial part of the notochord, and in lateral extent to the level of the basal foramina and cochlear capsule.

The basal plate in the embryo of $23.1 \mathrm{~mm}$. is represented in figures 1, 2 and 3. In the otic region it is very narrow; in the occipital region, on the contrary, very broad. Foramina are present at the margin of the basal plate, between it and the cranial side walls, but no openings exist in the plate itself. These marginal foramina are the fissura basi-cochlearis posterior, the jugular and hypoglossal foramina.

The anterior, or otic portion of the basal plate, subcylindrical in shape, lies between the cochlear prominences, and, within 
the. cranium, forms the bottom of a deep sulcus whose sides are constituted by the median walls of the cochleae. This sulcus is occupied by no part of the brain, but is filled with a loose web of mesenchymal tissue, in which the basilar artery and abducent nerves run (fig. 22). Continuity between the cochlear prominence and basal plate is brought about by means of a thin strip of cartilage interrupted by the marginal foramina above mentioned. This strip is merely a septum between two oppositely placed grooves, one outside, the other within the cranium, which, in their semicircular courses, demarcate the limits between the ear capsule and cranial floor (figs. 1, 2). These grooves extend anteriorly on the outside of the cranium beyond the confines of the basal plate and include the carotid foramina; posteriorly, both within and without the cranium, they have a somewhat lateral direction between the occipital division of the floor and the otic capsule. Here are two large openings, the jugular foramen, to be presently described, and the fissura basicochlearis posterior (figs. 2, 12). The latter is sickle-shaped, broad laterally where it approaches the jugular foramen, from which it is separated by the commissura basivestibularis. It gives passage to no nerve or large vessel.

The occipital portion of the basal plate forms the floor of the occipital region of the cranium. It presents a slightly concave intracranial surface and a convex face directed toward the nasopharyngeal duct; at the sides it is continuous, at the level of the hypoglossal canals and jugular foramina, with the lateral occipital walls. The caudal free margin is concave from side to side, forming the ventral margin of the foramen occipitale magnum, where on each side is the basal, smaller part of the occipital condyle (fig. 19); between these is a shallow incisura occipitalis anterior.

The following observations were made on the position, relations and termination of the cranial portion of the notochord. As shown in figures 14 and 19, this structure passes through the middle of the body of the epistropheus, inclines ventrally on entering the dens, and holds a position ventral of the middle of the dens throughout the rest of its vertebral course. It leaves 
the dens from the ventral surface, not at its extremity, and enters the ligamentum apicis dentis. It then passes over into the cranium, lying at first just beneath the perichondrium of the dorsal surface of the cranial floor, with the great thickness of the caudal edge of the basal plate beneath it. From this point the chorda dips into the cartilage of the floor as it extends forward, lying midway between the cranial and pharyngeal surfaces in the middle third of the plate. At no point does it sink nearer the pharyngeal surface nor was there observed any trace of a connection with the pharyngeal wall. Proceeding toward the sella turcica, the notochord gradually approaches the intracranial surface of the basal plate, until it attains the level of the dorsum sellae where it makes a rather abrupt bend so as to come to lie beneath the perichondrium of the caudal surface of the back of the saddle. Its terminal piece is marked by distortion to some extent and by a few irregular turns. Although shrunken in many places, and showing other evidences of degeneration, the head notochord is, nevertheless, continuous throughout. Within the apical ligament it is considerably expanded.

\section{Occipital region}

From the basal plate, the side walls of the occipital region, the lateral occipital arches, continue laterally and dorsally, becoming confluent with the otic capsule, parietal plate and tectum posterius (figs. 1, 2, 3, 4). They lie in a plane transverse to the longitudinal axis of the posterior half of the cranium, but, owing to the flexure of the long axis of the whole cranium, this is at the same time, parallel with the plane of the floor of the nose.

The lateral occipital arches are connected with the pars canalicularis of the otic capsule by synchondrosis, marked in the sections by a narrow plane of young cartilage extending a considerable distance from the jugular foramen toward the parietal plate. Within the cranium a deep, wide groove, the sulcus sigmoideus, lodging the transverse sinus, lies opposite the ventral portion of the synchondrosis and leads to the jugular 
foramen. Outside the wall a corresponding groove separates the paracondyloid process (figs. 2,3) from the pars canalicularis of the otic capsule. The caudal free margin of the lateral occipital arch enters into the boundaries of the foramen magnum (figs. 1, 2, 3). Its ventral portion forms the larger part of the occipital condyle; its dorsal portion, a rough angular process directed medially. The processes of opposite sides mark the dorsal limit of the foramen magnum at this stage and afford attachment to the spino-occipital membrane. Dorsad of the level of these processes the lateral occipital arches are continued into the broad, curved posterior portions of the parietal plates, between which the tectum posterius extends. in an arch from side to side.

Within the cranium, at the junction of basal plate and lateral occipital arch, is a rounded prominence, the cartilaginous precursor of the tuberculum jugulare, separating the entrance to the hypoglossal canal from the fossa occipito-canalicularis (fig. 1). At its cephalic end, this elevation, broadening considerably, becomes continuous with the basi-vestibular commissure (figs. 9, 10, 19). This commissure is united with the otic capsule at the boundary between the medial wall of the prominentia utriculo-ampullaris inferior and the cochlear capsule, and forms here a prominence making the posterior wall of the internal acustic meatus. The jugular tubercle, which presents much more the form of a ridge than of a tubercle, stands within the cranium opposite the paracondyloid process. Both processes contribute to the formation of the deep caudal wall of the jugular foramen, a relation observed by von Noorden in the human embryo. The occipito-canalicular fossa lies between the inferior ampullary eminence and the basivestibular commissure and connects the sigmoid sulcus with the jugular foramen.

The jugular foramen (figs. 1, 2, 12) when viewed from within the cranium is crescentic, the convex side being formed caudally by the tuberculum jugulare and medially by the commissura basivestibularis; the concave margin, directed laterad, is constituted by the medial wall of the prominentia utriculo-ampullaris inferior. The vena jugularis interna and the accessorius, vagus 
and glossopharyngeus nerves pass straight through the foramen. Although the paracondyloid process forms a deep wall for the foramen posteriorly, there is no inclination forward of this process nor a lamina alaris with attendant horizontal course of the nerves. On the extracranial surface, the foramen is divided into cephalic and caudal parts by an angular process of the cochlear wall (figs. 12, 19). The compartment posterior to the process is occupied by the jugular vein and the group of nerves; the anterior compartment, filled with connective tissue; lies within the fenestra perilymphaticum and forms a communication between the cavum cochleae and fossa occipito-canalicularis; it is the beginning of the aquaeductus cochleae.

The hypoglossal canal (figs. 1, 2, 12) transmits the three previously united ventral roots of the hypoglossal nerve. It runs in a ventro-lateral direction, beginning caudad and medialward of the jugular foramen and terminating on the external surface at the level of the medial edge of the paracondyloid process.

The broad, square paracondyloid process (figs. 2, 3, 12, 19) projects widely from the ventral part of the pars lateralis of the occipital region, with ventral and lateral free edges, cephalic and caudal surfaces. The narrow cephalic surface enters into the wall of the jugular foramen; the ventral broad free edge is continuous medially with that part of the extracranial surface lying between the jugular foramen and the hypoglossal canal.

The foramen magnum (figs. 1, 2) is hexagonal with rounded angles, the sides consisting of the free caudal margins of the basal plate and lateral occipital arches and, dorsally, the edge of the spino-occipital membrane. The foramen is divisible into a large ventral part included between the condylar portions of the occipital arches, and a smaller dorsal region extending thence to the spino-occipital membrane. The lateral boundaries of these two divisions come together in a notch of the lateral occipital wall just dorsad of each condyle (figs. 1, 2, $3,4)$. A number of small veins in the connective tissue of these notches, were connected with the sinus transversus. The plane of the whole foramen magnum is nearly transverse to the longitudinal axis of the posterior half of the cranium; however, 
the positions of the planes of the dorsal and ventral divisions differ from one another, that of the ventral, condylar part is transverse, whereas that of the dorsal division is very oblique. The latter faces ventro-caudad and forms an angle, open caudally, of approximately 145 degrees with the plane of the ventral part of the foramen (fig. 3).

The occipital condyles (figs. $2,3,19$ ) are a pair of oval eminences only slightly raised above the level of the ventro-lateral margins of the foramen magnum. Each condyle extends at first laterally from the incisura occipitalis anterior along the caudal margin of the basal plate to the level of the hypoglossal canal, then dorso-laterally upon the lateral occipital arch. The basilar portion is broader but shorter than the lateral which stretches out upon the occipital arch as far as the deep notch mentioned above (p. 291). The lateral and basal parts of the condyle are connected with the lateral mass and ventral arch of the atlas by intervening mesenchyma; an articular cavity is not present.

The tectum posterius (figs. 1 and 2) is a slender transverse bridge of cartilage arching over the brain and connecting the parietal plates from side to side. It is far from the auditory capsules caudally and dorsally, standing closer to the occipital side walls. The tectum expands laterally in joining the parietal plates, becomes narrow in its middle opposite the medulla oblongata. The caudo-ventral margin of the tectum is concave from side to side, bounds the incisura occipitalis posterior and affords attachment to the spino-occipital membrane; the cephalic, and at the same time dorsal, margin is straight, presenting no indication of a processus ascendens.

The term incisura occipitalis posterior (fig. 1) is given tentatively to the bay extending from the foramen magnum to the tectum posterius. Its lateral boundaries are the caudal margins of a pair of cartilaginous plates continuous with the occipital walls ventrally, and with the laminae parietales anteriorly. This notch is filled by the spino-occipital membrane.

Hypoglossal nerve. Three ventral roots unite to form a single nerve in the embryo of $23.1 \mathrm{~mm}$. A dorsal root opposite to, 
but not united with, the third ventral root, arises from the spinal cord between the atlas and occipital arch. In smaller specimens further evidences of a dorsal root and ganglion were observed. This component was best developed in an embryo of $15 \mathrm{~mm}$. (W. U. C. ser. 52, sl. 22-24) in which the dorsal root joined the third ventral root before reaching the hypoglossal foramen.

\section{Atlas and epistropheus}

In connection with the occipital region some observations on the epistropheus and atlas should be mentioned. These vertebrae have not reached their full chondrogenous development, the neural arches specially being very incomplete (fig. 9). The dens epistrophei is relatively very much longer in the embryo of the present stage than in the adult. Its relations are also different in that it projects beyond the anterior arch of the atlas so far craniad as to enter a little way into the cranial cavity through the occipital foramen (figs. 9, 14, 19). The atlas is remarkably massive. Just cephalad of the neural arches is a pair of processes of special interest. These project dorsad from the spot where the neural and anterior arches meet (the future lateral mass), inclining a little toward the median plane, and end in blunt extremities. These atlantal processes, which are the cartilaginous precoursors of the little bridges of bone of the adult atlas, completing the circumferences of the foramina atlantalia, form, with the neural arches, a notch on each side lodging the ganglion of the first spinal nerve and the vertebral artery. The articular surfaces of the atlas for the occipital condyles are formed at the meeting place of the neural and anterior arches. Two parts enter into the formation of the articular surfaces: (1) a thickening at the junction of the neural and anterior arches, which meets the basal portion of the occipital condyle; (2) the atlantal process which articulates with the lateral part of the condyle. 


\section{Basal plate and occipital region in smaller embryos}

In van Wijhe preparations of embryos of $10 \mathrm{~mm}$. (fig. 5) there appears in the floor of the occipital region a pair of faintly stained, elongate parachordal plates. These are united anteriorly by a commissure beneath the notochord, but are separated across the midline in the rest of their extent. Each plate is thickened at its caudal end, and is then continued laterally intc the occipital arch. The lateral margin of the parachordal plate presents a prominent angle subdividing it into an anterior oblique part opposite the mesenchymal cochlear capsule, and a posterior straight part opposite the jugular vein. In the angle between the straight part of the margin and the lateral occipital arch are the three roots of the hypoglossal nerve. Between the parachordal plates and behind their commissure is a vacuity traversed by the notochord. This space is constricted at its middle by opposite projections from the medial edges of the parachordals. The notochord extends forward as far as the hypophysis and appears to lie in a tract of blue-stained tissue which terminates just behind the hypophyseal cartilage. Each lateral occipital arch is slender and cylindrical medially where it joins the parachordal plate, expanded and flat laterally at its free extremity. Where these two parts come together the cartilage is only slightly stained. The lateral arches. at this stage lie far removed in a caudal direction from the otic capsules which are represented by parts of the anterior and posterior semicircular canals.

The atlas has the form of a transverse arch open dorsally. Each lateral extremity of the arch, deeply stained, is in the form of a broad plate presenting two processes, the neural and atlantal. The middle, slender hypochordal part of the arch is only slightly stained. The epistropheus likewise forms an arch, the ventral medial part of which includes the notochord. Here a darkly stained tract on each side is separated from the notochord medially and the deeply stained neural arch laterally by very lightly stained zones. The two tracts near the notochord are the beginnings of the centrum of the epistropheus. Just cephalad of the epistropheal centrum and separated from 
it by a transverse plane of unstained tissue is the broad conical mass of young cartilage surrounding the notochord, the beginning of the atlantal centrum. Between the apex of the latter and the commissure of the parachordals the notochord stands free of any chondrified tissue as evidenced by the absence of the blue stain about it.

Transverse sections of an embryo of $10.6 \mathrm{~mm}$. (fig. 15) make clear the relations of the notochord, dens epistrophei and parachordal plates at the stage of cartilaginous structure of the latter. The parachordals are connected across the median plane, ventrad of the notochord by loose tissue. This tissue presents more and more the characters of mesenchyma when traced toward the median plane, and more and more the condition of cartilage when followed toward the parachordals into which it passes. An imperfect basal plate is thus formed in the occipital region which extends from side to side ventrad of the notochord and which passes laterally into the lateral occipital arches. Figure 15 shows the notochord covered dorsally and laterally by a layer of cellular tissue lying upon the dorsal surface of the stretch of mesenchyma connecting the parachordal plates. When followed caudad this layer increases in thickness, especially on the dorsal side of the notochord, and passes over into the mesenchyma of the centrum of the atlas.

In van Wijhe preparations of $12 \mathrm{~mm}$. (fig. 6) the most important differences from the preceding stage in the posterior part of the cranium are the presence of a hypoglossal foramen, the beginning of the parietal plate and the slender cartilaginous basal plate of the otic region. The hypoglossal foramen has resulted from the development of a bar of cartilage uniting the lateral angle of the parachordal plate and lateral occipital arch outside the roots of the twelfth nerve. The beginning of the parietal plate appears standing free, dorsad of the posterior semicircular canal of the otic capsule. The basal plate of the otic region is continuous behind with the primary commissure of the parachordals, terminates in front in an expansion which extends nearly as far as the cochlear wall, and anteriorly projects somewhat dorsad of the hypophyseal cartilage. 
In sections of $12 \mathrm{~mm}$. embryos (fig. 17) the notochord, as it enters upon its cranial course, lies at first dorsad of the still imperfect basal plate, then sinks into the otic portion of the plate; it is now surrounded on all sides by cartilage at the level of the primary parachordal commissure. The notochord emerges from the basal plate at its free anterior end, which is inclined dorso-cephalad, and terminates in the mass of mesenchyma which fills the interval (fenestra basicranialis posterior) between the expanded end of the basal plate and the hypophyseal cartilage. Where the notochord enters the cranium it is surrounded, as in the preceding stage, by a layer of mesenchyma which extends caudally to join with the chondrifying tissue forming the centrum of the atlas. The centrum stands in the same transverse plane as the arches of the atlas, from which it is separated by a stratum of less compact mesenchyma. Sagittal sections show a plane of densely packed nuclei separating the centrum of the atlas from the centrum of the epistropheus already laid down in young cartilage. Chondrification of the hypochordal arch of the atlas is less advanced than that of the tissue beneath the notochord between the caudal margins of the parachordal plates; in the latter young cartilage is present, while in the hypochordal arch of the atlas mesenchyma alone is to be found.

Between the caudal margin of the parachordal plates and the lateral mass of the atlas is a transverse stretch of deeply staining tissue, dense laterally and thin medially where it meets the mesenchyma about the notochord. Its later history is not clear.

Two marked advances in development of the floor of the cranium appear in a van Wijhe preparation of $15 \mathrm{~mm}$. (fig. 7). First, the basal plate is nearly perfected, the unchondrified part in the occipital region being now considerably redured. The bar completing the boundaries of the hypoglossal foramen stands opposite the primary commissure of the parachordals, and is thickened at its origin, just where the jugular tubercle and paracondyloid processes later are developed. At the same spot a slight projection forward toward the cochlear capsules, medial to the vena jugularis, is probably the beginning of the basi- 
vestibular commissure. Second, the anterior expanded extremity of the basal plate is united with the hypophyseal cartilage forming the crista transversa. The carotid artery as it enters the cranium is pressed against the side of the expanded end.

The dorsal extremity of the lateral occipital arch is not united anteriorly with the pars canalicularis of the otic capsule; it is, however, joined with the parietal plate which now presents a prominent dorso-medial angle, the beginning of the tectum posterius.

In the atlas the hypochordal arch is partly chondrified. It is composed of two bars, right and left, which are continuous at each side with the lateral masses and approach each other medially. The lateral mass has been formed from the expanded end of the hypochordal arch of the preceding stage. The centrum of the atlas has united with that of the epistropheus so that $a$ dens epistrophei can be described. The anterior extremity of the latter projects cephalad beyond the transverse plane of the atlantal hypochordal arch. The lateral arches of the epistropheus.are connected with the centrum by a lightly stained zone.

Sagittal sections of the embryos of $15 \mathrm{~mm}$. show that the basal plate is chondrified and is continuous with the floor of the cranium in the hypophyseal region (fig. 18). Here, the anterior end of the plate is still recognizable as an elevation, the crista transversa, behind the hypophysis. The bent extremity of the notochord lies upon the transverse crest imbedded in a hill of mesenchyma. In the caudal region of the basal plate the notochord still occupies a position near the intracranial surface, covered by connective tissue continuous with the dens epistrophei. A superficial constriction marks the original plane of fusion of the centra of the first and second vertebrae. Chondrification of the dens is less advanced toward its extremity than at its base. Since the last stage described chondrification has extended forward in the mesenchyma about the notochord, in consequence of which the extremity of the dens has been lengthened and now lies upon the caudal margin of the basal plate. 
The hypochordal arch of the atlas is composed of young cartilage, least developed toward the midplane and continuous, right and left, with the lateral masses.

In embryos of 17 to $20 \mathrm{~mm}$. (fig. 8) the basal plate is chondrified from side to side. Boundaries of the jugular foramina are established by the presence of the basicochlear commissures and the more complete union of the lateral occipital arches and the otic capsules. In relation to the hypoglossal foramen, the jugular tubercle appears anterior, the paracondyloid process lateral; the one within the cranium, the other outside. The basal foramina are all relatively large. A long, wide basi-cochlear fissure is limited anteriorly by the basi-cochlear commissure which separates it from the carotid foramen. The tectum posterius is represented in cartilage by a spur springing on either side from the parietal plate. The hypochordal arch of the atlas is complete from side to side. The dens epistrophei is further chondrified cranially.

Otic region. Embryo of $23.1 \mathrm{~mm}$.

The otic capsule, externally, presents two well defined subdivisions, one serving as the framework of the semicircular canals, the other enclosing the cochlear canal (figs. 1, 2, 3). The vestibule, on account of its intimate relation both with the pars canalicularis and the pars cochlearis, will be included in the description of these subdivisions.

Regarding the position of the otic capsule at the stage represented by the model, a departure from the mammalian type is to be noted. The long axis of the whole auditory capsule of mammals is, as Gaupp has indicated, directed from behind and laterally, forward and medially; just the opposite of what occurs in lower vertebrates. . The long axis" of the otic capsule of the cat embryo of $23.1 \mathrm{~mm}$. is inclined somewhat transversely (figs. 1, 2). It is true that the broader canalicular part reaches caudally a little way beyond the cochlear division, but in the cephalic direction both attain almost to the same level.

Regarding the relation of the otic capsule to the walls of the cranium, the pars cochlearis lies wholly in the floor and the pars 
canalicularis stands nearly upright in the lateral wall. The external surface of this part rises straight toward the lamina parietalis; the internal surface inclines from above, ventrad and a little medialward. The cochlear capsule, very large and rounded, lies beneath the brain in the base of the skull, approaching closely its fellow opposite, the two making un almost the entire cranial floor in the otic region.

At its circumference the otic capsule is connected with neighboring parts of the side wall and base of the cranium by broader or narrower stretches of cartilage with intervening vacuities. The several connections between the otic capsule and the occipital wall and basal plate as well as the related openings have already been described (p. 289). There remain to be noted the bonds between the capsule and parietal plate, and certain parts in the orbito-temporal region.

The dorsal, narrow margin of the pars canalicularis is, in large part, free, forming the ventral boundary of the foramen jugulare spurium (figs. 3 and 4). Cephalad and caudad of this narrow fissure it is connected with the lamina parietalis; in the former situation, by the commissura parieto-capsularis, in the latter place with that part of the parietal plate which is continuous ventrally with the occipital wall. Between the cephalic pole of the pars cochlearis and the ala temporalis is the commissura alicochlearis which limits the carotid foramen laterally. Between this opening and the fissura basicochlearis posterior the cochlear capsule is united continuously with the basa. plate (p. 288).

\section{The pars canalicularis. Outer form}

Oval and laterally compressed, the massive pars canalicularis stands in the side of the skull, contributing a large part of its lateral wall. It presents an extracranial lateral surface, anterior and posterior surfaces mainly within the cranium, and a narrow arched dorsal margin. A vestibular region unites this subdivision of the otic capsule with the pars cochlearis.

The lateral surface (figs. 3,4) convex and smooth, shows only slight elevations corresponding to the semicircular canals. 
Rounded prominences at the cephalic and caudal poles, which appear on both the medial and lateral aspects of the otic capsule, are identified as the prominentia utriculo-ampullaris superior and the prominentia utriculo-ampullaris inferior, respectively (fig. 10). The lateral surface of the pars canalicularis terminates ventrally in a broad irregular ridge, the crista parotica, which, projecting basally, extends from the superior utricular prominence the full length of this surface. In its caudal half the crista parotica (figs. 2, 20) gives rise to an oval elevation connected medially with the base of Reichert's cartilage. The elevation bears a close relation to the future processus mastoideus, which in the cat belongs exclusively to the otic region; but that it gives rise to it I am unable to say. The parotic crest, especially in its caudal two thirds, projects from that part of the ear capsule lodging the lateral semicircular canal. · In its cephalic part is a slight depression of its lateral surface, the fossa incudis (fig. 3) where the cartilaginous incus is connected by a ligament. A tegmen tympani at the stage represented by the model is not present. Further relations of the crista parotica with Reichert's cartilage, and the facial canal will be discussed under these subjects. A deep groove separates the crista parotica from the pars cochlearis. This can be traced anteriorly beyond the limits of the crest upon the inferior cochlear prominence toward the foramen faciale; posteriorly as far as the jugular foramen. The facial foramen (fig. 1) transmitting the $\mathrm{N}$. facialis, is directed antero-laterally and lies without the plane of the membrana limitans (vide infra). Here is formed the geniculate ganglion and the origin of the great superficial petrosal nerve. In its anterior part the groove lodges the facial nerve and is identified as the sulcus facialis. At the base of Reichert's cartilage it becomes narrow through the approximation of this cartilage toward the crista parotica and the wall of the cochlea, here forming the promontory (fig. 12). Since, at this spot the nerve makes its exit from the groove, it is to be regarded as the foramen stylomastoideum primitivum. Caudad of this foramen, the groove is broad and deep, filled with connective tissue and occupied to a small extent by the hinder part of the 
cavum tympani. In it lies also the vena capitis lateralis. In the model the expanded posterior part of the groove communicates freely with the great foramen cochleae, opening at its medial side.

The intracranial surface of the pars canalicularis is depressed below the general surface of the cranium and presents an uneven contour (fig. 1). Ventrally it passes into the pars cochlearis. At the place of transition a great quadrilateral fenestra acustica transmits the divisions of the $\mathrm{N}$. acusticus. A ridge, eminentia cruris communis, produced by the crus commune of the anterior and posterior semicircular canals, subdivides the intracranial surface into anterior and posterior faces. The eminence presents the foramen endolymphaticum and inferiorly passes into the prominentia utricularis. The latter, corresponding to the utricle and saccule, reaches below to the acustic window. The posterior surface of the pars canalicularis looks caudad, mesad and slightly ventrad, contrasting in its position therefore with the caudally and ventrally directed corresponding surface in mammals generally. It passes caudally into the medial surface of the lateral occipital arch and ventrally into the prominentia utriculo-ampullaris inferior. The posterior surface is hollowed to form the sigmoid sulcus, occupied by the sinus transversus. The anterior surface of the pars canalicularis presents the fossa subarcuata anterior limited anteriorly and dorsally by the prominentia semicircularis anterior. This prominence begins at the dorsal pole of the pars canalicularis and curves anteriorly and ventrally to the prominentia ampullaris superior. On this surface, also, the stout commissura suprafacialis ${ }^{2}$ is found, connecting the medial wall of the prominentia utriculo-ampullaris superior with the anterior part of the roof of the pars cochlearis, and participating in the ventro-caudal circumference of the spheno-parietal fenestra. It is continued dorsally into a

${ }^{2}$ In van Wijhe preparations of embryos 17 to $30 \mathrm{~mm}$. long, the suprafacial commissure appears deeply stained and separated from the pars canalicularis by a zone of lightly stained cartilage. It continues directly into the commissura orbito-parietalis where this is united with the otic capsule (commissura parieto-capsularis) (fig. 9). 
prominent ridge which joins the orbito-parietal commissure (figs. 1, 3). The suprafacial commissure constitutes the roof of the short first portion of the facial canal, the floor of which is made by a cartilaginous septum between it and the cavum cochleae. The canal leads from the meatus acusticus internus to the foramen faciale. The dorsal circumference of the pars canalicularis is partly free, partly continuous with the cranial wall. Posteriorly it passes into the occipital wall; anteriorly it is connected with the commissura parieto-capsularis. Between these connections the dorsal margin is free, forming the ventral boundary of the foramen jugulare spurium. Upon the medial side of the dorsal circumference is a groove occupied by the transverse sinus and its main anterior tributary.

\section{Pars cochlearis}

The most conspicuous object of the cranial floor as presented by the model is the huge, rounded bulging of the pars cochlearis of the auditory capsule (figs. 1,2). The strong walls of this shell enclose the cochlear canal and the saccule. The form of the cochlear capsule is not quite round, but longer in a direction from behind, forward and medialward. Upon the ventral, extracranial surface a shallow groove, sulcus septalis, extends from behind and laterally, medially and anteriorly. Upon the caudal aspect is the large foramen cochleae. Where the cochlear and canalicular parts come together are three openings: the fenestra vestibuli, appearing outside the cranium, the fenestra acustica, within the cranium and the foramen perilymphaticum, appearing partly inside and partly outside the skull. The pars cochlearis shows no sharp boundary toward the pars canalicularis; as stated above, the two are continuous in the region of the vestibule. On the surface, this common vestibular zone corresponds to the intermediate stretch which includes the sulcus facialis laterally, and the region of the fenestra acustica, medially. The connections between the cochlear capsule and the floc of the cranium have already been described (p. 288).

Foramina acustica (figs. 10, 11). A large quadrilateral opening, fenestra acustica, the future porus acusticus internus, 
is situated upon the medial aspect of the ear capsule, partly in the wall of the cochlea, partly in that of the vestibule: Its plane faces dorsad and mesad, the lateral margin made by the prominentia utricularis being considerably higher than the medial cochlear edge. The fenestra leads into a short, imperfectly formed meatus acusticus internus; within is an incomplete floor presenting two openings, one transmitting the facial nerve, the other the branches of the acustic nerve. The former, which lies anteriorly, is the beginning of the primary facial canal. It will be recalled that this short canal passes beneath the suprafacial commissure and ends in the facial foramen outside the chondrocranium. The opening for the acustic nerve is an irregular gap; for convenience of description it will be referred to as the acustic fissure. It is shaped like a $\mathrm{V}$ with apex caudad, one limb lying almost wholly in the cochlear, the other in the vestibular region. The latter division, widened in the form of an oval notch, lies anterior and slightly dorsal to the cochlear division. It transmits the nerves to the utricle, and to the ampullae of the anterior and lateral semicircular canals. Its position and relations to the structures just named identify it with the superior acustic foramen of other mammalian embryos. The larger cochlear portion of the acustic fissure lies caudad medialward and somewhat ventrad to the superior acustic foramen. It gives passage to the nerve of the cochlea and the nerve to the saccule, and is identified with the inferior acustic foramen. In the dorsal caudal corner of the meatus acusticus internus is a notch opening into the cochlear part of the fissure and leading to a groove, lodging the nerve to the ampulla posterior. The notch is the forerunner of the foramen singulare and will be designated the incisura singularis.

The position and relations of the facial and acustic foramina having been noted, it now remains to describe the walls of the internal acustic meatus. Figures 13 and 14 show the meatus from the medial aspect. Of the stretches of cartilage intervening between the facial and acustic foramina two are of special interest: one, constituting the primary floor of the meatus, separating the two named foramina; the other forming the incom- 
plete lateral wall of the meatus. The primary floor of the meatus appears in the model as an extension from the roof of the anterior part of the cochlear cavity. It can be followed laterally from the dorsal part of the cochlear capsule at the medial margin of the fenestra acustica to pass into the first turn of the septum spirale. This part is the forerunner of the longitudinal bony ridge in the floor of the meatus of the adult, the crista transversa of human anatomy, which separates the superior cribriform area and entrance to the facial canal above from the middle cribriform area and the spiral tract of foramina below (Jayne '98, p. 200). Anteriorly it continues as the floor of the primary facial eanal and at the same time the roof of the fore part of ihn cochlear cavity. Lateral to the facial foramen the primery fer of thr meatus passes into the floor of the prominicnis liticu.o-smpu' aris superior and forms the ventral boundary of the superior acustic foramen. The posterior free edge of the floor constitutes the cephalic margin of the inferior acustic foramen. The lateral wall of the meatus is formed mostly of precartilage. Its free ventral margin bounds the acustic fissure dorsally. The wall itself covers the medial aspect of the saccule. The medial edge of the meatus, derived from the roof of the cochlear capsule, stretches from the suprafacial commissure to the posterior wall and is very low. The anterior and posterior walls, on the contrary, tend to become very high toward the vestibular part of the capsule, and are formed respectively by the suprafacial commissure and an elevation made at the junction of the basivestibular commissure with the prominentia ampullaris inferior and cochlear capsule.

Within the meatus acusticus internus are found, anteriorly, the nerve of the vestibule and its ganglion, together with the facial nerve, and, posteriorly, the nerve of the cochlea.

In the model of the chondrocranium, there is a small flattened surface of the cochlear capsule, lateral to the suprafacial commissure (figs. 3, 20). This, the planum supracochleare of Voit, supports the seventh nerve as it passes out of the foramen faciale, the geniculate ganglion and the beginning of the great superficial petrosal nerve. Upon it rest also the caudal part 
of the semilunar ganglion and the roots of the fifth nerve. As shown by the sections, these structures are embedded in mesenchyma which extends laterally to Meckel's cartilage and medially as far as the plane of the chondrocranial wall; here, in the form of a membrane, it becomes fixed to the margins of the fenestra sphenoparietalis. For this region the name cavum supracochleare has been proposed by Voit. The cavum supracochleare and the several structures therein are excluded from the cavity of the chondrocranium by the membrane of the sphenoparietal window.

\section{Cavities of the otic capsule}

A frontal section through the vestibular region shows a large irregular space containing parts of the membranous labyrinth (fig. 10). This space extends anteriorly into the pars cochlearis as the cavum cochleae, lodging the cochlear duct; posteriorly into the pars canalicularis in the form of the canales semicirculares. The main room opened by the section, vestibulum, contains the utricle and saccule.

Cavum cochleae (figs. 19, 20, 21, 22). The great oval cavity of the pars cochlearis, traversed by a low septum spirale, has already begun to asssume the form of a winding canal. This may be followed from the vestibule, with which it is in wide communication, ventrally, then in a spiral course into the anterior part of the cochlear capsule. At its commencement the canal is quite wide, and its limiting cartilaginous walls incomplete through the presence of large openings; caudally, the perilymphatic foramen; laterally, the fenestra vestibuli; dorsally, the inferior acustic foramen. The cochlear duct makes a little more than one complete turn and occupies but a small part of the cavity which is elsewhere filled by young connective tissue (fig. 9). This tissue extends into the perilymphatic foramen and to the edge of the spiral septum where, by condensation of its elements, it presents the form of a spiral membrane (fig. 22). No indication of cartilage formation was observed in this membrane in the present or in a later stage. The cartilaginous septum spirale takes origin in the primary floor of the internal 
acustic meatus (figs. 10, 11, 19), makes a steep descent toward the floor of the cochlear cavity, and continues as a low ridge to the extent of somewhat more than half a turn from the beginning of the septum. Its position externally, is indicated on the ventral surface of the cochlear capsule by the sulcus septalis (p. 302).

The oval fenestra vestibuli (figs. 3, 20, 21) appears externally at the bottom of a deep depression of the surface of the capsular wall, standing in a coronal plane, above and lateral to the perilymphatic foramen. Its superior and medial boundaries are very prominent; its inferior limit obscure. Within this depression is the foot-plate of the cartilaginous stapes, embedded in mesenchyma which completely fills the window. Within the cavum cochleae, the fenestra appears on an eminence of the lateral wall which projects posteriorly toward the vestibule.

The large foramen perilymphaticum (figs. 2, 12, 20) extends upon both the caudal and dorsal surfaces of the pars cochlearis and is incompletely divided by a process of the cochlear capsule into two parts, the fenestra cochleae and the aquaeductus cochleae. The former is located at the caudal pole of the cochlear prominence, stands in a transverse plane and is occupied by mesenchyma. In figure 11 it appears completely separated from the aquaeductus cochleae, but the septum between these openings is chondrified only in its medial part; laterally it is composed of precartilage. The aquaeductus cochleae, lying in a frontal plane, opens into the fossa occipito-canalicularis above (p.291), and communicates with the cavum cochleae below. It is filled with mesenchyma, through which small veins pass to the vena jugularis interna. The aqueduct of the cochlea at the present stage is an extension of the jugular foramen forward in the form of a deep notch between the commissura basivestibularis and the prominentia utriculo-ampullaris inferior. It constitutes a vacuity in the roof of the cochlear capsule. The aquaeductus cochleae is separated from the jugular foramen proper (i.e. the posterior part transmitting the vein and nerves) by the free angular projection of the cochlear wall above mentioned (indicated by ${ }^{*}$ in figs. $2,12,19$ ). 
Vestibulum. A frontal section through the middle of the vestibular region reveals a space within the cartilage stretching antero-posteriorly and lying nearer the medial than the lateral margin of the section (fig. 10). This space, a part of the future vestibule, is narrowed in its middle by the encroachment of a massive projection of the lateral wall and is expanded rather widely in front and behind this. The anterior wide room, containing in the section the utricle and recessus utriculi and the ampullae of the anterior and lateral semicircular ducts, will be described under the name of the cavum vestibulare anterius. The posterior room includes, in the section, the posterior part of the utricle, the ventral part of the ductus endolymphaticus, the beginning of the canalis utriculi-saccularis, the sinus inferior, ampulla posterior and the crus simplex of the ductus semicircularis lateralis. This room will be further considered under the name of the cavum vestibulare posterior. The parts of the membranous labyrinth mentioned do not fill completely the space limited by the cartilaginous walls of the pars vestibularis, but leave an interval filled by mesenchyma representing the future perilymphatic space.

Cavum vestibulare anterius (figs. 10, 11). This large, irregularly shaped cavity occupies the dorsal part of the vestibular region. Its contents have been noted. Its anterior wall swells out as the prominentia utriculo-ampullaris superior. This corresponds to an anterior extension of the cavity called recessus ampullaris anterior containing the ampulla anterior. The floor is broad, slopes ventrad in a medial direction, then drops abruptly to continue into the lateral cochlear wall. At this spot is located the fenestra vestibuli (figs. 19, 20). The medial wall bulges slightly into the cranial cavity forming the prominentia utricularis, in conformity with the subjacent surface of the utricle and saccule. The ventral free edge of this wall forms the dorsal boundary of the superior acustic foramen as already described (p. 304). The lateral wall presents a dorso-ventral ridge which projects into the cavity, fitting into the angle between the ampulla lateralis and ampulla anterior. The considerable space behind the ridge, containing the greater part of the lateral am- 
pulla opens posteriorly into the canalis semicircularis lateralis. The posterior wall is formed by the mass of cartilage already referred to which projects medialward from the lateral wall of the otic capsule (fig. 11). This crista intervestibularis, as it may be termed, intervenes between the anterior and posterior vestibular caves, but fails to meet the medial vestibular wall; there is left a communicating space between the two divisions occupied by a part of the utricle. Ventrally, the crista intervestibularis enters into the roof of the lateral semicircular canal; dorsally it becomes continuous with the massa angularis, the great body of cartilage encompassed by the semicircular canals. The dorsal wall of the cavum vestibulare anterius is made by that portion of the angular mass which fills the concavity of the canalis semicircularis anterior.

Cavum vestibulare posterius. In form, the posterior division of the vestibule is oval dorsally, narrow and tunnel-shaped ventrally, expanding into a roomy space in the region of the fenestra cochleae. The posterior wall bulges in adaptation to the adjacent recessus ampullaris posterior, forming on the surface of the ear capsule the prominentia utriculo-ampullaris inferior. The ventral part of the posterior wall presents the posterior orifice of the lateral semicircular canal. The dorsal part, at its junction with the roof of the cavum vestibuli posterius, shows the orifice of the posterior semicircular canal. The medial wall, continuous with the medial wall of the anterior cave, corresponds to that part of the otic capsule marked on the surface by the beginning of the prominentia cruris communis and the incisura singularis. It presents a ventral free edge looking into the inferior acustic foramen. The dorsal wall consists of that part of the massa angularis intervening between the canalis semicircularis posterior and the vestibule. In the highest part of the roof are two openings:- the great circular orifice of the cavum cruris communis, containing the crus commune of the anterior and posterior canals; the small irregular hole, foramen endolymphaticum, looking medialwards and transmitting the ductus endolymphaticus. A floor is present in the caudal half only, beneath the ampullary end of the posterior semicircular duct; 
where the floor is wanting anteriorly there is a wide communication with the cavum cochleae.

The semicircular canals (figs. 2, 9, 10, 11, 19) are cylindrical tunnels of a diameter from two to two and one-half times that of the contained membranous ducts. The future perilymphatic space between the ducts and walls of the canals, is filled with mesenchyma. Within the compass of the canals is the body of cartilage to which Gaupp has given the name massa angularis. The lateral semicircular canal lies in a frontal plane; its floor, lateral and medial walls go into the cartilage of the crista parotica; its roof is formed by the crista intervestibularis. The plane of the anterior semicircular canal is dorso-ventrad inclining lateromesad from before backward. Within its concavity is that part of the massa angularis which forms the roof of the cavum vestibulare anterius and which corresponds to the fossa subarcuata of the intracranial surface of the pars canalicularis. The posterior semicircular canal also runs in a dorso-ventral plane, which, however, is inclined from behind and laterally, forward and medially. It includes within its concavity that part of the massa angularis forming the roof of the cavum vestibulare posterius and which corresponds on the intracranial surface of the pars canalicularis to a fossa. From the bottom of this fossa, which is situated behind the prominentia cruris communis, a canal, transmitting some blood vessels, leads to a great vacuity within the angular mass.

The crista intervestibularis (fig. 11) is a projection of the base of the massa angularis. It begins just dorsad of the fenestra vestibuli as a ridge lying between the ampulla lateralis and the saccule; it reaches its maximum height opposite the ductus utriculo-saccularis.

The massa angularis (figs. 2, 10, 11), filling the space between the three semicircular canals and the vestibule, is composed of hyaline cartilage, fully formed. Its relation to the walls of the canals and vestibule have already been described. Ventrally the mass becomes continuous with the crista intervestibularis. The angular mass is not continuous throughout, being broken in its central portion by a space occupied by connective tissue 
and blood vessels (indicated by ** fig. 2). The latter find a passage to the cranial cavity by the opening in the fossa behind the eminentia cruris communis (vide supra); veins passing out of this opening join the sigmoid sinus. The space extends cephalocaudad and dorsad, approaching the anterior and posterior semicircular canals and the crus commune, and reaching ventrad as far as the level of the roof of the vestibular cavities and the crista intervestibularis. It does not at any point communicate with the vestibule.

Lamina parietalis (figs. $1,2,3,4$ ). This plate of cartilage stands in a sagittal plane dorsad of the pars canalicularis. The concave extracranial surface gives origin to part of the temporal muscle; the convex intracranial surface is smooth. The parietal plate is broad anteriorly and posteriorly and narrow between where it lies dorsad of the pars canalicularis of the otic capsule. It goes over anteriorly into the commissura orbito-parietalis posteriorly into the lateral occipital wall, and, in connection with these two parts, is fixed to the pars canalicularis. Between the four elements named is the foramen jugulare spurium, narrow and curved around the dorsal circumference of the otic capsule. Some minute veins traversing the foramen connect the transverse sinus with extracranial veins. The foramen of the right side is subdivided by a cartilaginous connection of the parietal plate and pars canalicularis. The hinder of the two resulting foramina is located opposite the summit of the posterior semicircular canal. In van Wijhe preparations of embryos 24 to $30 \mathrm{~mm}$. in length, union of the parietal plate and pars canalicularis was observed dividing the spurius jugular foramen into two parts. This connection was found on one side or the other, rarely on both, occurring, as in the stage modeled, at the summit of the anterior semicircular canal. The parietal plate at this level is very narrow, is notched in its dorsal margin and, compared with the regions anterior and posterior, is less chondrified. 
Otic region in smaller embryos

In cat embryos of $17 \mathrm{~mm}$. (H. E. C. ser. 492 and van Wijhe preparations, fig. 8) both pars canalicularis and pars cochlearis are largely chondrified and stand in connection with each other. At their margins they are united with the floor and walls of the cranium by commissures between which openings are found. The basal plate, sella turcica, parietal plate, orbito-parietal commissure and occipital wall, parts adjacent to the auditory capsule, are all formed of cartilage. The cartilaginous structure of the ventral portion of the occipital wall and that of the floor of the cranium are further advanced in development than the cartilage in the remaining parts.

In the pars canalicularis, cartilage has formed upon its lateral surface, anterior, posterior and dorsal margins, around and between the semicircular ducts; its medial surface is chondrified about the circumference and crus commune. The prominentiae utriculo-ampullaris superior and inferior present cartilaginous walls, that of the last named being continuous ventrally with the cochlear wall. A chondrified medial wall of the vestibule forms the dorsal boundary of the future internal acustic meatus. At the margins of the pars canalicularis the sections show that planes of prochondral tissue separate it from the parieto-capsular commiøsure in front and lateral occipital arch posteriorly.

As shown by the sections through the cochlear capsule, precartilage is everywhere present excepting at the anterior and posterior poles. At these two spots the cochlea is united with the cartilage of the cranial base by commissures, but between the commissures it is separated from the basal cartilage by an extensive basicochlear fissure filled with mesenchyma. The roof of the cochlear capsule is considerably further developed than the floor and is nearer the cartilaginous state toward the pars canalicularis than in the direction of the median plane. At the posterior pole young cartilage can be followed from the prominentia utriculo-ampullaris inferior medially and caudally into the cochlea. This area lies between the fenestra acustica and the foramen perilymphaticum; from it the basivestibular commis- 
sure, just caudad, can be differentiated by its more advanced state of development. At the anterior pole, cartilage formation is found in connection with the suprafacial commissure. Where this bar joins the cochlear capsule two regions of the capsule, distinguished by their different states of development, can be seen in the sections. One region, that next to the epithelial cochlear duct is composed of mesenchyma which passes peripherally into precartilage. The other is a circumscribed area superimposed upon the part just mentioned. Its form is somewhat circular in sagittal sections; it is composed of young cartilage. This area occupies the most cephalic part of the cochlear capsule. It can be followed medially through sections 198-192 (H. E. C. ser. 492) of the anterior portion of the pars cochlearis as a more or less distinct tract; further on it becomes completely fused with the deeper stratum of the wall of the cavum cochleae. In sections 191-186 the anterior pole of the cochlear capsule appears as a simple curved plate of young cartilage. In section 185 this is joined with the alicochlear commissure. The relations of the cochlear capsule to the latter and to the suprafacial commissure will be understood by reference to figure 8 . When traced in the lateral direction, the curved plate in question goes over into the suprafacial commissure, with which it conforms in the degree of cartilaginous differentiation, outward size and shape. A second connection between the anterior pole' of the cochlear capsule and basal cartilage is presented at this stage by the cartilaginous basicochlear commissure, or synchondrosis, which forms the posterior boundary of the carotid foramen. The parietal plate is partly separated from the canalicular division by the foramen jugulare spurium. It is continuous through young cartilage or precartilage with the occipital arch and pars canalicularis posteriorly and with the commissura orbito-parietalis anteriorly. The tectum posterius is represented by a short process of the lamina parietalis.

Cartilage is found in the otic capsules of a cat embryo of 15 mm. (fig. 7) about the walls of the semicircular ducts and the vesibule, as indicated by the deep blue stain in van Wijhe preparations; the cochlear capsule is unstained. The basivestibular 
commissure, the alicochlear commissure and the basicochlear commissure behind the carotid artery are likewise unstained; the commissura orbito-parietalis is represented by a faintly stained strip of cartilage independent of both the orbital plate and otic capsule. The parietal plate is a triangular cartilage surmounting the extremity of the occipital arch and joined to it; it is unconnected with, though close to, the pars canalicularis. Its medial and dorsal angle is the beginning of the tectum posterius. Sections (H. E. C. ser. 400) show the material of the basal plate and floor of the sella turcica to be young cartilage. The basivestibular, alicochlear and basicochlear commissures are composed of mesenchyma. The suprafacial commissure appears as a bar extending from the anterior pole of the pars canalicularis over the nervus facialis to the anterior part of the cochlear capsule. It is composed of precartilage, easily distinguished from that of the otic capsule by the more abundant, clear ground substance between the nuclei. 'The relations of this commissure are of high interest. Followed laterally across the facial nerve it meets the pars canalicularis over the prominentia utriculoampullaris superior. It then passes without the smallest difference in degree of chondrification, without boundary of any sort, into the commissura orbito-parietalis. Chondrification of these commissures is quite uniform, and represents a state of histogenesis different from that of the otic capsule. Between the orbitoparietal commissure and the otic capsule is a plane of mesenchymal tissue. The separation of the suprafacial commissure and otic capsule is not so sharp.

When now sections are followed in series from the spot where the suprafacial commissure joins the pars cochlearis, toward the median plane, an equally interesting connection becomes manifest. It was shown above that in embryos of $17 \mathrm{~mm}$. the cochlear end of the commissure became continuous with a stretch of precartilage in the anterior part of the cochlear capsule, corresponding in shape and state of development exactly with that of the commissure itself. In the present stage this stretch again appears and can be followed medialward and cephalad almost as far as the point of union of the commissura alicochlearis with the cochlear capsule. 
Figure 6 made from a van Wijhe preparation of $12 \mathrm{~mm}$. shows the otic capsule from its medial side. Only those parts appear which are chondrified. The three semicircular ducts are in large part walled by cartilage. The blue stain is most intense upon the lateral aspect, faint on the medial side of the ducts. The parietal plate is a small triangular cartilage, lying dorsad of the interval between the posterior semicircular canal and the lateral occipital arch. It is entirely independent of other cartilages of the cranium.

The first trace of chondrification of the otic capsule was found in embryos of about $10 \mathrm{~mm}$. (fig. 5). In van Wijhe specimens of this stage a narrow streak of blue follows the dorsal and lateral circumferences of the anterior and posterior semicircular canals.

\section{Nerves in the otic region}

A brief description of the nerves and blood vessels which have been referred to in the description of the otic region will serve to correlate the many structures which have just been described. The roots of the trigeminal nerve pass forward over the suprafacial commissure and through the septum transversum (vide infra), to the semilunar ganglion, the caudal half of which rests upon the planum supracochleare. The abducent nerve runs along the medial side of the cochlear capsule, leaving the otic region by passing forward between this structure and the dorsum sellae. The seventh nerve, together with the vestibular and eochlear divisions of the acustic, enter the intcrnal acustic meatus from before backward in the order named. The glossopharyngeal, vagus and accessory traverse the jugular foramen, behind the otic capsule.

The facial nerve, including the pars intermedia (figs. 2, 4, 20, 21 ), is close to the ganglion of the vestibular nerve as it lies in the internal acustic meatus. It passes through the primary facial canal and the facial foramen to enter the cavum supracochleare and there, outside of the cavity of the chondrocranium, presents upon its dorsal side the geniculate ganglion (fig. 20). Connected with the ventral surface of the latter is the great superficial petrosal nerve. Its position is entirely extracranial. 
It stretches across the lateral wall of the eochlear capsule, beween the geniculate ganglion and a plexus of nerves about the internal carotid artery. In the plexus it joins the $\mathrm{N}$. pterygoideus Vidiani (fig. 3). Leaving the region of the geniculate ganglion the facial nerve enters upon the second part of its cranial course. It undergoes first its characteristic bend and then passes nearly straight caudad, lying for a short distance upon the prominentia utriculoampullaris superior, then enters the sulcus facialis. Above the nerve is the lateral semicircular canal, separated by a floor of thick cartilage from the sulcus, facialis. Continuing its course, backward through the groove, the nerve crosses dorsad of the incudo-stapedial articulation, separated from the vestibular window and basis stapedis which lie ventrad. Passing beneath and laterad of the origin of the stapedius muscle (originates from the roof and lateral wall of the sulcus facialis) to which it supplies a twig, the facial reaches the base of Reichert's cartilage, where, bending sharply ventrad it leaves the groove. The term foramen stylo-mastoideum.primitivum has been given by Broman ('99) to the exit from the sulcus facialis bounded by the upper, proximal division of Reichert's cartilage and the ear capsule. After passing the confines of this ill defined foramen (fig. 19) the facial nerve descends upon the caudal side of Reichert's cartilage and leaves the otic region.

$\Lambda \mathrm{t}$ the side of Reichert's cartilage the facial nerve gives off its chorda tympani branch (figs. 2, 22). This stout nerve winds about the lateral side of Reichert's cartilage, ascends somewhat and, turning mesad and cephalad, enters the region of the first pharyngeal pouch. Here it lies at first upon the medial surface of the manubrium of the cartilaginous malleus, ventrad of the insertion of the M. tensor tympani and of the incudo-stapedial articulation. Proceeding forward it passes out of the tympanic region, following closely the medial and ventral surface of Meckel's cartilage.

Acustic nerve. Two chief branches were present, an anterior and posterior. The anterior ramus gives a twig to the recessus utriculi, one to the ampulla anterior, another to the ampulla externa. The posterior ramus gives rise to a ramulus sacculi, a 
twig to the posterior ampulla (the two together may be regarded as a ramus medius), and continues as the ramulus basilaris. In addition to the ramulus sacculi, described by Retzius ('84), a small twig to the sacculus coming from the anterior ramus was observed.

The vagus, together with the glossopharyngeus and accessorius, form a bundle which occupies a position in the fossa occipito-canalicularis close to the lateral occipital arch and considerably posterior to the pars canalicularis of the otic capsule (figs. $1,2,19)$. The vagus lies medialward of the vena jugularis with the glossopharyngeus anterior and the accessorius posterior to it. These relations are maintained in passing through the jugular foramen, excepting that the accessorius becomes incorporated with the vagus. The jugular ganglion is found upon the roots of the vagus as it lies in the fossa occipito-canalicularis and therefore above the jugular foramen. Some distance outside the cranium the ganglion nodosum appears.

The ganglion superius of the N. glossopharyngeus (figs. 1, 2, 19 to 23 ) is situated partly in the recessus occipito-canalicularis, and partly upon the roots of the nerve as they lie in the cranial cavity above the recess. The ganglion petrosum, much larger, is located on the nerve below the jugular foramen and above the level of the ganglion nodosum of the vagus. The tympanic nerve arises from the upper end of the ganglion petrosum and proceeds in the direction of the foramen cochleae. This nerve runs in the thick mesenchyma between the medial epithelial wall of the first pharyngeal pouch and the foramen cochleae. After much branching, it reaches the ventrolateral surface of the posterior cochlear prominence where it enters a plexus of nerves, derived in part from the sympathetic around the internal carotid artery.

\section{Blood vessels in the otic region}

A great blood sinus runs upon the inner surface of the cranial wall in the sulcus which circumscribes the pars canalicularis. This, a forerunner of the sinus transversus system, becomes continuous at the fossa occipito-canalicularis with the vena jugularis 
interna. Small tributaries enter from the connective tissue filling the foramen jugulare spurium; some of these are emissary veins. Behind the pars canalicularis the sinus is joined by a small vein formed by tributary systems, one being the plexus of veins in the mesenchyma which fills the vacuity of the massa angularis (p. 309). A plexus of veins in the facial sulcus empties into a large vein which, running backward in company with the facial nerve, joins the internal jugular. An extensive network of veins within the mesenchyma of the cavum cochleae is drained in part by two veins which pass to the vena jugularis interna by way of the aquaeductus cochleae.

Vestiges of a stapedial artery are present in the embryo of 23.1 $\mathrm{mm}$., perforating the stapes (fig. 21). These can be followed anteriorly toward the terminal branch of the internal maxillary artery and posteriorly toward a plexus of small vessels on the ventral surface of the cochlear capsule, which is connected with an offset from the internal carotid artery. In an embryo of $15 \mathrm{~mm}$. the stapedial artery is a relatively large branch of the A. carotis interna, extending forward through the mesenchymal beginning of the stapes to the semilunar ganglion whence it continues as the mandibular artery.

The internal acustic artery arises from the basilar and enters the internal acustic foramen together with the acustic and seventh nerves, giving off several branches to the membranous labyrinth.

Orbito-temporal region. Embryo of $23.1 \mathrm{~mm}$.

The basis cranii (figs. 1, 2, 3) of the orbito-temporal region is an unbroken bar of cartilage continuous with the basal plate of the otic region posteriorly, and with the nasal septum of the ethmoidal skeleton anteriorly. The extracranial surface, strongly convex from side to side looks toward the pharynx, from which it is separated by an interval filled by wide-meshed mesenchyma. The intracranial surface presents in its posterior one-third the sella turcica with the root of the ala temporalis on each side, and in front of this, in successively higher planes, the two roots of the ala orbitalis, the optic foramen intervening. At the level of the 
sella turcica the basis cranii is bent in a sagittal plane so that the otic and orbital portions form an angle, open ventrally. Also, where the orbito-temporal portion of the base goes over into the septum nasi, a similar angle is formed.

At the level of the sella turcica the base is flattened dorso-ventrally, becomes thicker opposite the optic foramina and finally triangular in its most anterior part. Here, the two extracranial surfaces incline medially and ventrally to meet in a keel, forming a short interorbital septum which passes forward into the septum nasi.

Sella turcica (figs. 1, 23). The elongate, shallow pitiutary fossa is limited anteriorly by a low tuberculum sellae and posteriorly by a well defined wall. The base of the latter is made by the crista transversa extending nearly to the cochlear capsules, a slight interval remaining between these parts transmitting the abducent nerve. The dorsum sellae is represented by a conical elevation of the middle of the crista transversa. Remains of a hypophyseal canal are present and are occupied by epithelial vestiges of the stalk of the anterior lobe of the pituitary body.

Ala temporalis (figs. 1, 2, 3, 4, 23). The ala temporalis of the $23.1 \mathrm{~mm}$. embryo extends from the processus alaris of the basis cranii, opposite the sella turcica, outward beneath the semilunar ganglion; it is limited by free margins in front and behind. Its structure is of young cartilage separate from that of the processus alaris, a stratum of mesenchyma standing between them. The temporal wing consists of a larger blade-formed lateral portion, the lamina ascendens, and a small, medial pterygoid process. A separate pterygoid cartilage is present, lying mesad of the pterygoid process below the basis cranii. In connection with the description of the ala temporalis the cavum epiptericum will be considered.

Processus alaris (figs. 2, 23). The alar process lies in front of the carotid foramen, supports the internal carotid artery in its forward course and forms the ventral boundary of the innermost part of the spheno-orbital fissure. Laterally it extends to the temporal wing, the layer of mesenchyma above mentioned limiting the two parts (fig. 23). This layer takes an oblique direc- 
tion from before backward and laterally, on account of which the ala temporalis stande in front, as well as to the side of the processus alaris. Between the latter and the anterior pole of the cochlear capsule extends a cartilaginous bridge, the commissura alicochlearis, forming the lateral boundary of the carotid foramen. It is quite distinct from the temporal wing, the two being separated by the continuation of the zone of mesenchyma just described. The processus alaris and commissura alicochlearis are, however, continuous, and together form an arch around the front and side of the carotid foramen.

The lamina ascendens (figs. 1, 2, 3, 23) of the ala temporalis is a cartilaginous plate which extends laterally and dorsally toward the commissura orbito-parietalis, but remains widely separated from it. It is somewhat triangular in form, presenting free margins, anterior and posterior, which meet laterally in a rounded free point, and a base directed toward the oblique line of junction with the alar process and alicochlear commissure. The dorsal surface slopes from an intermediate longitudinal ridge, forward and backward, thus presenting two subdivisions: an anterior face entering into the floor of the spheno-orbital fissure; and a posterior, supporting the cephalic end of the semilunar ganglion and forming the floor of the epipteric cave. The longitudinal ridge itself lies opposite the lower margin of the ala orbitalis and enters into the ventral boundary of the spheno-orbital fissure. The ventral surface of the lamina ascendens overhangs the mandible and gives origin to part of the pterygoid muscle. A short canal, the forerunner of the foramen rotundum, traverses the lamina ascendens from behind forward, giving passage to the maxillary nerve. The posterior margin of the ala is free and limits anteriorly a broad, deep fissure whose posterior boundary is the cochlear capsule. The fissure ends medially at the alicochlear commissure and, like the spheno-orbital fissure, is open laterally. To this gap, which has long been known, the name fissura alicochlearis may be given. Through it pass the mandibular and the great superficial petrosal nerves, the former through the incisura ovalis in the posterior margin of the lamina ascendens, the latter traversing another notch, incisura lacera, and 
joining beneath the lamina the great; deep petrosal nerve to form the N. pterygoideus. Incisura lacera is the name proposed for the deepest part of the fissura alicochlearis, a part distinguished by certain important relations. It reaches medially toward the carotid foramen, from which it is separated by the commissura alicochlearis, and here adjoins the posterior end of the mesenchymal zone dividing the commissure from the lamina ascendens. A prominent spine of the caudal margin of the ascending plate forms its antero-lateral boundary and stands between it and the incisura ovalis. On the anterior margin of the ala temporalis, adjacent to the processus alaris, is the broad processus pterygoideus (fig. 1), in connection with which is later formed the insignificant bony lamina lateralis processus pterygoidei of the adult. The pterygoid process projects forward and toward the midplane, lying medial of the foramen rotundum. Its medial end is separated from the adjacent pterygoid cartilage by a layer of mesenchyma. At this spot the Vidian nerve begins to turn from beneath the lamina ascendens to gain, eventually, a position dorsad of the pterygoid cartilage and within the spheno-orbital fissure.

The base of the ala temporalis is directed obliquely from behind, forward and medialward and for the most part corresponds to the synchondrosis between the ascending plate, alar process and alicochlear commissure. Two other regions, however, must be included in the base: posteriorly, the medial free margin of the spine separating the incisura lacera from the incisura ovalis, and anteriorly, the medial free margin of the processus pterygoideus. The relations into which the base of the ala enters with the rest of the chondrocranium are, therefore, the medial corner of the spheno-orbital fissure, processus alaris, commissura ali cochlearis and incisura lacera.

Ala orbitalis (figs. 1, 2, 3, 4). This great sickle-shaped cartilage forms, on each side, the larger part of the medial wall of the orbit and the lateral wall of the fore part of the cranial cavity. Its lateral and medial surfaces are respectively concave and convex, apparently in adaptation to the eye-ball and its adnexa. The anterior extremity is joined to the nasal capsule by the com- 
missura spheno-ethmoidalis; the posterior extremity is connected with the fore part of the basis cranii by two roots, named preoptic and metoptic, relative to the optic nerve which they embrace. The preoptic root is broad and straight whereas the metoptic root is narrow and bent so as to present a prominent angle of its caudal margin directed backward. The optic foramen, large and irregulary oval, is bounded medially by the basis cranii, on its other sides by the orbital wing and its two roots. Through the optic foramen a short, blunt process, processus orbitalis, extends into the orbit from the cephalic edge of the metoptic root. On the right side this process lies close to the basis cranii. From the roots of the orbital wing some of the ocular muscles take origin (vide infra). The short concave, anterior margin of the wing is free and separated from the nasal capsule by the fissura orbitoethmoidalis. This is filled by membrane and transmits the lateral branch of the nasal nerve. The extensive, convex, posterior margin, dorsally, passes into the commissura orbito-parietalis connecting the orbital wing with the parietal plate, and ventrally is free in the anterior boundary of the fenestra spheno-parietalis.

The spheno-orbital fissure (Wincza, '98) (figs. 1, 2, 3, 4, 23) in the present stage stands in marked contrast to the circular, completely walled opening of the adult cranium. It is a narrow, deep gap running in a frontal plane between the ala orbitalis above and the ala temporalis and pterygoid cartilage below. It is open laterally, but closed medially by that part of the basis cranii lying between the metoptic root of the ala orbitalis and the processus alaris. It gives passage to the oculomotor, pathetic, ophthalmic and abducent nerves, together with a number of veins which go to join the plexus about the semilunar ganglion and carotid artery.

The carotid foramen (figs. 1, 2) is completely walled, as described by Decker and later by Wincza. It is circular, not large as compared with that in Lepus, stands opposite the middle of the sella turcica and traverses the floor of the skull straight ventro-dorsad. In front is the processus alaris; behind, the cochlear capsule; laterally, the alicochlear commissure. Upon its medial side is the sella turcica. 
Pterygoid cartilage (figs. 1, 3, 24). In the model of the cranium of the $23.1 \mathrm{~mm}$. embryo the pterygoid cartilages appear as a pair of irregular but symmetrically formed bodies lying one on either side of the naso-pharyngeal duct and adjacent to the alae temporales. Each cartilage presents a short cylindrical, transversely placed pedicle and, continuous with it and in a dorso-ventral plane, an elongate, bent plate. The pedicle consists of dense mesenchyma continuous with the perichondrium of the margin of the pterygoid process of the lamina ascendens; in the center bone has begun to form. The N. pterygoideus (Vidiani) turns dorsad upon the posterior aspect of the joint between the pedicle and pterygoid process to enter the spheno-orbital fissure. The plate-shaped part of the pterygoid cartilage presents a flat free surface directed forward, a medial concave margin turned toward the naso-pharyngeal duct and a lateral convex margin giving attachment to the $M$. pterygoideus. In structure the lamina consists of mesenchymal syncytium, within which bone has formed in two regions. One center lies in the dorsal half of the plate and is continuous with the ossific center of the pedicle; the second is found in the ventral half and seems to be separated from the first by a stratum of unossified tissue, broad at the margin and surfaces of the plate, but becoming narrower toward the center. I find it impossible to state whether the two bony centers so clearly separated one from the other at the margins of the lamina are entirely distinct throughout. A mesenchymal condensation surrounds the pterygoid cartilage, extending forward, becoming somewhat less compact, and finally joining the mass of mesenchyma in which the palate bone is forming. This mesenchymal mantle extends dorsally toward the cranial base without, however, quite reaching it.

The region named cavum epiptericum by Gaupp ('05) and interpreted in its relation to the cranial cavity of mammals by this investigator ('02) as an acquisition of a space which, in reptiles, is extracranial, presents some interesting peculiarities in the embryos of cat. First, the epipteric cave with its contained structures is, in the absence of those bones which in the adult form the lateral wall of the skull in this region, wholly outside 
the confines of the brain case of the $23.1 \mathrm{~mm}$. embryo. The exclusion of the space from the cavum cranii is brought about by a strong membrane, conspicuous in the sections, which arises from the base of the cranium and is applied to the medial surface of the semilunar ganglion, excluding this structure, as it rests on the ala temporalis, from the cranial space occupied by the brain. Less dense mesenchyma surrounds the ganglion and extends laterally as far as the temporal muscle; forward through the sphenoorbital fissure and about the ala temporalis; backward, into the cavum supracochleare. The medial limiting membrane calls for special description. We may tentatively refer to it as the membrana limitans (figs. 19 to 23). It fills the foramen sphenoparietale attaching itself to its margins, i.e., to the commissura orbito-parietalis, commissura suprafacialis, where it is perforated by the roots of the trigeminus, and to the metoptic root of the ala orbitalis; then upon the base of the cranium, from the anterior pole of the cochlear capsule along the commissura alicochlearis, crista transversa and dorsum sellae, the lateral elevated margins of the hypophyseal fossa, and on to the tuberculum ephippii. In the bottom of the sella turcica and upon the dorsum sellae the membrane is continuous from side to side. At the saddle-back it is continuous with a stout meningeal membrane which ascends into the narrow space in the flexure of the mid-brain and diencephalon; this may be refered to as the septum transversum (see p. 327). The thickness of the limiting membrane is not the same throughout. It is densest at its broad attachment to the cranial base where it covers the carotid foramen. Also a definite band of condensed tissue extends through the septum transversum from the crista transversa, crossing the $\mathrm{N}$. abducens and the roots of the $\mathrm{N}$. trigeminus running paralkel with the commissura suprafacialis and reaching laterally the parietal plate. It is along this stretch that a small cartilaginous bar is later developed (embryo of $7 \mathrm{~cm}$.) over the dorso-medial surface of the semilunar ganglion and roots of the trigeminus where the latter cross the suprafacial commissure.

The floor of the epipteric cave is formed by the lamina ascendens of the ala temporalis. The following structures are found 
within the cave: the ganglion semilunare and the three divisions of the N. V., the NN. III, IV and VI. The caudal half of the semilunar ganglion rests upon the supracochlear plane, in its cephalic half upon the alicochlear commissure and the posterior subdivision of the dorsal surface of the lamina ascendens. Beneath it, the mandibular nerve passes to leave the cave through the incisura ovalis. The ophthalmic and maxillary nerves leave the region immediately in front of the ganglion, the one by way of the spheno-orbital fissure, the other by the foramen rotundum. Both the oculomotor and trochlear nerves run a long course in the loose tissue immediately surrounding the brain, proceeding from their origins ventrad and cephalad toward the sphenoorbital fissure, where they lie above the ophthalmic nerve. They pierce the membrana limitans just before entering the fissure, and their course in the epipteric cave is therefore very short (fig. 23). On the contrary, the course of the abducent nerve through the cavum epiptericum is very long; it enters the space from behind, passing between the dorsum sellae and cochlear capsule, over the crista transversa and beneath that strand of condensed mesenchyma in the septum transversum which is the forerunner of the cartilage referred to above. Running cephalolaterad, it crosses laterally the carotid artery and gains the medial side of the semilunar ganglion and ophthalmic nerve; in the sphenoorbital fissure it crosses dorsally the $\mathrm{N}$. maxillaris. The internal carotid artery enters the membrana limitans at the carotid foramen, turns forward in this tissue, crosses the processus alaris at the side of the hypophysis, then pierces the membrane in a dorsal and medial direction to enter the cavum cranii. At its entrance into the basal portion of the membrana limitans the artery is ventrad of the sixth nerve, but it turns immediately mesad beneath it. Several veins accompany the nerves through the spheno-orbital fissure and go to form, by anastomoses, a plexus in the membrana limitans which surrounds the carotid artery. The vessels of this plexus are separated by mesenchymal tissue, altogether constituting the beginnings of the channels and walls of the later cavernous sinus. 
The orbit (figs. $3,4,24,25,26$ ) is relatively shallow and is illdefined in extent and boundaries. The planum antorbitale and prominentia lateralis of the ethmoidal skeleton form its anterior wall; the ala orbitalis and its two commissures enter into the posterior wall. The dorsal limit is given by the frontal bone which extends along the spheno-ethmoidal commissure. The ventral limits are found in the zygomatic and maxillary bones. The ocular muscles arise in the following way. From the preoptic root springs the superior oblique; from the orbital process of the metoptic root arise the rectus superior, internus and externus. The origin of the inferior rectus is conjoined with that of the retractor oculi on the lateral surface of the cranial base, ventrad of the metoptic root and adjacent processus alaris; these muscles arise within the spheno-orbital fissure. The inferior oblique springs from the ventral margin of the planum antorbitale well forward of the origins of the other ocular muscles.

\section{Orbito-temporal region in smaller embryos}

Van Wijhe preparations of $10 \mathrm{~mm}$. (fig. 5) present the first trace of chondrification in the orbito-temporal region as a small crescentic cartilage ventrad of the anterior hypophyseal lobe. The concavity of the crescent embraces the hypophyseal stalk. Behind this hypophyseal cartilage and occupying a dorsal plane is the termination of the notochord.

Sections of an embryo of $12 \mathrm{~mm}$. (figs. 16, 17) show that the cranial floor beneath the hypophysis consists of a horseshoeshaped cartilage independent of other parts of the chondrocranium. The legs of the horseshoe lie on either side of the midline beneath the anterior pituitary lobe, reaching as far forward as the trabecular plate, but not united with it; the commissure of the horseshoe crosses behind the stalk of Rathke's pouch. Between the commissure and the terminal expansion of the basal plate is a small space, fenestra basicranialis posterior, occupied by mesenchyma in which the cephalic end of the notochord lies. In median sagittal sections of embryos of $12 \mathrm{~mm}$. (fig. 17) the anterior expanded extremity of the basal plate is turned somewhat in the dorsal direction above the line of the posterior parts 
of the hypophyseal cartilage. The trabecular plate makes its appearance in embryos of the present stage (fig. 17), consisting of a single thick mass of young cartilage continuous anteriorly with the beginnings of the septum nasi. Caudally it reaches almost to the hypophyseal cartilage. In the van Wijhe preparations the limits of the trabecular plate are clearer than in the sections (fig. 6). On its dorsal surface the sulcus chiasmaticus appears; on its sides, the beginnings of the pre- and metoptic processes.

In a frontal section passing through the hypophysis and cochlear canal of an embryo of $12 \mathrm{~mm}$. (fig. 16) the carotid artery appears in its course through the cranial wall. It lies in an oval area of less dense mesenchyma than that a little way behind its position. The denser tissue anterior to the area forms a curved bar, continuous with the side of the hypophyseal cartilage medially, thence extending in a curve outside the artery toward the cochlear capsule. This will be referred to as the commissural element; it is the beginning of the processus alaris and commissura alicochlearis. The oval, light area about the carotid is limited caudally and medially by the cochlear capsule and a bridge of mesenchyma (future basicochlear commissure) stretching from the latter to the hypophyseal cartilage.

In the mesenchyma laterad of the commissural element is a small condensation beneath the Gasserian ganglion, which proves to be part of the medial extremity of the future ala temporalis. This condensation will be refered to as the alar element. The less dense mesenchyma between the latter and the commissural element extends obliquely from before, backward and outward. The mesenchyma of the alar element becomes broader and denser as it extends laterally; its caudal concave margin, pressed against the mandibular nerve, forms the primitive incisura ovalis; within its anterior part appears the maxillary nerve. The ophthalmic nerve (whose ganglionic cells are in part separate from the semilunar ganglion) passes over the alar element toward the eye. The van Wijhe specimens of $12 \mathrm{~mm}$. (fig. 6) show a small darkly stained nodule far removed from the hypophyseal cartilages and lying immediately ventrad of the anterior end of the semilunar 
ganglion. This center is located at the site of the anterior part of the alar element.

In sections the ala orbitalis is a plate of condensed mesenchyma limited sharply in front, above and behind, but connected with the trabecular plate by two roots. The preoptic root extends from the trabecular plate anterior to the sulcus chiasmaticus and passes laterally without interruption into the main body of the ala. The metoptic root is joined to the side of the caudal portion of the trabecular plate. This root terminates laterally in a pointed extremity connected by less dense mesenchyma with the ala orbitalis. The extremity lies beyond the optic foramen, immediately dorsad of the third nerve where this enters the orbit.

The cavum epiptericum in the $12 \mathrm{~mm}$. embryo, is clearly defined toward the base of the neuro-cranium. The membrana limitans (figs. 16, 17) can be followed over the medial aspect of the semilunar ganglion to the anterior end of the basal plate, to the commissural element and over the carotid artery. Upon the lateral side of the membrane, opposite the vessel runs the abducent nerve. At its insertion into the anterior margin of the basal plate (the future crista transversa) the limiting membrane becomes continuous with the septum transversum. Within the latter immediately caudad of the hypophysis is a small, transversely placed precartilaginous rod (indicated by an * in fig. 17).

The pterygoid cartilage is represented by a condensation of mesenchyma lying anterior and ventral of the alar element and close to the epithelium of the pharynx. A constriction incompletely subdivides it into dorsal and ventral parts. Behind this mass is the first pharyngeal pouch; through its dorsal extremity runs the pterygoid nerve.

In embryos of $15 \mathrm{~mm}$. the hypophyseal cartilage has united anteriorly with the trabecular plate, forming the floor of the sella turcica, perforated by a foramen hypophyseos (figs. 7, 18). Union of the basal plate and hypophyseal cartilage has also occurred, but the confines of the originally separate cartilages are still evident (fig. 18). As a result of the incongruity in the meeting of these parts (indicated in the $12 \mathrm{~mm}$. stage) there remains a transverse ridge in the basis cranii behind the pituitary fossa, 
the beginning of the crista transversa. This is the stage of precartilaginous structure of the alar and commissural elements. The latter is continuous with the side of the sella turcica and separated from the alar element by an oblique layer of mesenchyma. The boundaries of the carotid foramen are well defined, the medial boundary being formed by the posterior part of the side of the sella turcica; the caudal limit by the prochondral union of the basal plate and cochlear capsule, the commissura basicochlearis; the anterior and lateral by the prochondral commissural element. The alar element has a homogeneous structure of young cartilage and is now recognizable as the ala temporalis; both the mandibular and maxillary nerves pass through notches in its margins.

In van Wijhe preparations of $15 \mathrm{~mm}$. (fig. 7) a continuous stretch of cartilage occurs in the floor of the cranium in the otic, hypophyseal, trabecular and nasal septal regions. The tuberculum sellae is apparently developed from the caudal and dorsal edge of the trabecular plate. The junction of the basal plate and floor, in the hypophyseal region, is marked by a broad expansion of lightly stained tissue (young cartilage). In a median section (fig. 18) the cartilage in the septum transversum behind the hypophysis, present in the preceding stage, appears as a small nodule. The ala temporalis is represented by a slender sickle-shaped cartilage standing ventrad of the anterior pole of the semilunar ganglion. It is laterally removed from the sella turcica and from the commissural element (the interval is exaggerated in figure 7 ). In the epipteric region the membrana limitans is clearly defined throughout. The origin of the transverse septum is marked by a band-like thickening, extending from the crista transversa laterad over the semilunar ganglion and roots of the trigeminus, and terminating on the suprafacial commissure and parietal plate.

The pterygoid presents no important change from the preceding stage. Chondrification of the ala orbitalis has begun over the eye-ball in the form of a triangular plate, separate from all neighboring cartilages (fig. 7). Posterior to the orbital ala is the independently chondrifying commissura orbito-parietalis; far removed anteriorly are the cartilages of the nasal capsule. One 
angle of the ala orbitalis is directed medially toward the trabecular plate and its two processes, preoptic and metoptic. The extremity of the latter presents the relation with the oculomotor nerve observed in the earlier stage. From the metoptic process a thick projection extends a short distance laterally, just behind the optic nerve, to end in the muscle mass about the nerve; this is the beginning of the orbital process of later stages.

Van Wijhe preparations of embryos of $17 \mathrm{~mm}$. (fig. 8) show a lightly stained curved bar, the combined processus alaris and alicochlear commissure, extending around the carotid artery, from the side of the sella turcica to the anterior pole of the cochlear capsule. Just in front and laterad of the commissure, and separated by an interval of unstained tissue, is the triangular ala temporalis, with the maxillary nerve against its anterior, concave margin, and the mandibular nerve at its posterior side. The separate cartilage behind the infundibulum in the preceding stage is no longer apparent in the sections, but there is now at this spot a clorsal, median process, partly cartilaginous, largely mesenchymal, of the crista transversa. Union of the orbital plate with neighboring skeletal parts has occurred (fig. 8): the medial angle, presenting a notch for the optic nerve, is connected with the pre- and metoptic processes of the trabecular plate; the anterior angle is prolonged to the paranasal cartilage as the commissura spheno-ethmoidalis, thereby completing the boundaries of the fissura orbito-nasalis; the posterior angle is fused with the commissura orbito-parietalis. This commissure, which has united also with the parietal plate, has extended ventrally to the pars canalicularis (commissura parieto-capsularis), but, as sections show, is separated from the otic capsule by a thin layer of mesenchyma (p. 313). Continuity of the cartilage of the orbito-parietal commissure and suprafacial commissure has been described above (p. 301).

\section{Ethmoidal region. Embryo of $23.1 \mathrm{~mm}$.}

The parts of the chondrocranium included in this most clearly defined region of the skull are the paired nasal capsules (figs. 1, $2,3,4)$. These conform closely with the membranous walls of 
the cavum nasi within, and are shaped externally somewhat like a pair of spindles pressed together, making a single strong framework, the cartilaginous ethmoidal skeleton, at the anterior end of the skull.

The length of the cartilaginous ethrnoidal skeleton is equal to about one-third that of the entire cranium. Its anterior half projects free beyond the brain case; its posterior half, terminating on each side in the posterior cupola, is subcerebral in position. Here it is continuous with parts in the orbito-temporal region: the trabecular plate passing into the septum nasi and roof of the posterior cupola, the commissura spheno-ethmoidalis joining the lateral nasal wall. An extensive roof, tectum nasi, is in the anterior half of the ethmoidal skeleton; an incomplete one, lamina infracribrosa, in the posterior. The roof goes over on either side into the paries nasi. The interior room of the nasal skeleton opens into the cranial cavity by the fenestrae olfactoriae, and upon the face through the fenestrae narinae. The floor of the capsule, solum nasi, is very incomplete, presenting a great fenestra basalis, within the compass of which are the paraseptal cartilages standing next to the nasal septum. The side walls within, present the beginnings of the complex of turbinals in the form of simple inrollings and elevations.

The tectum nasi (figs. 1, 3, 27 to 30 ) is furrowed in the midline of its dorsal surface by the sulcus supraseptalis, deepest anteriorly, extending from the fenestra olfactoria to the level of the fenestra narina. On either side the roof is highly arched and passes laterally into the anterior region of the paries nasi.

The side wall (figs. 3,4 ) presents three regions: an anterior, continuous with the tectum nasi, a middle region occupied by the rounded prominentia lateralis, and a posterior area, the planum antorbitale. Two grooves demarcate the prominentia lateralis from the anterior and posterior regions. One of them, the sulcus lateralis anterior, at first pursues a curved course from the olfactory window near the mid-line, cephalo-ventrad between the tectum nasi and prominentia lateralis. This part of the sulcus stands opposite the crista semicircularis within the nacal capsule and is interrupted by the epiphanial foramina of which 
there are two on each side. In its ventral one-third the groove is broad and shallow and adjoins the anterior region of the paries nasi and the lateral prominence. It occupies an area which passes ventrally into the maxilloturbinal and stands at a level anterior to the crista semicircularis. This part of the paries nasi corresponds to the lamina supraconchalis of Voit. The second groove, sulcus lateralis posterior, limits the lateral prominence posteriorly; it is broad and shallow and stands opposite ethmoturbinal I within the capsule. The anterior region of the paries nasi extends from the antero-lateral sulcus to the lateral margin of the fenestra narina. It is co-extensive with the roof dorsally, but becomes narrow ventrally where it joins the lamina transversalis anterior. The surface in this region is convex, corresponding to the internal concavity of this part of the lateral wall. The middle region, the prominentia lateralis, is narrow from before backward. Dorsally it is united with the commissura spheno-ethmoidalis and forms the lateral boundary of the olfactory window, between the posterior extremities of the crista semicircularis and ethmoturbinal I (vide infra). Ventrally it passes into the maxillo-turbinal. The posterior area, antorbital plane, corresponds to the region within occupied by the ethmoturbinals, and forms the antero-medial wall of the orbit. Where it adjoins the middle region of the paries nasi (sulcus lateralis posterior) there is present ventrally a rounded prominence, giving origin to the inferior oblique muscle of the eye. The dorsal margin of the antorbital plane at the orbito-nasal fissure, participates, anteriorly in the lateral boundary of the olfactory window, and posteriorly passes into the lamina infracribrosa. The ventral margin is straight and free in the lateral boundary of the fenestra basalis. Caudally, this division of the nasal capsular wall continues into the posterior cupola. This conical shell extends backward at the side of the nasal septum and trabecular plate beneath the preoptic root of the ala orbitalis. It is closed ventrally by the lamina transversalis posterior, which reaches to the septum nasi. The roof of the posterior cupola is formed by the unpaired lamina infracribrosa (figs. 1, 25). This plate presents a free edge anteriorly toward the fenestra olfactoria, con- 
tinues caudally into the dorsal surface of the trabecular plate and laterally goes into the planum antorbitale. A slight median ridge, crista interorbitalis, separates two shallow fossae lodging the olfactory tracts.

Ventrally, the nasal capsule presents the great fenestra basalis (figs. 1,2), the relations of which to the cavum nasi are somewhat complicated. It is limited laterally by the ventral margin of the planum antorbitale and by the maxillo-turbinal. In the region of the latter it is very narrow from side to side, and is partly covered ventrally by the paraseptal cartilage hanging down from the septum. Anteriorly the basal window reaches to the lamina transversalis anterior which stands between it and the fenestra narina. The caudal limit is formed by the lamina transversalis posterior. Further relations of the basal window will be better understood when considered in connection with the description of the nasal cavity.

The solum nasi is represented by the two transverse laminae and the horizontal portion of the paraseptal cartilage (figs. 2, 3, 13, 25, 26). The lamina transversalis posterior (figs. 2, 13, 25) forms the floor of the posterior cupola and appears in the sections and in the model as an inrolling of the caudo-ventral part of the planum antorbitale. Its medial margin is turned dorsad; in its caudal half it is applied closely to, but not actually joined with, the keeled trabecular plate behind the level of the vomer; in its cephalic half it is free, being separated from the nasal septurn by a narrow stretch of the fenestra basalis. Here the lamina is overlapped by the caudal end of the vomer. The bandlike lamina transversalis anterior (figs. 2. 3, 13), incompletely chondrified, bounds the fenestra narina ventro-laterally, connecting the septum nasi with the paries nasi. It is continuous with both parts, that is io say, a zona annularis is present. Its horizontal, broader, septal end stands opposite the anterior half of the os incisivum. Followed laterally, the lamina undergoes a curve in the dorsal direction, and comes to lic in a sagittal plane. ${ }^{8}$

${ }^{3}$ In eat embryos of about $70 \mathrm{~mm}$. the lamina transversalis anterior presents two backwardly directed processes which embrace the funnel-shaped depression of the floor leading into the incisive duct. These have been called by Zucker- 
Just ventrad of its junction with the anterior part of the paries nasi it is crossed by the naso-lacrimal duct. The caudal margin of the lamina is free and is separated by a wide interval from the paraseptal cartilage.

Behind the anterior transverse lamina, the tear duct lies upon the most ventral part of the paries nasi and is further supported by a cylindrical processus maxillaris anterior of the latter (figs. $3,13,30$ ) directed forward. At this place the os maxillare overlaps the nasal capsule and, in the model, hides from view the maxillary process and tear duct.

The cartilago paraseptalis (figs. $2,3,13,28,29$ ), scroll-formed in adaptation to Jacobson's organ, hangs from the septum nasi below the level of the plane of the fenestra basalis. It is unconnected with other parts of the nasal skeleton. The medial half of each cartilage lies in a sagittal plane applied against the ventral part of the septum. The lateral half is rolled dorsally to form a gutter lodging the vomero-nasal organ. The cephalic margin is free and straight; the caudal pointed. The long axis of Jacobson's cartilage extends from behind cephalo-ventrad, the caudal extremity lying at the level of the basal window, the cephalic end reaching a position ventrad of the plane of the anterior transverse lamina. At this stage the paired naso-palatine cartilage is represented by a stretch of prochondral tissue upon the lateral side of each incisive duct." The U-shaped beginning

kandl the medial and lateral limbs of the ventro-lateral process of the septal cartilage. The incisive duct is partly enveloped on its lateral side by a troughshaped nasopalatine cartilage, which reaches from a spot near the oral end of the duct, to the level of the entrance of the duct of Jacobsou's organ. The last named canal is surrounded completely by a cartilaginous tube which, as it ascends toward the cavum nasi, gradually loses its dorsal wall and becomes continuous with the anterior extremity of the paraseptal (Jacobson's) cartilage. The cartilage of Jacolsson's duct lies medial of the process of the lamina transversalis anterior; neither it nor the nasopalatine cartilage is joined with the processes of the anterior transverse lamina.

1 The paraseptal cartilage in embryos of $70 \mathrm{~mm}$. presents an anterior process, continuous with the cartilage of the duct of Jacobson's organ, and continues posteriorly into a slender cartilaginous paraseptal rod. The latter lies against the side of the ventral edge of the vomer and extends to the floor of the pusterior cupola, the lamina transversalis posterior with which it is directly continuous. 
of the vomer (figs. $2,26,27$ ) embracing the ventral edge of the septum nasi, lies at some distance behind the paraseptal.

The fenestra narina (figs. 2, 3, 4, 13), oval with its long axis dorso-ventral, faces rostro-laterad. Its medial boundary is formed by the septum, the lateral and ventral by the lamina transversalis anterior, the dorsal, by the paries nasi. 'The lateral margin presents a deep notch, the incisura lacrimalis, where the naso-lacrimal duct turns medialward toward its termination. The ventral margin of this notch is formed by the sagittal portion of the anterior transverse lamina; the dorsal margin by the rostral extremity of the atrioturbinale, or inrolled ventral margin of the paries nasi. The lacrimal notch is the meeting place of two divisions of the fenestra narina, a dorsal and a ventral. The former leads to the atrial region of the cavum nasi; the latter division receives the naso-lacrimal duct and opens into the inferor meatus. The names pars atrialis and pars lacrimalis, respectively will be used in further reference to these divisions of the fenestra narina. In the present stage the superior alar process is represented in dense mesenchyma. It is chondrified in the $7 \mathrm{~cm}$. embryo.

Fenestra olfactoria (figs. 1, 13, 26). The paired, quadrilateral olfactory fenestrae offer wide communications, in the present stage, between the nasal and cranial cavities. Their position is in the caudal half of the nasal capsules, that is, in the subcerebral division, between the tectum nasi, anteriorly, and the roof (lamina infracribrosa) of the posterior cupola, posteriorly. The plane of each opening looks dorso-caudad and also somewhat mesad. The anterior boundary, formed by the caudal free margins of the tectum nasi and prominentia lateralis, is considerably wider than the posterior limit, made by the infracribrous plate. The medial side is formed by the dorsal concave margin of the septum nasi. The oblique lateral boundaries of the olfactory fenestrae are formed by the dorsal margins of the prominentiae laterales and the antorbital plates. On the anterior and lateral sides of the fenestra olfactoria of the model are three processes, the caudal extremities of the crista semicircularis, ethmoturbinal I and ethmoturbinal II. Between these processes, the 
olfactory fenestra extends in the form of three bays or sinuses. In the present stage there is no cartilaginous cribriform plate; its place is occupied by mesenchyma perforated by the olfactory nerves. These are in two groups, one near the septum, the second represented by bundles passing through the sinuses at the side of the window. The sheet of mesenchyma perforated by the olfactory nerves does not quite fill the fenestra olfactoria. It is closely applied to the septum nasi, then crosses the midline to be continuous with the membrane of the opposite side; it is fixed at the anterior boundary of the window (tectum nasi). Posteriorly the membrane passes over the lamina infracribrosa against which it is closely applied. In the lateral direction it becomes continuous with the membrane filling the sphenoethmoidal fissure. This is fixed to the dorsal but not to the ventral boundary of the fenestra, which, it will be recalled, is formed by the antorbital plate. In relation to this membrane is the lateral branch of the nasal nerve (fig. 26). 'The latter appears in the sections through the anterior part of the orbit, running toward the spheno-ethmoidal fissure. This it enters, passing ventrad of the membrane, a position it retains in its course forward to the olfactory fenestra. Here it enters the nasal capsule, pursues a short course through the crista semicircularis and then passes to the exterior by one of the epiphanial foramina.

Seplum nasi (figs. 1, 2, 25 to 30). This median partition is the direct continuation of the trabecular plate forward into the ethmoidal region. It is low and broad caudally where it lies between, and enters into the median walls of the posterior cupolae. As it extends forward the dorsal margin ascends, the height of the septum increasing gradually toward the fenestrae olfactoriae; between the olfactory fenestrae it increases rapidly and reaches its maximum height at the tectum nasi; then decreases gradually in approaching the level of the fenestrae narinae. The ventral margin of the septum presents a longitudinal concavity, and is thickened between the paraseptal cartilages and again opposite the vomer. Anterior to the paraseptals it is united on each side to the anterior transverse lam- 
ina, the line of junction being marked ventrally by a longirudinal groove. The anterior frec margin is straight and reaches further rostrad than the lateral wall of the nose. Dorsally, the septum presents between the olfactory fenestrae a free concave edge (there is no evidence of a crista galli) and, in its precerebral portion, continues into the tectum nasi. The latter relation appears in the sections of the anterior third of the nose as a bifurcation of the septum into two laminas, which extend on either side into the roof of the nose (fig. 28). In this way the sulcus supraseptalis is formed.

Interior of the nasal capsule (figs. 13, 25 to 30). The conformation of the nasal capsular walls from within is extremely simple at the present stage as compared with that of the adult. 'Turbinal processes are in evidence in the form of ridges, the maxilloturbinal alone showing any degree of scroll form. The bones in relation to the nasal cavity are the yomer, incisivum and maxilla.

Lateral wall of the cavum nasi. In figure 13, which represents the left lateral wall of the nasal capsule from within, the following parts, already referred to, will be recognized: the tectum nasi extending from the fenestra narina to the fenestra olfactoria, the posterior cupola and lamina transversalis anterior, parts showing cut surfaces at their junction with the septum nasi; ethmoturbinale I and II presenting at the olfactory fenestra; the crista semicircularis and the nasoturbinal; the inrolled ventral margin of the paries nasi forming the maxilloturbinal and atrioturbinal. The lateral wall of the cavum nasi presents two unequal divisions: a small region ventrad of the level of the maxillo- and atrioturbinals, and an extensive region dorsad of this level. The former includes the sagittal portion of the lamina transversalis anterior and the incisura posttransversalis; the latter corresponds to the rest of the lateral nasal wall.

Ventral region of lateral wall of the cavum nasi. The sagittal portion of the lamina transversalis anterior presents a smooth, concave surface toward the cavum nasi, becoming broad ventrally where it passes into the floor of the nose (frontal portion of the lamina transversalis anterior). Caudad of the lamina 
the cartilaginous lateral wall of this region is deficient; here the great notch, the incisura posttransversalis is found (figs. 2, 3, 4, $13,29)$. This space is entered from behind and ventrally by the cartilaginous anterior maxillary process. The post-transverse notch is closed toward the nasal mucosa, by a layer of mesenchyma and by the incisive and maxillary bones which lie just outside the plane of the cartilaginous nasal wall (figs. 29, 30).

The dorsal region of the lateral wall of the cavum nasi corresponds on the exterior to the paries nasi as described on p. 380 and may, like it, be considered as presenting three divisions, anterior, middle and posterior.

In the anterior division (pars maxillo-nasoturbinalis) will be included, for convenience, the inner surface of the lamina supraconchalis, although, as will be seen later, its primary relation to the components of the nasal side wall was not established. This division, then, extends from the level of the fenestra narina to the crista semicirculars, and is limited ventrally by the maxilloand atrioturbinals. The most cephalic portion reaches the atrioturbinal ventrally, and forms the lateral boundary of that part of the nasal cavity here designated the atrium. The atrioturbinal is in line with the maxilloturbinal but is separated from that process by a notch, the incisura maxillo-atrioturbinalis. The succeeding part of the anterior division stands opposite the area of the lamina supraconchalis and sulcus lateralis of the external surface of the nasal capsule, and further includes the maxillo-turbinal and crista somicircularis in its ventral and caudal limits respectively. The maxilloturbinal, triangular in general form, is continuous laterally by its base, with the paries nasi at the eminentia lateralis. It stands mainly in a frontal plane; its medial margin, opposite the septum, inclines ventrocaudad to meet the caudal margin at an angle opposite the paraseptal cartilage. Antcrior to the level of the paraseptal it participates with the paries nasi in the caudal boundary of the post-transverse notch; posteriorly to the paraseptal it forms, by its free margin, a wide notch or sinus with the ventral free border of the antorbital part of the paries nasi, both entering into the boundary of the fenestra basalis. The maxilloturbinal 
reaches its greatest breadth opposite the base of the crista semicircularis; from this point caudad it rapidly diminishes in width. On the lateral wall, dorsad of the maxilloturbinal, is a low antero-posterior eminence produced by a slight inward bulging of the paries nasi in the region of the lamina supraconchalis. This elevation is at the base of the great naso-turbinal body composed of mesenchyma in the present stage (figs. 13, 29). Posteriorly; the elevation in question and the nasoturbinal continue into the crista semicircularis (figs. 13, 27, 28, 29). The latter, at present, forms the anterior boundary of the entrance into the recessus lateralis (figs. $23,27,28,29$ ) ; it extends ventrodorsad to the tectum nasi, sweeping in a fine curve caudally, alongside the septum, and terminating at the olfactory fenestra as already described (p. 334, fig. 1). Where the crest approaches the tectum nasi, more or less complete discontinuity of the cartilage occurs in the line of the sulcus lateralis. A small fissure here, made by the foramina epiphanialia (figs. 28, 29), separates, for a short distance, the wall of the recessus lateralis from the tectum nasi. A wide meatus of the lateral nasal wall (here termed meatus supraconchalis) runs between the naso- and maxilloturbinal bodies, continuing anteriorly into the atrium. Posteriorly this meatus extends ventrad of the crista semicircularis (here it is very narrow) and enters into a wide space which opens into the fenestra basalis (fig. 13). Just where the meatus passes into this space, and at a spot anterior to the ventral end of the crista semicircularis, the lateral nasal glands lie under cover of the mucosa (fig. 27). In its posterior half the meatus supraconchalis is extended into a groove between the maxilloturbinal ventrally, and paries nasi (lamina supraconchalis) laterally, the sulcus supraconchalis of Voit.

The middle division corresponds to the prominentia lateralis of the exterior and presents the recessus lateralis to which reference has been made. This large cavity communicates with the general room of the nasal capsule by a wide opening behind the crista semicircularis. Anteriorly it undermines the crest for a short distance in the form of a blind pocket; caudally it reaches the first ethmoturbinal, and dorso-caudally opens into 
the olfactory fenestra through the sinus between the crista semicircularis and ethmoturbinal I (p. 335). Although at this stage the cartilaginous parts fail to meet in forming a medial wall for the inferior portion of the lateral recess, the soft parts which stretch between ethmoidal I, the crista semicircularis and the floor shut off this part of the recess from the common meatus of the nose and convert this part of the cavity into a blind pocket. Similarly, the entrance from the common meatus into the recessus lateralis between ethmoidal I and crista semicircularis is very broad, as shown in the models, but by the presence of the soft parts over these elevations, it is reduced to a narrow fissure, the hiatus semilunaris of later stages. The lateral recess is incompletely subdivided into dorsal and ventral rooms, recessus lateralis superior and recessus lateralis inferior, by a slight frontal ridge springing from the lateral surface of ethmoturbinal I, and by an oppositely placed ridge of the lateral wall of the recess (fig. 27). The superior lateral recess opens into the common meatus of the nose through the dorsal part of the hiatus semilunaris. Within it are two antero-posterior, curving ridges of the mucosa, one upon the roof, the other on the lateral wall. Each includes a condensation of the mesenchyma which is in contact, but apparently not continuous by any transitional zone, with the cartilaginous wall. These ridges separate three outpocketings of the recessus lateralis superior, a lateral, a superior and an inferior groove (fig. 27). The recessus lateralis inferior is incompletely walled medially, as already explained. It lodges a blind sac of mucosa which communicates with the common meatus through the ventral part of the hiatus semilunaris.

Posterior division. (Pars ethmoturbinalis). This region of the dorsal part of the lateral nasal wall corresponds to the antorbital plane of the exterior. It is characterized by the presence of the bases of the ethmoturbinals. Ethmoturbinal I appears in the model as a massive irregular ridge, extending dorso-ventrally on the lateral nasal wall at the caudal margin of the entrance into the recessus lateralis (fig. 13). Anteriorly, the process goes over into precartilage in the form of a broad, 
thick piece, triangular in section, extending cephalad toward the crista semicircularis (fig. 27). Its medial surface bounds the common meatus; a dorso-lateral surface enters into the floor of the recessis lateralis superior; the ventro-lateral face is turned toward the recessus lateralis inferior. Ethmoturbinal I reaches the olfactory fenestra in the thick layer of mesenchyma filling this space (fig. 1); ventrally it is separated by a wide stretch from the level of the solum nasi; anteriorly it enters into the caudal boundary of the hiatus semilunaris. Ethmoturbinal II (figs. 1, 13, 26) is represented by a small cartilaginous plate, with precartilaginous margins, jutting mesad from the lateral nasal wall between ethmoturbinal I and the posterior cupola. From the level of the olfactory fenestra its long axis extends ventro-rostrad. It terminates a considerable distance above the plane of the fenestra basalis.

The cavity of the posterior cupola lies behind ethmoturbinal I, occupying the caudal extremity of the nasal capsule. The walls formed by the septum nasi, lamina infracribrosa, lamina transversalis posterior and antorbital plane, are smooth. The cavity opens anteriorly and ventrally into the common meatus of the nose and the fenestra basalis.

\section{Ethmoidal region in smaller embryos}

The first evidences of chondrification in the ethmoidal region were found in embryos of $12 \mathrm{~mm}$. in which the process was manifested in the septum nasi (fig. 17). In van Wijhe preparations the ventral part of the septum was stained blue (fig..6), appearing in the form of two streaks extending from the trabecular plate forward, side by side and separated by a less deeply stained tract. In embryos of $15 \mathrm{~mm}$. chondrification of the septum has extended dorsally, reaching its greatest height in front. It is now a single median cartilage (fig. 18). The septum is continuous with the trabecular plate caudally, and in front gives off a pair of arching processes from its dorsal margin (fig. 7). The latter, which may be called the parieto-tectal cartilages, are at this stage in relation to the roof and lateral wall of the anterior one-third of the nasal cavity. Whether these processes are pri- 
marily outgrowths of the septum is brought into question by the fact that they are most deeply stained in the van Wijhe preparations in their lateral parts and less so next to the septum. In the midline dorsally a deep groove, the beginning of the sulcus supraseptalis, lies between them. Besides the paired parietotectal cartilages, there is, in the nasal region of van Wijhe preparations of $15 \mathrm{~mm}$., a mass of cartilage quite independent of other chondrifying tracts. This is a curved plate, overlying, on each side, the diverticulum of the cavum nasi, which later is included in the recessus lateralis of the cartilaginous wall. This cartilage may be referred to, tentatively, as the paranasal cartilage. The parietotectal and paranasal cartilages stand close together, the one in front of the other. It is of importance to note that the dorso-cephalic margin of the latter overlaps the dorso-caudal edge of the former. Van Wijhe preparations of $17 \mathrm{~mm}$. exhibit still a third chondrifying tract in relation to the nasal wall (fig. 8). This is a small plate of cartilage at the very back of the cavum nasi, on either side of the nasal septum. It appears to be entirely free from the septum and paranasal cartilage. This lamina antorbitalis, as it may be called, lies in a plane anterior to that of the origin of the preoptic root from the trabecular plate, and behind the paranasal cartilage. It is curved about the caudal end of the nasal sac, thus indicating the beginning of the posterior cupola. The anterior margin of the antorbital lamina projects into the fold of ethmoturbinal I behind the diverticulum of the lateral recess, and is overlapped by the caudal edge of the paranasal cartilage. The latter is larger than in the preceding stage and presents anterior and ventral incurved margins, continuous with each other. The ventral edge projects into the fold of the maxilloturbinal and represents the base of the cartilaginous process of that name. The anterior incurved margin overlaps the lateral and, at the same time, caudal margin of the parieto-tectal, and fusion has occurred to some extent between them. A double layered curved ridge is thus formed, projecting into that fold of the nasal wall which bounds the lateral recess anteriorly; this is the beginning of the crista semicircularis. Where fusion has not occurred be- 
tween the paranasal and parieto-tectal cartilage, spaces remain, one of which is traversed by the lateral branch of the nasal nerve; this is the beginning of the foramen epiphaniale. The overlapping and fusion in the ventral region occurs between the inrolled anterior and ventral margins, where, in later stages, the lamina supraconchalis and nasoturbinal are found. The formation of these parts, however, was not observed. The dorsal margin of the parieto-tectal cartilage lies next the olfactory bulb and is joined with the commissura spheno-ethmoidalis. The triangular parieto-tectal cartilage has grown backward along the septum nasi nearly its full length, thus forming the roof of the nose. Its caudal and lateral oblique margin enters into the formation of the crista semicircularis. In its anterior part it reaches, in a ventral direction, as far as the naso-lacrimal duct. The lamina transversalis anterior is unchondrified. The paraseptal cartilages are represented by incompletely chondrified tracts, independent of other skeletal parts.

\section{PART II. DISCUSSION}

\section{Occipital region}

Basal plate. As we have seen, the first evidence of a basal plate was in the form of a pair of small cartilages on either side of the notochord of the occipital region, united anteriorly by a hypochordal commissure. Wincza has already observed this early form of the base of the cranium and called the two component laminae the parachordal plates.

Regarding the chondrification of the basal plate in mammals, several authors have shown that the initial stage is characterized by the presence of a pair of cartilaginous centers or tracts, one on either side of the notochord in the occipital region. Parker refers to the basal chondrification in the embryo pig, first ('75), as the 'investing mass,' later ('77) as the parachordal 
cartilages. It is not clear Irom the description that there are two separate elements present. The term "investing mass" is misleading with respect to the notochord; Parker expressly states that the former lies beneath the notochord and so represents the relations of these two parts in the figures. Froriep ('86) recognized a tendency to the formation of bilateral symmetrical anlagen of the caudal part of the occipital floor in the calf ( $p$. 91, woodcut to fig. IV, fig. IV, 2). This author remarks on the striking difference between cervical vertebrae and the occipital vertebra presented by the bilaterality of the anlagen of the bodies. In the former it becomes more pronounced in the cranial direction, whereas in the occipital vertebra this condition is presented in a lesser degree. In reference to the anlage in the occipital floor, Froriep says: "In einem Querschnitt dagegen wie Fig. IV, 2, ist eine bilaterale Sonderung des Knorpelgewebes nicht zu bemerken, die Knorpellage ist hier ventralwärts der Chorda fast ebenso mächtig wie zu beiden Seiten" (p. 91).

In the light of recent studies the condition represented in the figure might justly receive a different interpretation with respect to bilaterality of the anlage; the figure shows two cartilages in the occipital floor, one on each side of the notochord and some distance removed from it, united by continuous cartilage across the midline ventrad of the notochord. Levi ('00) described a pair of precartilaginous and cartilaginous anlagen for the middle piece (basilar portion) of the occipital region in a human embryo of about $13 \mathrm{~mm}$. These were united across the midplane by connective tissue in which ran the notochord, and which was continuous in a caudal direction with the connective tissue of the first cervical vertebral arch (p. 355). Bardeen ('08) also observed the beginning chondrification of the base of the occipital in man in two bilateral centers. Other investigators have recorded an unpaired chondrogenous beginning of the occipital basal plate, or, again, its development in connection with the lateral occipital arch. Weiss ('01) found, in the white rat, that chondrification of the floor of the occipital region was manifested, first, by centers in the hypochordal region, one of them in Froriep's apparently unsegmented portion, the other in the 
region of Froriep's occipital vertebra. Noordenbos ('05) found the occipital basal anlage to be single in the mole, calf and pig and also in the rabbit. Regarding the parachordal plate in the latter, this author found that it was formed by the fusion of the opposed ends of the two free occipital arches which were first to develop and from this starting point, grew forward ( $p$. 375). Here are then, apparently, three different conditions presented in the origin of the cartilaginous basal part of the occipital in mammals: the appearance of a hypochordal center; a pair of bilaterally placed masses; origin by growth and fusion of the apposed ends of the lateral occipital arches.

Regarding the relation of the notochord to basal plate, it was found that in cat embryos of about $10 \mathrm{~mm}$. the former enters the occipital region between the parachordal cartilages and lies in the dorsal part of the mesenchymal sheet which unites these cartilages across the midplane. This mesenchymal sheet later becomes chondrified in connection with the parachordals, forming thus a hypochordal bridge closing the space which originally separated these cartilages (Terry, '13). Where the notochord lies between the parachordals it is surrounded by a layer of denser mesenchyma than that concerned in hypochordal arch formation; this specialized sheath is continuous with the mesenchyma about the notochord in the region of the atlas-that in which the atlantal centrum is later formed. In regard to a cartilaginous hypochordal layer in the occipital region of mammals generally, there seems to be no doubt of its constant occurrence. My own observation of the position of the notochord with reference to the basi-occipital region in cat is in agreement with that of Williams ('08), namely, that after chondrification is well established, the caudal portion of the basal plate is hypochordal. Recently Kernan ('15) has observed the hypochordal position of the basal plate in cat embryos. Parker, Froriep, Levi, Noordenbos, and Weiss have observed, in various mammals, that the caudal part of the occipital basal cartilage is ventrad of the notochord.

The parachordals in cat are united at their anterior ends across the midplane (embryos of about $10 \mathrm{~mm}$.) by a hypo- 
chordal commissure of young cartilage. This lies at a level cephalad of that of the anterior root bundle of the hypoglossal nerve. Cartilage afterwards forms dorsad of the notochord in the region of the primary commissure, so that the former comes secondarily to lie within the basal plate. I am aware of the fact that some observers have described this anterior commissure of the parachordal in other forms as lying dorsad of the notochord, but in cat I have found it primarily hypochordal. Weiss, however, found the primary process of cartilage formation hypochordal in the apparently unsegmented division of the basal plate. The next cartilaginous union to be established between the parachordal cartilages in cat is the hypochordal arch uniting their caudal extremities. This has formed somewhat earlier than the anterior arch of the atlas, next to which it stands. The posterior hypochordal commissure is in the same transverse plane as the primitive lateral occipital arch. Between the two hypochordal arches, anterior (primary) and posterior, there remains a sheet of mesenchyma, stretching from side to side beneath the notochord, and continuing into the medial edges of the parachordals. The direction in which chondrification proceeds in this tissue is lateromesad. In the middle of this tissue a third commissural process is indicated where the medial edge of each parachordal sends a projection toward the midplane, producing a constriction in the vacuity between the parachordals. These two symmetrical processes are directed ventro-mesad to a hypochordal plane and lie at a level corresponding to the middle of the future hypoglossal foramen. In the smaller embryos $(9 \mathrm{~mm}$.) four membranous arehes in the occipital region were noted by Kernan, who states that the two cranial have a tendency to fuse.

When, in the cat, the parachordal plates have formed, the three root bundles of the hypoglossal lie against their lateral margins, in the angle formed by the lateral occipital arch. The foramen is later completed by the formation of a cartilaginous bar in front of the nerve roots, which extends laterally and dorsally from the anterolateral corner of the parachordal, to unite with the primary lateral occipital arch beyond the 
nerve roots. The three roots are united in passing through the hypoglossal notch of the primitive cartilaginous occipital element, and there is no indication of a subdivision of the margin into smaller notches for each root, as appears to be the case in an earlier stage and before cartilage has formed. This condition varies in mammals; in rabbits for example, (Noordenbos, Voit) two canals are present on each side. That two canals occur occasionally in the human skull as an anomaly is well known. It will be recalled that the hypoglossal nerve in cat embryos shows a tendency to conform with a spinal nerve in presenting a posterior root and ganglion in relation to the third motor root. The presence of this ganglion was discovered by Vulpian ('62) and I can confirm this observation here.

The presence of more than two cartilaginous hypochordal commissures in the development of the occipital basal plate has, I believe, not been recognized. Also, the recognition of the primary hypochordal nature of the anterior commissure apparently rests on only one other observation, that of Weiss, in the rat. Until further distribution of these phenomena be discovered, or the present observation confirmed, it would seem of little profit to attempt an interpretation of their significance. The antero-posterior succession of a series of transversely placed bar-like structures in the base of the skull at once suggests the idea of segmentation. A relation of these bars laterally with the hypoglossal nerve roots may or may not be a primary one. But in utilizing the results of chondrocranial study in any discussion of the segmentation of the cranium, it must be borne in mind that such evidence can be of high value only when the relation of chondral to blastemal developmental processes is known. It seems highly probable that the cartilaginous commissures here described and the membranous bars observed by Kernan ('15) are two developmental phases of one and the same process, which subsequent investigation will elucidate.

In regard to the condensed tissue sheath about the occipital notochord found in cat, it may be said that a number of observations made on different animals point to the presence of such a layer as probably of general occurrence. Froriep ('86, p. 92) 
records the presence in the calf of a connective tissue layer dorsad of the chorda. Weiss ('01) found, in embryos of the white rat, an exceptional development of the perichordal sheath in the occipital region, not separated from the horizontal plate of the primitive arch of the atlas (p. 511). The work of Gaupp ('06) on Echidna, and Weigner ('12) on man, support the view, first brought forward by Weiss, of a special development of perichordal tissue about the occipital notochord in mammalian embryos. Weiss described the notochord as occupying, in the blastemal stage, a position at the dorsal surface of the segmented portion of the floor of the occipital region; he found that the cranial end of the perichordal sheath grew to assume a globular form; in the chondral stage, cartilage appeared in the perinotochordal sheath, quite independently of the process of chondrification which takes place lateral to and beneath the notochord in the formation of the lateral occipital arches and the basal plate. The more or less spherical cartilage so formed about the notochord is fused, in later stages of development, with the cartilaginous centrum of the atlas, and becomes eventually the extremity of the dens epistrophei. Weiss saw in the cartilage forming the end of the dens epistrophei, which is marked off from the cartilaginous centrum of the atlas by grooves, an element comparable with a vertebral centrum, and concluded that it represented the body of an occipital vertebra, or of a proatlas. Gaupp ('06) found the dens epistrophei in Echidna embryos to be composed of the centrum of the atlas and, in addition, of material lying cephalad (and perhaps derived from the basis cranii). This author is of the opinion that the dens epistrophei and the ligamentum apicis dentis represent the anterior reduced end of the vertebral column in which a number of vertebral centra lie imbedded. Weigner ('11) found in a human embryo of $13.5 \mathrm{~mm}$. paired anlagen in the floor of the occipital region, presenting a notch laterally for the hypoglossal nerve, with a deep groove between their caudal extremities occupied by mesenchyma, in which the notochord lies. In the ventral part of this sheet, the hypochordal arch of the occipital region was observed. In the atlantal region, in the tissue dorsad of the notochord, the 
paired anlagen of the atlantal centrum were noted. Evidence of the beginning of the occipital centrum was presented in an embryo of $14.5 \mathrm{~mm}$; t the anlage was clearly defined in a later stage $(15.3 \mathrm{~mm}$.) as a pair of centers behind the notochord, which pass in a caudal direction gradually into the older centers of the body of the atlas. In man, according to Weigner, the body of the definitive epistropheus with its tooth-process, is developed from three vertebral bodies; those of the occipital vertebra, atlas and epistropheus. The dens itself is formed from the centrum of the occipital vertebra and of the atlas. In the present work no separate centers, in advance of that for the atlantal centrum, were seen, but the tissue about the occipital notochord became condensed next to the chondrifying center of the atlas, and eventually became the cartilaginous apex of the dens epistrophei. In the ossification of the dens epistrophei of cat (as in several mammals) there is, in addition to the bilateral atlantal centers, a single center for the apex of this process (Jayne '98).

Since Froriep's work on the development of the occipital region ('83, '86, '02), the interpretation which that investigator drew from his own results of the relation between cranial and vertebral development and structure has been, in general, sustained; some of the conclusions have, however, been modified by new evidence brought out by recent research. Noordenbos, in 1905, attacked the evidence which has been used in support of the vertebral theory of the skull, claiming in effect that it does not support the homology of parachordal plate and occipital arches with vertebral centra and vertebral arches. Noordenbos rightly objects to the comparison of vertebral bodies, arising as separate, rounded cartilaginous masses, with the parachordal plates, continuous unsegmented masses presenting no trace of special chondral centers. He states that vertebrae arise around the body notochord while the parachordal plate does not. This plate takes origin in one of the three ways mentioned above: as an independent center at the side of the notochord; in connection with the lateral occipital arch; in connection with a hypochordal plate. By the van Wijhe method the vertebral 
centra in the mole were found to arise in connection with intravertebral capsules, outside the sheath of the notochord. Furthermore, the relation of the neural arch of a vertebra to its centrum differs from that between the lateral occipital arch and parachordal; in the former the parts are primarily independent, in the latter continuous. On account of these discrepancies between vertebral and occipital chondrogenous development, Noordenbos finds weak support for the vertebral theory in the chondrocranium. He says (p. 373): "Ich möchte aus diesen Erscheinungen, im Gegensatz zur allgemein giltigen Auffassung, schliessen, dass für das Chondrocranium die Wirbeltheorie nicht aufrecht zu halten sei." But the vertebral theory, notwithstanding the blows dealt it from the time of Huxley's attack to the present, has shown itself tenacious of life, and the thought uttered by Oken more than one hundred years ago demands deference of the worker of today.

Recent investigations into vertebral development, (Bardeen, Weiss, Weigner) demonstrate the presence of a pair of chondrogenous centers, lying close to the midline and reaching a somewhat higher level dorsally than the notochord, which grow to surround the latter, and so form the cartilaginous vertebral body. There is, in general, apparently a fundamental difference in the original relation to the notochord of the parachordal plate and vertebral centrum. At one spot, only, does the relation of the parachordal to the notochord approach that of a vertebral centrum, namely at the level of the anterior commissure; cartilage is here developed around the notochord. The discovery of processes of chondrification in the perichordal sheath of the occipital region, related eventually to the dens epistrophei and which fulfill the conditions of vertebral central development in general, have been mentioned. It would seem that the evidence presented by these investigators (Weiss; Gaupp, Weigner) justifies the interpretation which has been put forward of rudimentary centra in the occipital region. To this evidence must be added that given by cat. By the interpretation of Weiss of the hypochordal nature of the caudal part of the basal plate, the objection to comparing the lateral occipital arch with the 
neural arch of an ordinary vertebra is largely overcome. The lateral occipital arch presents the same relations to a centrum as does the atlantal neural arch, and also the same relations to a hypochordal arch as obtains between the neural and ventral arches of the atlas. That the order of formation of the hypochordal and lateral occipital arches varies somewhat in different species is no obstacle to the interpretation of their equivalency to vertebral structures; the work of Weiss ('01) and Levi ('08) has shown that there is also great variability in the development of the ventral arch of the atlas among mammals.

The fundamental differences between occipital and vertebral development, which have been so clearly indicated by Noordenbos, must, I think, be recognized; but if the interpretation of Weiss be correct, that the occipital develops not as a typical vertebra, but like a specialized vertebra, namely, the atlas, we must admit that there is still evidence of vertebral structure in the skull. This interpretation is in accord with the physiological environment of the region: a transitional zone between a rigid (cranial) and a movable (spinal) division of the axial skeleton. Regarded from this aspect, the structural conditions are seen to change as we pass along the vertebral column toward the head, the form of the vertebrae becoming less typical, due to tendencies along certain definite lines (regression of centrum, development of hypochordal parts). The occipital region shows by its structures the culmination of these tendencies; extremely rudimentary centrum separated from all connection with highly perfected arches, lateral and hypochordal; characters which, to a lesser extent, mark the atlas from a typical vertebra.

There is probably more than a superficial resemblance between the lateral occipital arch and neural atlantal arch in respect to the relations of these parts to nerves. The primary notch formed for the hypoglossal nerve bundles at the side of the parachordal plate, in front of the base of the lateral occipital arch (Noordenbos describes it in the occipital arch), and its subsequent conversion into a foramen, are phenomena which seem to parallel the development of the atlas in the region of the first spinal nerve. In cat embryos of 15 and $23 \mathrm{~mm}$. the first spinal 
nerve makes its exit through a notch at the side of the lateral mass of the atlas, between the base of the neural process posteriorly and a short but prominent atlantal process directed dorsad from the lateral mass. The articular regions of the atlas and occipital are comparable, in respect to their relations, to the components of these two skeletal elements. In cat the occipital condyles are formed at the spot where the lateral and hypochordal arches come together, that is on the parachordal plate. This is in agreement with Levi's and Weigner's observation of the relation of condyle and parachordal in man. Likewise, the corresponding articular surfaces of the atlas are formed where ventral arch and neural arch come together, namely at the massa lateralis. The early establishment of similar relations to nerve and articular surface offers a basis for a comparison of parachordal plate and lateral mass of atlas. Apparently these parts are not distinct elements in their relation to the occipital and atlantal arches, but mark a definite locus between the hypochordal arches on the one hand, and neural or lateral occipital arch on the other, constitute the region of articulation, and mark the ventral limit of the exit of the nerves. In this sense the parachordal plate could not include the cartilage ventrad of the notochord; this would fall into the category of the hypochordal arches. The term occipital basal plate would include the originally paired parachordals and the hypochordal cartilage. Comparison of parachordal plate and lateral mass which is here proposed, while attempting to bring out the relations of the occipital and atlas in further detail does not at the same time close the way to a better understanding of a possible relation of atlantal centrum and lateral mass which has been advanced by authors (Hagen, '00).

Atlas. Reference has been made to a peculiar character of the atlas, namely the foramen, in the neural arch of the adult bone and its relation to the notch in the arch of its cartilaginous predecessor. This atlantal foramen transmits the vertebral artery and the first spinal nerve in cat. It is present normally in most, if not all mammalian orders, holding a position nearer or farther from the cephalic margin of the neural arch, through which varia- 
tion of its position the bar of bone forming its cephalic limit is narrow or broad. In man the first spinal nerve and vertebral artery normally traverse a notch in the superior margin of the neural arch; in some instances, however, they pass through a foramen produced by osseous bridging of the notch. Bolk ('99) has pointed out that the usual conditions are indicative of regressive processes in the formation of the human atlas, that in man this bone is reduced in mass as compared with the atlas of those animals in which an atlantal foramen obtains. The bony reduction goes hand in hand with the imperfect development, and probable loss to some extent, of muscle and nerve in the dorsal part of the neck at the level between epistropheus and occiput. The recognition of the human atlas as an atypical example of the form which generally prevails in mammalia is helpful in approaching problems of structure in the head-neck region. Out of the recently much discussed phenomenon of manifestation of an occipital vertebra or assimilation into the occiput of the atlas (Swjetschnikow '06,' Kollmann '07, v. Schumacher '07, Smith '09, Glaesmer '10), the question has presented itself to me as to the development of parts in relation to the atlantal foramen. A number of observations on the development and comparative anatomy of the atlas have been made and will be reported in another place. At present I wish to discuss only those which have some bearing upon the occipital region.

The atlas of the smallest cat embryo studied $(10 \mathrm{~mm}$.) was represented in cartilage by a pair of neural arches, a small centrum about the notochord, and the beginnings of the hypochordal arch. The expanded base of the neural arch (lateral mass) sends dorsad in front of the latter a small, blunt atlantal process. The notch between the process and arch lodging the first spinal nerve and vertebral artery, is the first step toward the formation of the atlantal foramen. In the stage represented by the model, the notch is relatively deeper, owing to the increase in length of the atlantal process, which is now in the form of a short bar. The base of this bar, anteriorly, participates in the articulation with the occipital condylar surface; its dorsal extremity is free. The boundaries of the foramen are 
completed, in the full term fetus, by connective tissue stretching between the free extremity of the anterior bar and the neural arch, anterior to the first spinal nerve.

Observations on the sulcus in the atlantal neural arch for the first spinal nerve in man have been made by Macalister ('93), who gave the name post-glenoid tubercle to the process which rises from the lateral mass and limits the sulcus anteriorly. This process was found to vary considerably in its extent, an observation easily verified in even a small series of specimens. Macalister also noted the presence of an independent bony center in the ligament completing the atlantal foramen in the atlases of young skeletons. The question, . whether this represents the typical mode of origin of the bony rod which, in man, completes the atlantal foramen, remains for future enquiry. Separate ossifications in the region of the neural arch of the atlas, between it and occipital, have several times been observed in man. Trolard ('92) found, in two instances, in the posterior ligament of the atlanto-occipital joint an osseous bar placed horizontally, in one case nearly reaching the midplane. The possibility of relation of these independent ossicles in man to the arch of the atlas has, I believe, not been considered. It is well known that an osseous element in the posterior occipito-atlantal ligament, compared with the proatlas of reptiles and extinct amphibia, has been described for Erinaceus (see Baur, '94). The possibility of the proatlas being a component of the atlas in a persistent type was many years ago suggested by Osborn ('00). The question of special interest which I wish to mention here in regard to the post-glenoid tubercle, the bar of bone completing the atlantal foramen and the ossicles in the posterior occipitoatlantal ligament, is whether these structures may not possibly represent parts of one element which, in a primitive state, was separate from, but closely related to the atlas.

Occipito-atlantal articulation. The discovery by Fischer ('01) of a single, horseshoe-shaped surface at the ventral margin of the foramen magnum in embryos of Talpa, articulating with the ventral arch of the atlas would seem to lessen the gap between reptilian monoconydlic and mammalian dicondylic articulation. 
That the condition in Talpa is primitive, and not secondarily acquired, is supported by Gaupp's ('08) observation of a similar atlanto-occipital articulation in Echidna. Whereas, in cat, the occipito-atlantal articulation is apparently dicondylic primarily, the joint surfaces are located to a considerable extent upon the basal plate, as well as on the lateral arch, and meet corresponding surfaces of the ventral arch of the atlas and its lateral mass, including the atlantal process. The participation of the basal plate in the articular surface is evidence of greater proximity of the two condylar surfaces toward the median plane than in those mammals (Lepus) where the surfaces are restricted to the region lateral to the foramen magnum. This embryonic state of the condyles is, therefore, apparently intermediate between typical dicondylism and the condition observed by Fischer in Talpa. In the later development of cat embryos the condylar surface grows further dorsad by the side of. the foramen magnum.

If we accept the comparison of occipital and atlas, we must throw aside the idea of that form of articulation between them, such as exists between the centra of typical vertebrac.

The basal plate in the cat is a derivative of the parachordal cartilages and hypochordal arches and therefore the development of an articular surface upon its caudal margin must involve either one or both of its constituent elements. The point to be emphasized now is the fact that a part of the occipital element, which apparently is as distinct from the centrum as the lateral mass is distinct from the body of the atlas, enters in to the constitution of the condyle; that is to say, the condyle belongs to an arch structure.

Further study of that region dorsad of the condyle which is characterized by a notch traversed by veins is necessary before any conclusion can be drawn regarding its significance; it seems not improbable that it may have to do with the foramen condyloideum.

Plane of the foramen magnum. Although a marked flexure exists between the head and trunk of cat embryos, this does not explain the basal position of the plane of the foramen magnum 
and the occipital condyles referred to on p. 292, which is in contrast with their caudal position in the adult. The immediate cause of this basal position is not difficult to find. Since the lateral occipital arches are quite narrow antero-posteriorly and are joined directly with the otic capsules, it is evident that their basal inclination cannot be attributed either to growth, as in man, or to the presence of wide fissures between them and the ear capsules. The explanation is to be found in the flexures to which the whole chondrocranium is subjected. One result of these flexures upon the longitudinal axis of the cranium is to put its anterior and posterior halves nearly at right angles with each other. It follows that the plane of the foramen magnum stands parallel with that of the floor of the nose. It is of interest to find that, with the formation of the bony cranium, a nearly straight longitudinal axis is substituted for the primary angular axis and, with it, the plane of the foramen magnum becomes less oblique.

A primitive condition, and an exceptional one in the primordial skull of mammals, it seen at the stage represented by the model in the abrupt ascent of the lateral occipital walls from the basal plate. The mammalian chondrocranium, as contrasted with that of lower animals, shows a tendency toward lateral extrusion of these walls; as Gaupp ('06) says: "Die Seitenteile der Occipitalregion sind bei Säugern nicht mehr steil aufgerichtet, sondern nach hinten hin basalwärts niedergelegt am stärksten und vollkommensten beim Menschen."

Basal fissures. The fissura basicochlearis posterior of cat is apparently comparable with the opening of the same name in the chondrocranium of Talpa, first described and named by Noordenbos ('05). Mead has noted a probable homologue of the posterior basicochlear fissure in Sus. In Lepus this opening is not present in the stages of development studied by Voit, but an anterior basicochlear fissure was observed by that investigator. These fissures are filled with mesenchyma, which, in the cat embryo, passos into a zone of precartilage at the edges of the opening. The posterior basicochlear fissure, present in Talpa embryos of $14 \mathrm{~mm}$., disappears in embryos of 19 to 20 
mm. and older, being replaced by cartilage (Noordenbos). Parker ('85) and Fischer ('01) had already shown continuous cartilage in the region between basal plate and cochlear prominence in Talpa embryos of later stages. Tarsius exhibits still another phase of vacuity at the basicochlear junction, presenting an extensive slit separating the ear capsule and cranial floor (Fischer, '05). In the adult cat, a fissure separates the pars petrosa from the basi-occipital and it appears that in the adult pig the foramen lacerum anterius and the foramen jugulare are connected by a fissure median to the auditory bulla (Mead, '08). The persistence of an original fissure, growing larger as the cranium enlarges, is an interesting phenomenon calling for further study. The posterior basicochlear fissure of Talpa is one of several spaces which, as Noordenbos has shown, are de rived from the original space separating the independently arising otic capsule from the basal and lateral parts of the chondrocranium. That part of the original space between the base of the skull and the ear capsule is broken up by the later formation of synchondroses, uniting the auditory capsule with the parachordal plate and with the basal region which later enters into the sphenoid; and so there arise a canalis caroticus, an anterior basicochlear fissure and a posterior basicochlear fissure. The observations on cat embryos, presented here, show that the origin of the cartilaginous basal plate and otic capsule are independent and that the fissura basicochlearis posterior is derived from the original space separating the parts.

Foramen magnum. In Lacerta the dorsal boundary of the foramen magnum is the tectum synoticum. Fischer ('03) found the apparent foramen occipitale magnum of the Semnopithecus embryo larger than the future real foramen magnum, the hinder part of the former being closed by membrane. This author remarks on the probability of the membrana atlanto-occipitalis in part undergoing ossification. Bolk ('03) described this region in human embryos, and applies the name incisura occipitalis posterior to a little space filled with membrane made secondarily by the approximation of the dorsal extremities of the occipital side walls in the formation of the foramen magnum. Between 
this notch and the tectum posterius is a broad space filled by membrane continuous with that of the incisura posterior. A pair of chondral centers lies in this membrane and a third center stretches through the cranial roof anterior to the tectum posterius. The latter disappears in further development; the pair of centers remaining help to complete the boundary of the incisura posterior, while the membrane between the latter and the tectum posterius undergoes ossification. Voit ('09) also found a space (incisura occipitalis posterior) in Iepus between the dorsally open foramen magnum and the tectum posterius, and since, as is explained, the latter belongs to the otic region, the side boundaries of the incisura occipitalis posterior are regarded as the dorsal portions of the occipital pillars. If we compare now the extent of the region between the dorsal confines of the foramen magnum and the tectum posterius in lizard, rabbit, cat, ape and man, it at once appears that there is a progressively increasing area exhibited. This begins with Lacerta, where, as Gaupp observed, the tectum is so shaped as to give to the foramen magnum an angle in the dorsal median line, and reaches the great expanse described by Bolk in the human embryo, in which the tectum is far removed from the foramen magnum. It is evident, also, that the term incisura occipitalis posterior has not the same value throughout its application; in the rabbit Voit apparently regards the space limited laterally by the dorsal portions of the occipital pillars as the incisura occipitalis posterior, while Bolk limits the term to only a small part of the region encompassed by the dorsal limits of the occipital walls.

\section{Otic region}

Position of the otic capsules. It has been noted (p. 298) that the approximately transverse position of the plane of the otic capsules in the stage represented by the model forms an exception to the general rule in mammals of obliquity of the principal otic axis toward the longitudinal axis of the skull. It will be recalled that the degree of differentiation exhibited by the stage of the model is one, expressed in terms of the skeleton, wherein bone formation has advanced but little; of the mem- 
brane bones several have still to make their appearance and none of the purely endochondral ossifications is present. Talpa of $27.3 \mathrm{~mm}$., Semnopithecus of $53 \mathrm{~mm}$., Homo of $8 \mathrm{~cm}$., in which the obliquity of the principal otic axis has been recorded, are all at stages of development in which bone formation is well established and therefore can hardly be compared with cat embryos in the stages under consideration. On the other hand, obliquity of the otic axis is present in the mole of much younger stages, if one can judge by the photographs of Noordenbos, and the same is true for the Sus cranium described by Mead, which is at approximately the same stage as the Felis cranium modeled. Again, Voit states that in Lepus the two canalicular parts stand parallel, and only a slight convergence of the cochlear parts is present; the stage is one in which osseous development is advanced (45 mm. gr. L.). Therefore, it appears that the definitive oblique direction of the long axis of the auditory capsule, typical of mammals, is attained at different periods in the species considered, the tendency being toward its early establishment. As in the case of the occipital region, so also with the otic capsule, the position changes with the development of the bony cranium. The shifting of the otic axis from a position at right angles to the cranial base in the chondral stage to one of marked obliquity (cephalo-ventro-mesad) in the osseous stage, can hardly be a result of the straightening of the cranial axis. The factors involved in influencing the change must remain for future inquiry.

Another characteristic of the position of the mammalian otic capsule is its location in the base of the skull rather than it the lateral wall as is the case in increasing degree from this class back to lower vertebrates. In mammals, not only does the cochlear capsule hold a basal position, but the phylogenetically older canalicular part is rotated ventralward as well as caudalward. Toward the attainment of this mammalian peculiarity the cat cranium, in the stages under discussion, presents what seems to be the initial steps. Though the cochlea, a phylogenetically later acquisition to the ear, asserts itself early in claims for space, the relations established in the chondocranium 
are readjusted in the bony cranium, the cochlear capsules being widely separated by a broad processus basilaris, and are themselves relatively smaller in the adult skull.

Origin of the cartilaginous otic capsule. In discussing the observations which were made on the chondrification of the otic capsule two questions of special interest present themselves: the relation which the origin of the cartilaginous capsule as a whole bears to the rest of the cranium; the original relation between the pars cochlearis and the cartilaginous basis cranii. The first question was raised by Huxley and there was sufficient evidence, notwithstanding the crude methods of his time, for the advancement of the theory of intrinsic skeletal capsules for each of the sense organs, ear, eye, and nose. Subsequent discovery has tended to confirm the truth of this theory, the evidence coming, as might be expected, chiefly from the lower vertebrates. What mammalian crania will show must wait until the study of successive developmental stages of species has been repeated by modern methods. By the van Wijhe method, Noordenbos has presented, recently, very strong evidence of the independent origin of the cartilaginous otic capsule in Talpa; similar results were obtained for rabbit, ox and pig.

The second question has arisen in connection with Gaupp's theory of the reformation of the cranial base to contribute a supporting wall for the cochlear duct. There appears to be in the reptiles a beginning development of the cochlear capsule at the expense of the basal plate. Is the theory supported by evidence from the mammalian chondrocranium and, what concerns us here, does the development of the cochlear capsule in cat throw any light on the problem? So far as mammals are concerned, it is convenient to consider these two questions together. First, it should be borne in mind that only the circumstances of chondrogenous development will be reviewed; the conditions of blastemal structure are here excluded.

In regard to the pars canalicularis the evidence afforded both by sections and van Wijhe preparations indicates that this component of the ear capsule arises independently of other parts of the cranium. There is some difference as to the form of the 
cartilage first appearing in the pars canalicularis from what has been observed in other animals. I refer to the observation of a plate of cartilage upon the lateral side of the semicircular canals; in the cat, cartilage forms upon the lateral surfaces of the canals in more or less separate stretches for each canal. The canals are subsequently completely walled and the intervals between them filled through the development of cartilage, but whether this is by extension of cartilage formation from the canalicular walls already established or from independent chondrifying. centers was not observed. The more or less compact mass constituting the pars canalicularis is secondarily connected with the lateral occipital arch and parietal plate, although its dorsal margin remains free in the fissura jugulare spurium, and the posterior margin is clearly indicated, even at the $23.1 \mathrm{~mm}$. stage, in the stretch of young cartilage between it and the lateral occipital arch directed toward the jugular foramen. The pars canalicularis is also apparently formed independently of the suprafacial commissure, if one may judge this by the difference in degree of development of these two closely associated parts.

In the pars cochlearis, cartilage was first observed in the region next the pars canalicularis and in the anterior and posterior poles, i.e. in the neighborhood of the suprafacial and basivestibular commissures. There was no actual separation of these chondrifying tracts from one another, no independent centers of cartilage formation. At the stage when the medial wall of the cochlear capsule is in precartilage, the capsule is separated from the chondrified basal plate by a fissure filled with mesenchyma. Union of the capsule by cartilage with the basal plate behind the carotid foramen, with the alicochlear commissure and basivestibular commissure, is brought about secondarily. $\mathrm{Be}-$ tween the commissura suprafacialis and anterior pole of the cochlear capsule a smaller degree of difference in development obtains than is the case between this commissure and the pars canalicularis; the ventral end of the commissure, however, appears to be blended, if not actually continuous, with the cochlear capsule. In this discussion, the fact of the continuity of these two parts is important because of the possibility of pa- 
rietal if not actual basal relationship and significance of the commissure. The evidence of the parietal nature of the suprafacial commissure may be considered at once, since upon its interpretation depends to a large extent the question of the cochlear relations to the basal plate.

The relations of the suprafacial commissure in cat appear to differ somewhat from those described in other mammals. In Talpa, according to Fischer ('01), the roof of the facial canal is made by a thin lamella of cartilage stretching from the pars canalium semicircularium to the highest elevation of the cochlear capsule. Fischer regards the walls of the facial canal as made entirely by the ear capsule, and contrasts this condition with the formation of the canal in Lacerta, in which, as Gaupp ('00) has found, the foramen for the seventh cerebral nerve lies in the boundary zone between the basal plate and ear capsule. Noordenbos ('05) named the roof of the facial canal the tectum nervi fascialis, and found it connected with the medial wall of the anterior ampullary swelling of the pars eanalicularis. Voit ('09) found, in the rabbit, that the suprafacial commissure stretched from the anterior end of the pars posterior of the otic capsule, beneath the prominentia utriculo-ampullaris posterior and right above the superior acustic foramen, to the roof of the anterior part of the pars cochlearis. In comparing the facial foramen in rabbit and lizard, Voit evidently agrees with Gaupp that, in mammals, the walls of the foramen are in part contributed to by the cochlear capsule. In the dog, the suprafacial commissure bridges over the facial foramen, from the borders of the pars utriculo-canalicularis and the pars sacculocochlearis, according to Olmstead ('11). De Burlet ('14) described the commissura praefacialis of Balaenoptera rostrata as a cartilaginous bridge between the pars cochlearis and pars canalicularis. In* De Burlet's plates VI and VII, however, there is shown what appears to be a connection between the praefacial commissure and lamina parietalis. The relations of the lateral end of the suprafacial commissure in the cat differ from those in the mammals mentioned, with the exception possibly of Balaenoptera. Connection between the commissure 
and pars canalicularis is likewise seen in cat, but the relation is apparently not the primary one. The primary lateral termination of the suprafacial commissure in the cat is not in the otic capsule, but in the commissura orbito-parietalis, where the latter meets the prominentia ampullaris superior. Continuity with the orbito-parietal commissure (a part of the lateral cranial wall) and, at the same time, partial separation from the otic capsule, is to be regarded as evidence pointing toward the parietal nature of the suprafacial commissure. While I find no reference to a relation between the suprafacial commissure and cranial side wall in descriptions of mammalian chondrocrania, the constant proximity of these parts strongly suggests that the continuity seen in cat may obtain in other mammals. De Burlet's figures of the Balaenoptera chondrocranium are of great interest in this connection. Further support of the view of the parietal nature of the suprafacial commissure is offered by the relation of this structure to the exit of the trigeminus. As stated in the description of the orbito-temporal region, the roots of this nerve and the semilunar ganglion lie between the suprafacial commissure and a thickened band of the transverse septum in which is developed an accessory cartilaginous rod resting upon the dorso-medial surface of the ganglion. A similar structure was observed in the rabbit by Voit who interpreted the 'Restknorpel 'b' as possibly representing the pila prootica of Lacerta, a structure of the primary cranial wall. In Lacerta the trigeminus makes its exit by way of the prootic fenestra whose boundaries are the prootic pillar and prefacial commissure. In the cat the fifth nerve leaves the cranial cavity between the accessory cartilaginous rod and the suprafacial commissure. Continuity of the anterior part of the otic capsule with a portion of the lateral wall of the cranium in the cat should make us hesitate in assigning entirely otic boundaries for the facial canal. The evidence so far indicates possibly that the foramen faciale in the cat stands in the boundary zone between the pars cochlearis of the otic capsule and the cranial wall, represented by the suprafacial commissure. Such a relation is in harmony with that which obtains in reptiles, to the 
extent that the foramen for the facial nerve stands between a sense capsule (otic) and cranial wall (basal plate).

In accordance with our observations, the cochlear capsule in the cat is developed in connection with the pars canalicularis and with the suprafacial commissure which gives evidence of being, in part at least, a parietal structure. The cochlear capsule chondrifies independently of the basal plate, with which it is secondarily united by commissures. Its precocious growth and great bulk encroach upon the broad region occupied in lower vertebrates by the basal plate. If we can, on the evidence given, interpret the suprafacial commissure as a parietal structure in the cat, it would appear that its relation to the cochlear capsule (continuity) affords support to the theory (Gaupp) of the latter having preempted the territory of the basal plate and developed at its expense.

Foramina acustica and meatus acusticus internus. The acustic foramen or fissure and the entrance to the facial canal are established early in the development of the otic capsule. These openings lie between the suprafacial commissure behind and, in the $23.1 \mathrm{~mm}$. stage, are found at the bottom of a shallow internal acustic meatus. The single acustic fissure is constricted in its middle so as partly to separate two wide divisions accommodating the vestibular and cochlear nerves. Completely separated foramina were not observed in any of the stages studied. Comparable with this form of acustic nerve entrance is the single dumb-bell shaped foramen which Mead has described in Sus. In the rabbit (Voit) and the dog (Olmstead) there are separate foramina for the vestibular and cochlear nerves. In the cranium of Talpa of the stage described by Fischer there are also two separate acustic foramina; but in younger embryos Noordenbos found a round porus acusticus internus, in the bottom of which openings for the cochlear and vestibular nerves were not clearly separated on account of lack of chondrification. The persistence of a single opening in the cat speaks for tardy development of the medial wall of the ear capsule, a tendency characteristic of the lower vertebrates. The relative positions of the foramina, one to the other, or of the nerves, where a single 
opening exists, while in general constant for mammals, shows an interesting variation in the cat. In mammals these openings lie approximately one above the other, so that a superior and an inferior acustic foramen, for the vestibular and cochlear nerves respectively can be spoken of. In the cat, at the stage of 23.1 $\mathrm{mm}$. the vestibular nerve occupies the antero-lateral part of the fissure; the cochlear nerve the medio-caudal end. The anteroposterior order of the acustic rami recalls the condition in reptiles. Although a common meatus for the two divisions of the acustic nerve occurs in birds (Tonkoff, '00) this is separate from the exit of the facial nerve, and therefore is not comparable with the internal acustic meatus of mammals, which includes separate passages for the vestibular and cochlear rami and for the nervus facialis. The development of the internal acustic meatus begins very early and seems to be a result, not of a depression of the medial otic wall, but, as Voit remarks, of the elevation of the surrounding cartilaginous parts. In the cat, the elevations are made by the suprafacial commissure anteriorly, the otic extremity of the basivestibular commissure posteriorly and the prominentia utricularis dorsally and laterally. These three parts rise above the level of the cochlear roof and form three sides of the meatus acusticus internus and porus acusticus. The low, medial and ventral side is the roof of the cochlea. Of these three elevations, that of the suprafacial commissure is most prominent and is probably the chief factor in determining the presence of the meatus.

Foramen perilymphaticum. Since Fischer's ('03) description of the derivation of the aquaeductus cochleae and fenestra cochleae from the perilymphatic foramen, several observations have been made by other investigators concerning this interesting phenomenon. Fischer found in an embryo Semnopithecus that the downward directed opening at the basal side of the ear capsule was divided into two parts by a process which sprang from the anterior margin of the opening and extended backward. The larger lateral part looked out from the free outer surface of the skull and was closed by thick membrane; it was identified as the fenestra cochleae. The medial smaller opening, on a 
higher plane, looked inward, was traversed by the perilymphatic duct and was recognized as the aquacductus cochleae. Following his observation, Fischer states that Hertwig's enlarged model of the otic region of man shows obscurely the process in question. I find in this model a free comer of the cochlear wall projecting forward from the posterior margin of the large foramen so as to divide the opening into a large lateral and a very small medial part. In the rabbit, Voit found the conditions exactly as Fischer saw them in Semnopithecus and named the dividing process the processus intraperilymphaticus. Macklin ('14) described the intraperilymphatic process in the human embryo as a "short conical projection directed forward from the inferior utriculoampullary prominence." In the cat, a process of the caudal wall of the cochlear capsule, adjacent to the basivestibular commissure, projects laterally, and tends to separate the perilymphatic foramen into two parts. We find, therefore, that the perilymphatic process in the ape and the rabbit is directed backward, and in man forward, while in the cat the process which separates the perilymphatic foramen into intraand extracranial openings is directed laterally. If these be comparable processes they probably indicate, merely, differences in the place where chondrification begins in the septum dividing the perilymphatic foramen.

Cavum vestibulare. It is apparent from the foregoing description of the vestibular cavity that the conditions present in the embryo of $23.1 \mathrm{~mm}$. are far from what obtains in the adult mammalian temporal bone. Only on the most general lines are the form and relations seen in the bony walled vestibular spaces of adult cat referable to the conditions of the cartilaginous otic capsule. Such characteristics of adult structure as the sharp delimitation of special recesses for the utricle and saccule, apparently are not even indicated in embryos considerably further developed than those of the stage modeled. Between these early stages and adult conditions many processes of formation are involved, about which almost nothing is known.

If the vestibular cavities of the cat embryo of the stages described present but few indications of their adult form, they 
do show a certain agrement with conditions observed in the lower groups. The tendency to subdivision of the vestibule into anterior and posterior rooms is strongly suggestive of the conformation of the cavum vestibulare in Lacerta, as described by Gaupp. The contents of the anterior and posterior vestibular cavities in the cat appear to be comparable with the parts contained in the cavum vestibulare anterius and cavum vestibulare posterius of lizard. The anterior and posterior acustic foramina in lizard and cat are similarly related to the vestibular cavities. FuIthermore the relative positions of the two spaces, one to the other, and to the otic capsule as a whole, are strikingly similar in the two forms. Such a comparison must accept of necessity the homology of the boundary structure between the vestibular cavities. In the cat this is the medialward projecting ventral part of the massa angularis, the part designated crista intervestibularis. In the lizard it is the septum intervestibulare. Gaupp describes the latter as a transverse vertical partition betwcen the two vestibular cavities, presenting a lateral opening filled with membrane and a medial foramen for the utriculus. The crista intervestibularis is likewise transverse in position, but it cannot be called a partition since it fails to extend entirely across, between the anterior and postcrior cavities. While it possesses no opening, yet, by its failure to reach the-medial vestibular wall, a space is left between the latter and the free medial edge of the crista, by which the anterior and posterior cavities are put into communication and which is occupied by the utriculus.

Lamina parietalis and tectum posterius. Decker ('83) found the parietal plates in cat embryos of 5.5 to $6.1 \mathrm{~cm}$. bent inward, which is not the case in the younger embryos of the present study; rather, the dorsal, irregular margins are turned a little laterally. Decker's observation is interesting in proving that the parietal plate participates in the cranial roof, to only a slight extent, as his figure shows, but, nevertheless, marking an unusual development of this part of the cranial wall for mammals. The lamina supracapsularis of Echidna, remarkable for its great breadth and its continuity with the ear capsule, is, in its anterior part, com- 
parable with the lamina parietalis of placental mammals, also to the hinder portion of the taenia marginalis of Lacerta (Gaupp, '08, b).

Chondrification of the parietal plate independently of the ear capsule was not observed in the series of Echidna studied by Gaupp, but it was noted that the plate was separated from the occipital pillar caudally and from the ala orbitalis rostrally by stretches of unchondrified tissue. Noordenbos is apparently the first to have observed the independent origin of the parietal plate and its secondary union with other parts of the skull. In Talpa of $11 \mathrm{~mm}$. this cartilage was dorsad of the ear capsule and immediately in front of the tectum interoccipitale; its union with the otic capsule occurred very soon after its appearance. Evidently the parietal plate in Talpa does not unite posteriorly with the occipital arch, but with the tectum interoccipitale. The latter appears in the mole at the same stage as does the parietal plate, in the form of an independent piece arched over the cerebellar region. Noordenbos observed its union, first with the occipital arch, then considerably later with the parietal plate. On account of the primary union with the occipital arch Noordenbos is inclined to adopt the term 'tectum interoccipitale' as more correctly expressing its relations than the terms 'tectum synoticum' and 'tectum posterius.' Whether the tectum arises by paired anlagen in the mole could not be stated; its origin in the rabbit was observed by Noordenbos to be paired.

In regard to the origin of the parietal plate in cat, I am unable to present a conclusion, owing to lack of material at a critical stage in the development of this part. Apparently primary conditions similar to those described for Talpa obtain in Felis. A cartilage, which I have called lamina parictalis, arises by paired beginnings in the form of triangular plates, above the interval between the occipital arch and pars canalicularis. At a later stage the parietal plate has united with the lateral occipital arch and presents a prominent angle toward the mid-dorsal line, which is the beginning of the tectum posterius. At this stage $(15 \mathrm{~mm}$.) there is a faintly stained tract of cartilage in the region of the future commissura orbito-parietalis, but extending caudad into 
the otic region. There remains, however, a wide gap, equal in extent to the dorsal margin of the ear capsule, between this tract of cartilage, which I have referred to as the beginning of the commissura orbitoparietalis, and the parietal plate. Now in the mole, Noordenbos found a cartilaginous plate immediately anterior to the tectum interoccipitale and identified it as the parietal-plate. It united subsequently with the otic capsule, opposite the junction of the anterior and middle thirds of the anterior semicircular canal (synchondrosis parieto-canalicularis), with the anterior margin and ventral end of the tectum interoccipitale, and also with the ala orbitalis. The last connection came about through the synchondrosis orbito-parietalis, by extension of the lateral hinder angle of the ala orbitalis.

In sections of cat embryos of $17 \mathrm{~mm}$. a parietal plate of young cartilage extends from the occipital arch to the commissura orbito-parietalis. The arch of the tectum posterius is represented merely by a prong, springing on either side from the broad plate of cartilage forming the caudal end of the parietal plate, and which is united by stretches of young cartilage with the pars canalicularis and lateral occipital arch. The anterior end of the parietal plate, while approaching the otic capsule at the level of the middle of the anterior semicircular canal, is still not united with it, but is separated by a plane of mesenchyma. In later stages $(24$ to $30 \mathrm{~mm}$.) van Wijhe preparations show that chondrification is less advanced, in the narrow part of the parietal plate, where the inconstant union with the pars canalicularis occurs (p. 310), and where union has occurred with the occipital arch and otic capsule. There seems to be no doubt of the cartilaginous plates, identified as the beginnings of the parietal plate, going to form also the tectum posterius (the arch is complete in the $23.1 \mathrm{~mm}$. stage) and also the posterior part of the parietal plate. The relation of the commissura orbito-parietalis to the otic capsule anteriorly (the so-called parieto-capsular commissure) is evidence of the probable homology of this cartilage with the parietal plate of Talpa, as described by Noordenbas. There is no evidence of another center of chondrification between the termination of the orbito-parietal commissure and the tectum pos- 
terius, and it is doubtful, notwithstanding the great space between these parts, if another center does develop and enter into the formation of the parietal plate. In favor of this assumption is the brief period between the stage when the orbito-parietal commissure and tectum posterius are separate $(15 \mathrm{~mm}$.) and the stage when they are joined $(17 \mathrm{~mm}$.). Apparently, in the cat, the parietal plate is formed by the coalescence of two cartilages arising independently, one, mostly anterior to the otic region, which gives rise also to the larger part of the orbito-parietal commissure and to the parieto-capsular commissure; the other dorsad of the interval between the lateral occipital arch and pars canalicularis which unites with these parts, forms the broad caudal portion of the parietal plate and also gives rise to the tectum posterius.

Facial and acustic nerves. The suprafacial commissure, forming the roof of the primary facial canal, separates the facial. nerve from the ganglion semilunare. As the seventh nerve (including the pars intermedia Wrisbergii) leaves the canal, the geniculate ganglion is formed on its dorsal side. This is in contact with the ganglion of the trigeminus, both structures lying outside the plane of the fenestra sphenoparietalis. The lateral opening of this primary facial canal should be compared with the foramen faciale of reptiles. A foramen or canal, traversed by the facial nerve beyond the ganglion geniculi, is a new acquisition for mammals and not to be found in the reptilian cranium. Such is the stretch which Fischer ('01) has described in Talpa, roofed over by the "ganz dünne Knorpelspange" (p. 504), separating the proper facial opening from the hiatus spurius. Also the foramen faciale externum of the tegmen tympani of the rabbit forms an acquisition to the primary facial canal, whose lateral opening in the tympanum is the apertura tympanica. This conception of the facial canal is partly in accord with that of Vrolik ('73). In the cat, at the stage modeled, the exit of the primary facial canal is at the level of the ganglion geniculi (position of the future bony hiatus canalis facialis) and outside the cavity of the chondrocranium. In the bony cranium of cat, and probably in later stages of the chondrocranium, the exit from the cranial cavity is by the apertura tympanica. 
Regarding the course of the seventh nerve in the sulcus facjalis, it is to be remembered that in adult Felis domestica the second part of the facial nerve traverses an open groove in the medial tympanic wall (the rule in mammals), whose lateral boundary is the ossified processus paroticus (crista parotica of van Kampen, '04). Neither in the embryo nor in the adult does the free margin of the parotic crest incline toward the vestibular wall in the formation of a canal. In Felis pardus, however, the nerve does run in a closed canal (Denker, '99). The groove in the adult domestic cat begins anteriorly at the apertura tympanica and terminates posteriorly opposite the level of the tympanohyale.

Finally, reference should be made to the discovery by Spence ('90) in the adult and new born cat of a bony or cartilaginous support of the chorda tympani, projecting from the tympanic bone. Bondy ('07) has confirmed this observation, finding the process not only in cat but in a number of other mammals. No evidence of the support was found in the stages described here; its formation takes place according to Bondy, late in fetal life.

Acustic nerve. Retzius ('84) described the nervus acusticus of the cat as dividing into two or three chief branches, preferring two in his account. I found this mode of branching in the cat embryo of $23.1 \mathrm{~mm}$., and it may be remarked that, in our present state of knowledge of the distribution of the acustic nerve in the cat, the nomenclature of Retzius seems preferable to one which attempts to represent the origins of the nerve fibers. For, in the case of the ramus posterior, cells of the vestibular and spiral ganglia are intimately associated, and no safe conclusion on the origin of fibers of this ramus can be reached without further neurological investigation. The small twig from the anterior ramus to the sacculus appears to correspond with the ramulus maculae sacculi pars superior found by Voit ('07) in Lepus.

\section{Orbito-temporal region}

Hypophyseal cartilage. Chondrification of the base of the cranium in the hypophyseal region has been observed in several mammals to take place independently of the rest of the chondro- 
cranium. Parker ('75) observed "a secondary growth of cartilage beneath the pituitary body" in Sus. A sphenoidal cartilage, independent of the occipital skeleton of the ox, is described by Froriep ('86) as lying beneath the hypophysis. This observation is confirmed by Noordenbos (' 05 ) who found, moreover, that the cartilage was paired. Noordenbos has discovered, by van Wijhe's method, the origin of the middle piece of the cranial base by the fusion of several small islands of cartilage in the crania of mole, rabbit and pig. For these pieces, which surround the stalk of the hypophysis, Noordenbos has proposed the name 'insulae polares.' Wincza ('96) noted the independence of the cartilaginous basi-sphenoid and alisphenoid (ala temporalis) in cat. As we have seen, the cranial floor, beneath the hypophysis, is first represented by a crescentic cartilage, which soon grows around the stalk of the hypophysis, probably completely surrounding it, although this was not actually observed. The formation of the sella turcica is brought about by the union of the hypophyseal cartilage anteriorly with the trabecular plate and posteriorly with the basal plate, the former contributing the tuberculum sellae, the latter the crista transversa which is the beginning of the dorsum sellae.

Fenestra basi-cranialis posterior. 'The existence of an opening in the basis cranii between the anterior end of the basal plate and the hypophyseal cartilage is merely temporary in the cat. In embryos of $12 \mathrm{~mm}$. the fenestra basi-cranialis posterior has no lateral limits, since the cochlear capsule is not yet joined with the basal plate. The anterior boundary is made by the hypophyseal cartilage, so that the fenestra lies, not within the basal (parachordal) plate, but anterior to it, as Noordenbos insists.

Crista transversa and dorsum sellae. The crista transversa represents the anterior, dorsally turned, free edge of the basal plate. The upward bend of this margin just prior to the fusion of the basal plate and hypophyseal cartilage, can be seen in sagittal sections of embryos of $12 \mathrm{~mm}$. and its identity with the crista transversa proved by sections of $15 \mathrm{~mm}$. specimens in which the line of fusion of the two plates is still distinct. Noordenbos found that the dorsum sellae of Talpa is formed from the anterior mar- 
gin of the parachordal plate. In the cat, the dorsum sellae is also in part at least, derived from it, but probably the greater part is derived from the mesenchyma above the crista transversa and in front of the end of the notochord, in which the small cartilaginous nodule was found in the smaller embryos.

Let us consider briefly some observations regarding the dorsum sellae. I believe no comparative study of its formation has been made. This structure reaches a high development in man and apes. Fischer ('03) found in a Macacus embryo the upper border isolated from the rest of the dorsum sellac, lying as a transverse bar, and terminating laterally in the posterior clinoid processes. 'This author also points out that in the adult human cranium a groove or ridge stands between the dorsal border and the clivus and puts forth the suggestion that this structure, isolated in Macacus, is probably genetically foreign to the basal plate. Voit ('09) supports this view by the discovery in Lepus of a partial separation of the dorsal part of the saddle-back by a wide foramen from the rest of that structure. Fawcett ('10) found in human embryos of 19 and $21 \mathrm{~mm}$. a rounded mass of cartilage, behind the pituitary body, connected with the clivus region by a fibrous bridge; he concluded that the dorsum sellae arises independently in man. In his study of the primordial cranium of Talpa, Fischer ('01) found the hypophyseal fessa to be a slight depression and noted the absence of a dorsum ephippii. Noordenbos ('05) speaks of a weakly developed dorsum sellae turcicae in mole embryos and states that it is a structure of the parachordal plate. This investigator observed that in embryos of $11 \mathrm{~mm}$. the caudal end of the polar plate, lay somewhat beneath the cranial end of the parachordal plate. With the union of these parts the hypophyseal fossa is formed, limited posteriorly by the projecting anterior end of the parachordal plate.

Fischer's and Voit's observations point to the origin of the upper part of the dorsum sellae as possibly distinct from the basal plate in Macacus and Lepus, and, according to Fawcett, the origin of the dorsum sellae in man is from an independent center of chondrification. Noordenbos found the dorsum sellae of Talpa as a product of the parachordal (basal) plate. These observa- 
tions suggest the possibility of the dorsum sellae of different species not being strictly homologous. Gaupp says ('00, p. 538) "Dass die hinten begrenzende Crista sellaris, wie sie bei dem Chondrocranium der Saurier (und auch bei dem der Vögel) vorkommt, der Sattelsehne des Säugercranium entspricht, ist allgemein anerkannt." But does the crista sellaris of reptiles compare with the corsum sellae of mammals? And are the latter strictly homologous in the different orders of mammals?

This is not the time for a full discussion of these questions which requires a larger basis of observations, but a few comments may be offered. Regarding the homology of the dorsum sellae among the mammals the following may be noted. The saddleback of the chondrocranium of Echidna (Gaupp '08), Talpa (Noordenbos, '05), Caluromys and Didelphis (my own observation) is very low. As already stated, Fischer denies its presence altogether in the Talpa embryo he studied. In contrast with the insignificant low ridge-like dorsum ephippii of these species is the high saddle-back of the chondrocrania of man, apes, rabbit and cat. In all these species evidence is at hand indicating the presence of an element in the dorsal part of the saddle-back, more or less independent of the base of that structure. In embryos of cat smaller than the stage modeled, the notochord terminates in a mass of mesenchyma which surmounts the crista transversa, whereas in the latter stage it ends in the perichondrium of a cartilaginous tubercle which rises from the middle of the transverse crest. This tubercle is developed from the mesenchymal mass, and may possibly have its beginning in the prochondral nucleus observed in the embryos of earlier stages (p. 327). In the cat embryo of the stage modeled, the dorsum sellae is formed to some extent also from the up-turned edge of the parachordal plate (crista transversa). It would seem, in respect to the contrast between the caudal limits of the hypophyseal fossa in the two groups here presented, that there is an element present in the one which is not found in the other, or that in one group a simple crista transversa forms the back of the pituitary fossa, whereas in the other a crista transversa plus an additional element enters into the construction of a dorsum sellae. 
There is nothing in the model of the cat embryn to indicate the presence of post-clinoid processes, which are found in the bony cranium and are therefore formed later. These processes in connection with the processus interclinoideae, Voit regards as vestiges of the primitive cranial wall in this region. Interclinoid processes have of ten been observed in the adult cranium of man, and Fischer has noted them in the chondrocranium of Macacus.

Foramen hypophyseos. The foramen hypophyseos is converted into a canal by the growth in thickness of the floor of the sella turcica. In embryos of $17 \mathrm{~mm}$. the stalk of Rathke's pouch is still intact as it lies in the canal. In the floor of the sella turcica of the stage modeled, the hypophyseal canal is present, but only vestiges of the stalk are apparent in it. Arai ('07) has described a bony walled canalis cranio-pharyngeus in the cat, containing a vein and a hypophysis accessoria cranio-pharyngei; also an epithelial-lined blind canal interpreted as a possible vestige of the stalk of Rathke's pouch. Voit has criticised Arai's homology of the cranio-pharnygeal canal and the hypophyseal foramen in the rabbit, asserting that the former is a secondary development, occurring in a position caudad of the location of the hypophyseal foramen. This criticism is not pertinent in the cat; the foramen and the canal have the same location.

Ala temporalis. Wincza ('96) described the boundary line between the alisphenoid and basisphenoid (properly lingula) in embryos of the cat. My observations are in accord with this description; a zone of perichondral tissue standing between a chondrified processus alaris of the basis cranii and a broad cartilaginous plate, ala temporalis, in relation to the Casserian ganglion. The complete independence of the alisphenoid in the cat led Wincza to investigate its relation to the cranium in other mammals with the following results: In the dog embryo, a separating zone was found between the cartilaginous alisphenoid and basisphenoid; in embryos of the polar bear complete separation of the two parts, with a small wedge-shaped cartilage in the cleft; in man, a joint between alisphenoid and basisphenoid, recalling the relation between the head of the femur and the acetabulum; in hedgehog embryos a boundary between the basi- 
and alisphenoid behind, both parts united in front in three of the stages studied. Wincza's observations have since been confirmed for man by Levi ('00), Gaupp ('02) and Fawcett ('10); for the dog by Olmstead ('11). Noordenbos ('05), Voit ('09) and Fuchs ('10) have seen the separating zone in Lepus. Noordenbos also found the ala temporalis a free process in the pig and horse. A characteristic of the synchondrosis between alisphenoid and basisphenoid of the cat described by Wincza, is its oblique course from behind, forward and medialward. Whether the obliquity is a constant feature of the separating zone of the ala temporalis in other forms studied by Wincza is not specfically stated. Figure 8 of Wincza's paper shows a cleft separating the two parts in the polar bear, having the same direction as the boundary zone in the cat. Macklin ('14) found in a $40 \mathrm{~mm}$. human embryo that the connection between the lateral portion of the ala and the processus alaris took place between the ventral surface of the latter and the subjacent ala.

In contrast to the type of independent ala temporalis there has been observed another type, characterized by its continuity with the basis cranii. Wincza saw no trace of a boundary between basisphenoid and alisphenoid in the chondrocranium of embryos of the horse, pig, sheep and calf. Noordenbos, however, as just stated, disagrees with the observation on the horse and pig; he finds the ala temporalis in mole to be a process of the side of the sella turcica. In Echidna, Gaupp identified the ala temporalis in the small continuous process which springs from the side of the sella turcica, laterad of the carotid foramen.

From these records we learn that, in a variety of mammals, the ala temporalis is more or less distinct from the rest of the cranium, being separated from a basal process by a stratum of some tissue other than cartilage, or even by a cleft of greater or less extent; whereas in others the ala. is a simple process continuous with the cranial base. Furthermore, Noordenbos, from his own observations, recognizes two types of embryonic origin of the ala temporalis in mammals; one type represented by the mole, in which the ala arises as a lateral process of the pole-plate; the other type, represented by the rabbit, wherein the ala arises 
independently and unites secondarily with a process (processus alaris) of the margin of the sella turcica.

Of the many questions yet unanswered regarding the significance and relations of the ala temporalis, one only will be discussed here. The cat belongs to the type in which the temporal wing is more or less separate from the rest of the cranium, and in which the connection is an indirect one through a processus alaris. The successive stages of development of the ala temporalis in the cat seem to throw some light on the nature of the differences between the temporal wing of the continuous type and that of the separate type. The following discussion deals with this question.

We may first compare the development of the ala temporalis in the two types, i.e., the one in which the temporal wing is continuous with the rest of the cranium and that in which it is more or less separate. For the first, Talpa may be chosen as an example; for the second, the cat. The following results have been brought out by Noordenbos in his study of the mole. In embryos of $12-13 \mathrm{~mm}$. three lateral processes at the side of the pole-plate (basisphenoid) are described. With the posterior one of these processes (basicochlear synchondrosis) we are not here concerned. The intermediate process, knee-formed, extends from the poleplate in front of, and then bends laterally around, the carotid artery passing backward to join the cochlear capsule. The anterior process ends free. In embryos of 14 to $17 \mathrm{~mm}$. the latter has grown so as to come into relation with the Gasserian ganglion. In still older embryos (17-19 mm.) the anterior limb and knee of the middle process grow out in connection with the anterior process to reach the under surface of the semilunar ganglion and thus is formed the ala temporalis. "This little plate is connected with the lateral margin of the basisphenoid through the processus anterior and the anterior limb of the processus intermedius." Noordenbos states that the largest part of the ala temporalis is contributed by the anterior lateral process of the pole-plate; a small part arises from the knee of the middle lateral process. Union of the two elements of the ala occurs in embryos of 20 to $25 \mathrm{~mm}$., but there remains for a long time, a small 
fissure-like opening in the root of the ala as the last vestige of the original gap between the anterior and middle lateral processes of the pole-plate. The middle process, the synchondrosis sphenocochlearis lateralis, is, in its caudal half, the part named by Fischer in a later stage the 'trabecula alacochlearis.' Noordenbos has shown, however, that the trabecula alacochlearis genetically has its anterior connection, not with the ala, but with the basisphenoid, and only secondarily unites with the hinder margin of the root of the ala temporalis.

Let us consider now, the development of the ala temporalis in the cat and compare it with that of the mole, taking as a point of departure the stage of $17 \mathrm{~mm}$. In the cat there arises from the side of the sella turcica, a precartilaginous bar, which bends about the carotid artery, its anterior limb (processus alaris) crossing transversely in front of the vessel, its posterior limb (commissura alicochlearis) extending backward upon the sido of the artery and joining the cochlear capsule. Here, then, are elements present in both mole and cat which are in agreement in several important relations. In order further to identify this combined alar process and alicochlear commissure of cat with the middle process of mole, it should be recalled that it is derived from the commis:ural element of the earliest stage $(12 \mathrm{~mm}$.) the relations of which to the base of the cranium, to the cochlear capsule and to the carotid artery are equivalent to the relations of the middle process of mole at its first appearance (12 to $13 \mathrm{~mm}$.). Comparing, next, the relations of the middle process of mole and the precartilaginous derivative of the commissural element in cat, with parts lying laterally, there is present in each case an element, separate from the process under consideration, related to the semilunar ganglion. In Talpa this element, derived from the anterior process, grows out alongside the anterior limb of the middle process, from which, however, it is at first separate. It is noteworthy that the former extends somewhat caudally as well as laterally, and, in conformity therewith, the space intervening between it and the middle process extends from behind, forward and medialward. In embryos of 20 to $25 \mathrm{~mm}$. these two pieces of the ala temporalis unite, the anterior limb of the 
middle process being thereby taken into the root of the ala. In cat embryos of $17 \mathrm{~mm}$., the ala temporalis, the derivative of the mesenchymal alar element in relation to the Casserian ganglion, stands lateral to and in front of the anterior limb of the commissural element from. which, however, it is separated by a layer of mesenchyma (p. 329). Caudally the ala temporalis is separated from the posterior limb of the commissural element by the space which later results in the incisura lacera. The lamina presents then an oblique line of junction with the anterior limb of the commissural element, extending from behind, forward and medially. Later stages $(23.1 \mathrm{~mm}$.) as already described, show along this line a persistent sign of the separation of ala temporalis and the arch made by the processus alaris and alicochlear commissure, in the perichondral boundary zone first described by Wincza. The anterior process, which in mole forms the greater part of the ala temporalis, is entirely separated by an interval from the anterior limb and knee of the middle process for a time; the alar element, which in the cat forms the entire ala temporalis, is separated from the commissural element by an interval (incisura lacera) only in its caudal part. It will be recalled that Wincza found in the polar-bear the alisphenoid separated from the basi-sphenoid by a cleft which, as the figure shows, runs from behind forward and medialward. Also the same author found in the hedgehog a limiting zone in the posterior part only of the ala temporalis.

Apparently the alar element of the cat and the anterior lateral process of the pole-plate of the mole are, in several respects, comparable. The one real difference between the alar element of the cat and the anterior process of the mole lies in the relation of these parts to the side of the sella turcica: in the mole the element in question is connected medially with the sella; in the cat it passes medially into the commissural element, without independent connection, if any at all, with the side of the sella turcica. There is a reduction, if not entire absence, of a medial part of the alar element, next to the hypophyseal cartilage comparable with the root of the anterior process of mole. 
The differences between the independent ala temporalis of the cat and the continuous ala of the mole are apparent rather than real. A very simple explanation removes these apparent differences. 1) The alar element of the cat is wanting in a medial part, comparable with the origin of the anterior process from the pole-plate in the mole. Excepting in the undifferentiated mesenchymal continuity of the alar element and anterior limb of the commissural element, there is no indication of a connection between it or its derivative, the ala temporalis, and the side of the sella turcica. 2) The processus alaris is compound in the mole, being derived from the root of the anterior process plus the anterior limb of the middle process; it is simple in the cat, being composed of the anterior limb of the commissural element only. The processus alaris of the cat is therefore comparable with only the caudal part of the ala temporalis of the mole, i.e., with that part derived from the anterior limb of the middle process. 3) The alar element of the cat and its derivative fails to unite with the commissural element and its derivatives, and there remains throughout the cartilaginous stage of the ala temporalis, a synchondrosis representing the limiting margins of the two elements. In the mole, partial fusion takes place between the comparable elements, but a cleft-like vestige remains locating the original separating space. Perhaps the conditions in the hedge-hog and bear described by Wincza may be similarly explained.

The eonclusions reached therefore are: 1) the reduction or the absence of a medial part of the alar element of the cat, comparable with the origin of the anterior process from the sella turcica of mole; 2) the presence of a simple processus alaris in the cat, of a compound one in the mole; 3 ) the persistence of the original boundary between the lateral and commissural elements in the cat and the obliteration of the limits between the comparable anterior and middle processes in the mole. It follows that the ala temporalis of mole and cat are in the main comparable. It is probable that other examples of the types of continuous and independent temporal wings may be similarly explained. 
Whether the lamina ascendens of the cat should be regarded as an independent element in origin, or continuous with the basis cranii, is a question which could be answered either way from the evidence here presented, and would be purely a choice of interpretations. The whole ala temporalis is shadowed in mesenchyma, continuous with the basis cranii; in this adumbration condensations appear which are distinct from one another or confluent at the edges, as you choose to describe the conditions. Comparison of the lateral element of the cat with the anterior process of the mole inclines me to regard this element and its derivative, the ala temporalis, as not an independent element genetically. There appear to be two parts under consideration in comparisons of the ala temporalis of different mammals, (1) a part which is related chisfly to the carotid artery, represented by the middle process of the mole and the commissural process of the cat; (2) a part which is related to the semilunar ganglion and the three divisions of the fifth nerve. These two parts are typically both connected with the cranial base, the one arehlike, the other process-like. Both are typically originally separate from one another, the process standing in front and at the side of the arch. In some forms the process unites with the arch completely (mole), in others partially (hedge-hog), in still others not at all (polar-bear, cat). Finally, this conception of the comparison of the anterior process of mole and the ala temporalis of cat, supports the homology of the ala temporalis of placental manmals with the ala temporalis of Echidna.

Pterygoid. The pterygoid cartilage is developed relatively late, not until after bone has begun to be formed in its dorsal part. It is represented by a rather ill-defined mesenchymal condensation, even at the time when the ala temporalis is well chondrified. Only its caudal part is cylindrical and thus bears some resemblance to the cartilage of the medial lamella of the pterygoid process in Talpa. It is unlike this process in not reaching forward to the ethmoidal region. However, as pointed out, it develops in the same morphological plane as the palate bone, lies next the ductus nasopharyngeus, in front of the first pharyngeal pouch and is crossed dorsad by the Vidian nerve. 
Jayne ('98) has described, in the skull of the adult cat, a pterygoid process presenting a well defined internal pterygoid plate or process and a variable external plate or process. Union of the originally separate pterygoid bones with the alisphenoid takes place very early, and sutures or lines indicating their boundaries cannot be found in the adult. The pterygoid elements are represented therefore, as processes of the alisphenoids. Reighard ('02) describes an external pterygoid muscle, taking origin from the external pterygoid fossa whose surface includes the lateral aspect of the external pterygoid plate of Jayne, and an internal pterygoid muscle springing from the internal pterygoid fossa; the latter is bounded in part by the medial surface of the external plate. The internal pterygoid plate terminates in a hamular process, related, in the usual manner, to the tendon of the tensor palati. The origin of these two bony processes was found in the present study in cat embryos of $7 \mathrm{~cm}$., and $23.1 \mathrm{~mm}$., the external process being an extension of the endochondral ossification of the pterygoid process of the ala temporalis, the internal process consisting of an ossification, at first in membrane and subsequently in cartilage, in connection with the separate pterygoid cartilage. The latter accords with an early stage of the human internal pterygoid plate as described by Fawcett ('10), both in its early ossification (it is the first part of the sphenoid to ossify in the cat) and in the ossific process, proceeding primarily in membrane and later in cartilage. The external plate is feebly developed in the cat, but its ossification in relation to that of the ala temporalis is nevertheless, in principle, the same as in man. It will be remembered that the Vidian nerve runs along the mesenchymal junction of the pterygoid cartilage and pterygoid process of the ala temporalis; now, although no suture or line can be found in the adult skull indicative of the original limit of the pterygoid bone toward the alisphenoid, as Jayne has stated, yet the course of the bony walled Vidian canal of the adult can be taken as marking this boundary.

Carotid foramen. The epipteric cavity in the cat embryos is limited, toward the primary cranial cavity, by a membrane whose relations to the base of the skull are of considerable interest as 
affecting the question of the nature of the region about the carotid artery. In Echidna the carotid enters directly the primary cranial cavity, but the position of the foramen through which it passes lies within the lateral confines (trabecula basis cranii) of the hypophyseal fossa and therefore may be compared with the entrance into the cranium of this vessel in Lacerta. In placental mammals the carotid foramen lies laterad of the sella turcica, a position which has been explained by two assumptions: (a) lateral migration of the vessel, (b) non-equivalency of the mammalian and reptilian carotid. In accordance with the theory of lateral migration, the carotid foramen is supposed to have moved outward across that part of the cranial floor equivalent to the trabecula; or both the trabecula and artery have moved lateral while still retaining their primitive relations to each other. The trabecula cranii of Lacerta is represented in mammals, according to Gaupp ('02), by the alicochlear commissure. The unity of this commissure, including both the processus alaris and commissura alicochlearis, its distinction from the ala temporalis, and its relation to the base of the cranium were recognized by Gaupp. In one place ('06), he says: "The processus alaris of man appears as a process only through the decadence of the cartilaginous bridge which closes laterally the carotid foramen. It belongs to the median cartilaginous mass in the base of the orbito-temporal region." Voit, who has advocated the view of non-equivalency of the internal carotid in mammal and reptile, locates the carotid foramen in Lepus laterad of the trabecular region. He concludes that the commissura alicochlearis plus the processus alaris alae temporalis should not be compared with some part of the trabecula, but rather the processus alaris should be referred to the processus basipterigoideus of Lacerta and ala temporalis of Fchidna. The commissura alicochlearis is regarded by Voit as a new structure, in mammals, in the floor of the epipteric cavity, a continuation of the floor of the cavum supracochleare. Fuchs ('10) also, compares the medial part (root) of the ala temporalis with the processus basipterigoideus of reptiles. In accordance with Voit's interpretation, the carotid artery first enters the epipteric cave, then, after traversing the medial limiting membrane 
of the cave, comes into the primary cranial cavity. Recently, De Burlet ('13) has brought forward evidence of the carotid in Phocaena traversing the trabecula or its equivalent. In the porpoise the carotid passes directly into the primary cranial cavity. As we have seen, the limiting membrane in the cat is fixed to the basis cranii, neither to one or the other side of the carotid foramen, but broadly. over the region where the vessel enters. It is attached both to the alicochlear commissure and to the lateral margin of the sella turcica. The former does not, in the cat, enter into the floor of the cavum epiptericum, nor does the carotid artery pass directly into the primary cranial cavity. The vessel first traverses that part of the membrana limitans which is fixed to the cranial floor, before passing into the original cavity of the skull. As to the homology of the commissura alicochlearis, it is evident that if the processus alaris is not included as a part of it, the difficulty of comparing the commissure with the trabecula cranii is much increased; if the alar process be recognized as the continuation of the alicochlear commissure forward, in continuity with the median basal cartilage of the orbito-temporal region, the comparison is far less difficult. Reviewing the conclusions stated above, we may note, first, that the name commissura alicochlearis is a misnomer, since it does not express the true relation of the commissura, but implies a connection with the ala temporalis which does not exist in the mammals so far studied. Secondly the studies of Noordenbos on the mole and my own on the cat show that the so-called processus alaris may be simple or compound in different animals, but that it is primarily a part of the commissura alicochlearis (its anterior end in fact), continuing into the median basal cartilage; relation of the processus alaris to the ala temporalis is secondary and obtains in those types (mole) where the ala springs from the basal cartilage; its root, at first separate from, later becomes fused with the processus alaris to produce the compound form of alar process. When the ala temporalis is independent of the basal cartilage (cat) the former has nothing to do with the processus alaris, which then is the simple extension forward of the commissura alicochlearis into the sella turcica. 
A word may be said regarding the membranous structure here called septum transversum. The development, in its basal part, of a marked thickening which extends from the crista transversa to the parietal plate, together with the presence in it of a cartilaginous bar over the semilunar ganglion are suggestive of structures in the reptilia, such as Shino ('14) has described in the crocodile and compared with the pila prootica of Lacerta. A cartilage over the semilunar ganglion in Lepus recorded by Voit was interpreted as a vestige of the primary cranial wall; in the cat, a cartilaginous mass, having the same position and relations, was found within the septum transversum.

Ala orbitalis. The occurrence generally, in a wide range of types, of the independent origin of the ala orbitalis has been emphasized by Noordenbos. This phenomenon, as shown above, is also characteristic of the cranial development of the cat. The idea of the association of the ala orbitalis, primarily with the optic nerve and eye-ball, seems to be well founded and receives further support from the early form and relations of this cartilage in the cat. The relations of the origins of the ocular muscles may be interpreted as further indicating a close connection between the orbital wing and the organ of sight. The definitive origins of these muscles are in the main related to the optic foramen, about as they are in the chondrocranium, but some shifting has evidently taken place as comparison of the two states shows (Wilder and Gage '86; Corning '02). Four definite separate spots in the chondrocranium are occupied by, and one of them apparently specially adapted to, the attachment of the muscles of the orbit. How these attachments compare with those in the mammalian types represented in the literature of the chondrocranium I cannot say, since this question does not seem to have received attention. Does the superior oblique constantly spring from the preoptic root; does the orbital process of the metoptic root function generally as a point of attachment of a definite group of eye-muscles; is the side of the basis cranii in the orbital fissure a special locus of origin of another group, and is the origin of the inferior oblique constantly the planum antorbitale? Regarding the metoptic root, it has been noted that, in contrast to the 
straight direction of the preoptic, it presents a marked bend, convex caudally. This curve is apparent to a slight extent in the bony cranium. Judging from figures of the chondrocranium of several mammals, the bend in question seems to be a characteristic of this cartilaginous rod. In cat the knuckle of the curve apparently mark the place of union of the metoptic process of the trabecular plate and the corresponding process of the ala orbitalis. Opposite this spot the oculo-motor nerve leaves the cranium by the orbital fissure. What significance there is in the form and relations of the metoptic root, which are early established and permanently retained, must await future inquiry.

\section{Ethmoidal region}

Region of the olfactory fenestra. The floor of the condrocranium of mammals, between the levels of the preoptic root of the ala orbitalis and the fenestra olfactoria, is made by the lamina infracribosa, which is the roof of the posterior cupola of the nasal capsule and an extension of the planum antorbitale. The lateral branch of the naso-ciliary nerve runs upon this lamina on its way toward the interior of the nasal capsule, having come through the spheno-ethmoidal fenestra from the orbit. The lamina cribrosa, a structure peculiar to mammals, develops over the fenestra olfactoria. Now, in reptiles the ethmoidal nerve and the whole of the posterior cupola, with the olfactory fenestra, are extracranial. A study of these contrasting conditions of the mammalian and reptilian ethmoidal skeletons has led Gaupp to the conclusion that a new region, named by him recessus supracribrosus, has been added to the mammalian brain case, and that this region is comparable, in reptiles, with the extracranial parts about the olfactory fenestra. In the cat, the form and relations of the posterior cupola and olfactory fenestra are essentially as in other mammals. The fenestra olfactoria opens directly into the chondrocranial cavity. As already stated, the lamina cribrosa was not present in the stages of the cat studied, consequently no data have been presented bearing on the question of its pasition relative to the walls of the chondrocranium. The 
lamina infracribrosa is a part of the antorbital division of the nasal capsule, entering into the floor of the cranium. The course of the ethmoidal nerve is, strictly speaking, outside the chondrocranial cavity, since the layer of mesenchyma (probably in part giving rise to dura), which covers the lamina infracribrosa, stands between it and the cerebral cavity. In the cat, in the stages studied, there is no overhanging anterior wall of the chondrocranium such as is shown in the model of Echidna; a flat anterior margin of the fenestra olfactoria marks the anterior limit of the cranial cavity. Consequently, the term 'recessus' supracribrosus is hardly appropriate for the cat; the term 'supracribrous region' is preferable. From these data, it seems that the ethmoidal region of the cat, like the orbito-temporal and otic regions, gives evidence in support of Gaupp's assertion of the nonequivalency of reptilian and mammalian crania, and also, by its relations to the chondrocranial cavity, indicates that the latter is enlarged over that of reptiles by the acquisition of a region wholly extracranial in that class. A factor having a large share in bringing about this mammalian characteristic is the backward growth of the nasal cavity (Weber, '04; Gaupp, '08) whereby the interorbital septum is encroached upon by the posterior cupola of the ethmoidal skeleton. That this occurs to a slight extent in the ontogeny of the cat was indicated by the difference in position of the posterior cupola relative to the preoptic process in earlier and later embryonic stages.

In Lepus, according to Voit, the foramina of the lamina cribrosa are separated into two groups by a crista intercribrosa, olfactory filaments from the recessus lateralis traversing the foramina of the antero-lateral group, those from the recessus posterior (ethmoturbinal region) passing through the holes of the posteromedial group. Voit also found the dorsal end of ethmoturbinal I continuous with the crista intercribrosa. Continuity between these two parts is present in Caluromys philander, as observed by Dr. Denison in this laboratory. In the cat, at the stage modeled, the dorsal end of ethmoturbinal $I$ is very prominent and stands between the group of olfactory filaments coming from the epithelium of the recessus lateralis and those from the ethmo- 
turbinal region. The latter group is further subdivided by the dorsal end of ethmoturbinal II into two bundles coming, one from the area in front of, the other from the area behind this turbinal process.

The floor of the nose and Jacobson's cartilage. In cat embryos of the stage modeled, the secondary palate is nearly complete, forming a floor for the nasal cavities. The latter are separated from each other by the septum nasi, excepting for a stretch posteriorly, where the ventral margin of the nasal partition is free from and above the level of the palate. Between the maxilloturbinal dorsally and the nasal floor is a broad groove of the lateral nasal wall, which extends from before backward to the choanae. This groove, the inferior meatus of adult anatomy, the lower furrow of Legal ('83) or the choanal passage of Fleischmann and Beeker ('03), besides differing from the other nasal passages by its origin from the primitive mouth, is specialized through its relation to the naso-lacrimal duct and Jacobson's organ. A striking feature of this ventral part of the cavum nasi is the variability among mammals of its cartilaginous walls and floor. This characteristic stands in marked contrast to the usual condition of stability of the dorsal part of the ethmoidal skeleton (Spurgat, '96).

The peculiar characteristics of the nasal floor cartilages in the cat have been described by several investigators. Our observations must be regarded as confirmatory of Broom's ('96) description and of Zuckerkandl's ('08) more recent representation of the paraseptal and related cartilages. Both of these authors found an inner and outer division or process of the nasal floor cartilage (lamina transversalis anterior) and a cartilage related to the nasopalatine duct.

The significance and homology of these parts of the ethmoidal skeleton have been much discussed. Division of the lamina transversalis anterior, into medial and lateral cartilages (inner and outer parts of the nasal floor cartilages) embracing the nasopalatine duct, has been observed by I3room ('96) to occur with considerable constancy in the mammalian series. The outer portion of the nasal floor cartilage stands lateral to the nasopalatine 
canal. In Ornithorhynchus and Echidna this cartilage expands at its caudal end and unites with its fellow across the midline to form a broad plate beneath the organ of Jacobson and its cartilaginous capsule. The conditions in the Marsupialia were traceable to those of the monotreme type. In Lepus, as representing the rodents, Broom found an independent cartilage supporting the outer side of the nasopalatine canal, which was homologized with the outer nasal floor cartilage of the Monotremes, and was regarded as a much modified form, compared with the simple higher eutherian type. Voit has also described, under the name cartilago nasopalatina, the supporting cartilage for the nasopalatine duct in the rabbit, and, with Gaupp, compares it with the processus palatinus (outer nasal floor cartilage of Broom) of Echidna.

This comparison is founded by Voit mainly on the fact that in certain mammals (horse, pig and sheep) the processus palatinus (cartilago basalis lateralis as described by Spurgat, '96) is united with the lamina transversalis anterior (processus septi cartilaginei lateralis ventralis) in the same relationship as is the case with the processus palatinus of Fchidna; and further, that in at least one form, Vesperugo noctula, described by Grosser ('02) the 'cartilagines posteriores laterales' (cartilagines nasopalatinae of Voit) are considerably broadened posteriorly and fused across the median line, as is true for the palatal processes of Fchidna.

Two conditions, presented by the cat, seem to indicate that the significance of the nasopalatine cartilage and the processus posterior lateralis of the lamina transversalis, is not fully brought out by the above comparisons. These conditions are (a) the presence, at the same time, of two separate cartilages, one in relation to the nasopalatine duct (nasopalatine cartilage) the other in the floor of the nose next to the entrance of the nasopalatine duct (posterior lateral process of the transverse lamina); and (b) the independent origin of the former. Furthermore, in regard to the first condition, it seems evident, from Grosser's description of Vesperugo, that both paired nasopalatine cartilages (cartilago ductus incisivi) and posterior lateral cartilages are present and separate, the one pair from the other. 
A cartilage, having the position and relations to the nasopalatine duct and to the anterior transverse lamina, such as presented by the posterior lateral cartilage of Vesperugo and the lateral process of the lamina transversalis anterior of Felis, is of frequent occurrence in the mammalian series. It stands as a support to the floor of the nose at the outer side of the entrance to the nasopalatine duct and probably possesses, as Grosser says, a great significance as a supplementary structure to the palate. It is found in forms in which a nasopalatine cartilage (as here defined) does not exist, notably in mammals having a very short nasopalatine duct (Echidna) and also in forms where the nasopalatine cartilage is present, in which cases it may be separate from or united with the latter.

In accordance with this view, the processus palatinus of Echidna would be comparable with the posterior lateral cartilage of Vesperugo, the lateral process of the lamina transversalis anterior of Felis, and not with the cartilage ductus incisivi of these forms. The primary relation of the nasopalatine cartilage (cartilago ductus incisivi), on the other hand, appears to be directly with the nasopalatine duct, as in the cat. There is some evidence in the series of mammals of its correlation with the presence of a long nasopalatine canal. Absence of a nasopalatine cartilage in the lower mammals and its independent origin and late appearance in davelopment in the cat may be interpreted as indicating that it is phylogenetically a recent acquisition to the palatal skeleton, and also that its connection with the lateral posterior cartilage may be regarded as secondary.

Jacobson's cartilage, relatively short, arises independently, as recorded by Schwink ('88) and as observed in the present study, and remains ununited with other parts of the chondrocranium in embryos of the cat up to $23.1 \mathrm{~mm}$. In later stages, as Zuckerkandl has observed, this cartilage has elongated and taken on connections with the lamina transversalis posterior, through the development of a slender paraseptal rod. Zuckerkandl believed that Jacobson's cartilage represents the anterior half of a cartilaginous ridge which is derived from the primitive floor of the nose. This is in accord with Seydel's ('99) conception of the 
paranasal cartilage forming a part of the primitive nasal floor which, by reduction, came eventually to be represented by more or less separate parts (Jacobson's cartilage) in the mammals. In the light of this interpretation, the slender cartilaginous paraseptal strip which appears late in the development of the cat, and unites Jacobson's cartilage with the posterior transverse lamina, may be regarded as evidence of a partial restoration of the primitive floor.

Tectum nasi. Noordenbos has observed the beginning of the tectum nasi in mole embryos of $9 \mathrm{~mm}$. as bilateral divisions of the anterior margin of the trabecular plate, forming curved lamellae. In the dorsal middle line a shallow groove stands between the two halves of the tectum. In the cat the nasal tectum arises apparently similarly in connection with the nasal septum, as the parieto-tectal cartilages, although, as already mentioned, some evidence of the independent origin of these cartilages was presented. The groove between them, dorsad of the septum, is the beginning of the sulcus supraseptalis. In the cat, the parieto-tectal cartilages grow back, along the dorsal margin of the septal cartilage, as far as the fenestra olfactoria, becoming gradually narrower from side to side and assuming the form of triangular plates. These cartilages contribute the entire roof of the precerebral division of the nose and the side wall anterior to the recessus lateralis. What the relations of the parieto-tectal are to the development of the lamina transversalis anterior were not determined. Eventually a complete zona annularis is established behind the level of the fenestra narina, the roof being derived from the parieto-tectal cartilage, the floor from the lamina transversalis anterior, the lateral wall from the union of these two parts. The relations of the lateral margin of the parietotectal with the anterior free margin of the paranasal cartilage are at first similar to those in Talpa, as observed by Noordenbos. This cartilage does not seem to be concerned in the formation of the maxilloturbinal, although in the stage of $23.1 \mathrm{~mm}$. this process is connected with the anterior part of the lateral nasal wall through the lamina supraconchalis. Within the nasal cavity the atrioturbinal appears as the inrolled ventral margin of the parietotectal cartilage. 
Paranasal cartilage. Independent origin of a plate of cartilage lying in the anterior part of the lateral wall of the nose has been observed by Noordenbos in embryos of Talpa of $9 \mathrm{~mm}$. length; also in the embryos of calf and pig. Following Mi:alkovics, the cartilage was called cartilago paranasalis. In Talpa, the paranasal cartilage and the tectum nasi are separated by a fissure, bounded by the anterior border of the former and the free margin of the latter. In the cat, also, an independent paranasal cartilage occurs which bears similar relations to the parietotectal cartilage. It is directly over that diverticulum of the cavum nasi which later is included in the recessus lateralis of the ethmoidal skeleton. The little cartilaginous plate, bent upon the convex bulging of the nasal sac, presents free margins: one toward the side of the olfactory lobe; one backward toward the eye; a ventral margin, and a long anterior side, opposite the free, oblique edge of the parieto-tectal cartilage; relations comparable with those observed in the mole.

Great interest attaches to the ventral and anterior margins of the paranasal cartilage. The latter overlaps the parieto-tectal, and, whereas in younger embryos it is separated from that cartilage by a fissure, it is later fused with it. The result of this fusion is a curved, intranasal ridge, the crista semicircularis, perforated by the foramen epiphaniale, which is the remains of the original fissure. Thus is explained the position and extent, quite to the olfactory fenestra, of the semicircular crest. It follows from its mode of formation that, in later stages, the crista semicircularis may be taken as the boundary between two originally distinct territories of the nasal wall. During the period occupied by the process of fusion of the incurved anterior margin of the paranasal and the hinder margin of the parieto-tectal cartilage, and for some time thereafter, an interval of variable extent (derived from the space of the original separating fissure) is enclosed within the encompassing cartilaginous margins; that is, for a time the crista semicircularis presents double walls with an intervening space; this space is crossed by the lateral nasal nerve at the level of the future epiphanial foramen. 
Now in the nasal capsule of Lacerta, at the place where the zona annularis joins posteriorly the broader, bulging portion of the side wall, a conchal fold is present, projecting into the nasal cavity; within the aditus conchae, or entrance to the conchal fold is the foramen for the lateral nasal nerve. The fissure-like aditus extends dorso-ventrad, its convex lateral margin overhanging the medial margin made by the zona annularis. Gaupp says of it ('00, p. 484): An der Muscheleinstülpung sind zwei Lamellen, eine mediale und eine laterale, zu unterscheiden. Die mediale Lamelle der Concha liegt in der direkten Fortsetzung der Seitenwand der vorderen Nasenkapselhälfte, sie endet ventral mit freiem Rande. . . . . Die laterale Lamelle der Concha geht ventralwärts in den Boden des Recessus extraconchalis über.

The aditus, in Lacerta, lodges the external nasal gland; its duct passes forward across the outer side of the zona annularis to enter the nasal mucosa through a gap in the side wall of the nasal capsule, behind the processus alaris superior. Finally, the concha itself forms a ventral and anterior partial partition between the general space of the nasal capsule and a lateral diverticulum which Gaupp has named the recessus extraconchalis. The incomplete floor of the recessus is made by the ventral prolongation of the lateral lamella of the concha.

It seems evident that in the stage of development of the ethmoidal skeleton in cat when fusion is occurring between the parieto-tectal and paranasal cartilages, certain conditions are presented which reflect the structure of the reptilian nasal capsule, as shown by the embryo of Lacerta. The general direction of the space between the parieto-tectal and paranasal cartilages on the one hand, and the aditus conchae on the other, is the same, and its boundaries are made by lamellae similarly placed in respect to each other; it is traversed by the lateral nasal nerve in both forms. The position of the external nasal gland in the aditus conchae of Lacerta and of the externally coursing duct is, apparently, impossible to reconcile, on our present knowledge, with the lateral nasal gland of Felis and the intranasal course of its duct, if these glands be comparable at 
all. Peter ('06) seems to regard the mammalian gland as a new acquisition. It will be remembered, however, that the lateral nasal gland in the cat embryo of $23.1 \mathrm{~mm}$. is located just in front of the base of the crista semicircularis.

Next, we may attempt to compare that part of the nasal wall (paranasal cartilage), which stands just behind the fissure in the cat, and the aditus conchae in lizard. We have seen that the commissura spheno-thmoidalis unites, in cat embryos of $17 \mathrm{~mm}$., with the dorsal margin of the paranasal cartilage, where the latter bounds the olfactory fenestra, thus presenting relations which recall those between the posterior half of the side wall of the nasal capsule and the cartilago spheno-ethmoidalis of Lacerta. For, at the junction of these parts, in the cranium of the lizard, the lateral wall limits by its upper margin the olfactory fenestra while, medially, it passes into the posterior wall, the planum antorbitale, as is also true for the cat. It has been noticed that the ventral and anterior margins of the paranasal, are continuous inrolled edges, which form the cartilaginous maxillo-turbinal and, with the free posterior margin of the parieto-tectal cartilage, form the beginning of the crista semicircularis. In Lacerta, the part of the side wall in question goes over anteriorly into the lateral overhanging plate of the bilaminar concha, the medial plate of which is the direct continuation of the side wall of the anterior half of the nasal capsule. Furthermore, the lateral plate passes ventrally into the floor of the recessus extraconchalis. Of great interest is the resemblance between the concha and floor of the recessus extraconchalis of Lacerta on the one hand and the crista semicircularis and maxillotirbinal of the cat on the other.

This comparison brings out a certain degree of similarity of form and relation between the skeletal parts of the region of the recessus extraconchalis of Lacerta (embryo of $31 \mathrm{~mm}$. total length) and of the recessus lateralis of the cat (embryos of 17$20 \mathrm{~mm}$.). An opinion as to a possible homology between these parts should not be ventured on a comparison limited to the data here presented. Greater knowledge of the development of the ethmoidal skeleton in the lizard is required, and additional 
data on the history of the paranasal cartilage in mammals is essential.

As to the origin of the lamina supraconchalis and the broad base of the naso-turbinal, unfortunately little evidence was found. The region of the side wall occupied by these parts corresponds to that between the antero-inferior quarter of the paranasal and the adjacent region of the parieto-tectal cartilage. I cannot say to what extent, if at all, these two cartilages enter into the lamina supraconchalis and naso-turbinal.

One other matter should be mentioned with which, possibly, the paranasal cartilage may be related - the origin of the inferior oblique muscle. In the adult eat, this muscle arises from the orbital surface of the maxilla behind the lacrimal bone (Reighard, Jayne, Corning). In the embryo of $23.1 \mathrm{~mm}$. its origin is from a prominent angle of the lateral nasal wall, at the junction of the paries nasi and planum antorbitale. In the $17 \mathrm{~mm}$. embryo this angle corresponds with the ventral inferior corner of the paranasal plate, overlapping the anterior margin of the antorbital plate. Now, although no posterior maxillary process is developed in cat in the stages studied, yet the angle here referred to possibly represents this process. I have not noted in the literature the origin of the inferior oblique from the chondrocranium in mammals. Corning ('02), quoting Weber on its origin in Lacerta viridis, says (p. 122): "Der M. obliquus inferior 'entspringt von der Cartilago ethmoidalis, wo diese sich an den Knochen der vorderen Orbitalwand ansetzt.'"

Lamina antorbitalis. Noordenbos is apparently the only one who has observed in mammals the isolated origin of the cartilage forming the posterior part of the nasal capsule. This element of the ethmoidal skeleton, found in mole embryos of $\mathbf{1 0 . 5}$ $\mathrm{mm}$. and $11 \mathrm{~mm}$., finds its parallel in the cat, where, as stated, a separate plate of cartilage forms the planum antorbitale and cupola posterior. Union between the antorbital plate and the paranasal in the cat must take place rapidly, as no trace of an interval between the two parts is to be seen in embryos of 20 $\mathrm{mm}$. Complete union, that is, fusion, with the septal cartilage is not present in the embryo of the stage modeled. Of much in- 
terest is the relation of the antorbital plate to the ethmoturbinal bodies. $\Lambda$ well developed, epithelial ethmoturbinal fold can be seen behind the recessus lateralis in embryos of 15 to $17 \mathrm{~mm}$. We have seen that the posterior margin of the paranasal cartilage overlaps the anterior edge of the antorbital plate, and that the latter projects forward and medialward into the base of the epithelial fold of ethmoturbinal I. Sections show that the anterior, free cartilaginous extremity of this ethmoturbinal, in embryos of $23.1 \mathrm{~mm}$., is formed, in connection with mesenchyma, within the fold of epithelium and independently of the wall of the nasal capsule. The mesenchyma can be followed, however, backward to the base of the fold and to the ridge of cartilage derived from the antorbital plate of earlier stages, which bounds posteriorly the opening into the recessus lateralis.

The development of the ethmoidal skeleton in the cat indicates a certain degree of correlation between its cartilaginous components and regions of the nose more or less sharply defined by particular functions. The dorsal, larger, and more completely walled division includes the olfactory and paranasal territories and the atrium opening toward them; whereas the ventral, smaller and imperfectly formed division stands in relation to the respiratory air passage, nasopalatine and lacrimal ducts. Even the original components of the dorsal division present evidence of specific adaptation to functional territories. Thus, the antorbital plate forms the wall of the ethmoturbinal territory of distribution of the olfactory nerve, the paranasal cartilage incloses the diverticulum of the lateral recess, later the frontal sinus; and the parieto-tectal develops into the wall of the atrium. I do not wish to imply that the evidence at hand justifies the conclusion of rigorous specificity of these components, it certainly does not; but facts are sufficient to indicate that each of these original cartilages is, in the main, developed in relation to recognized functional territories of the nose. 


\section{SUMMARY}

1. The basal plate of the occipital region in the cat is derived from a pair of parachordal cartilages and from two, probably three, hypochordal commissures or arches. The parachordals are continuous with the lateral occipital arches and, topographically, are to be compared with the lateral masses of the atlas. Chondrification of the perinotochordal sheath in the occipital region forms the apex of the dens epistrophei, which, in certain respects, is comparable with a vertebral centrum.

2. The observations on the developmental processes of the occipital region in the cat indicate that, in principle, they are comparable with those of an atypical vertebra of the atlas kind. The basal plate of the occipital region falls into the category of arch structures, not centra.

3. In the atlas, the beginning of an atlantal foramen is very early indicated by a notch, traversed by the first spinal nerve, the sides of which are formed by the neural arch and a process of the lateral mass. The possible significance of this atlantal process was discussed.

4. The occipital condyles are located primarily on that part of the basal plate derived from the parachordal cartilages and, in accordance with the interpretation of the form of the occipital element, belong to arch structures and not to centra.

5. The position of the lateral occipital arches and the plane of the foramen magnum, parallel with the floor of the nose in embryos of $23.1 \mathrm{~mm}$., is correlated with flexures, in a sagittal plane, of the cranium as a whole.

6. The fissures around the otic capsule, between it and the basal plate and walls of the chondrocranium in the $23.1 \mathrm{~mm}$. embryo, are vestiges of the spaces primarily existing between these independently arising cranial elements.

7. The incisura occipitalis posterior of the cat embryo is intermediate in relative size between that of the reptile (Lacerta) and that of man. There is apparently a tendency for this space to inerease in area from lower to higher forms. 
8. The upright position of the axis of the otic capsules in cat embryos of the stage modeled is exceptional for mammals. There is evidence in the literature that the obliquity of the otic axis characteristic of the mammalian chondrocranium is attained at somewhat different periods of development in different species.

9. The origin of the cartilaginous pars canalicularis of the otic capsule is independent of other parts of the cranium. The pars cochlearis arises in connection with the pars canalicularis and the suprafacial commissure. The latter is continuous with the orbito-parietal commissure, and is therefore, in part at least, to be regarded as a parietal structure. The cochlear capsule forms independently of the basal plate, which in the cat is reduced to a narrow bar in the otic region. The observations on the relationship of the cochlear capsule to the basal plate and suprafacial commissure are interpreted to support Gaupp's theory on the development of the cochlear capsule and reformation of the cranial base.

10. A single acustic fissure, transmitting the two divisions of the acustic nerve, is situated at the bottom of a shallow internal acustic meatus. The latter results, principally, from the elevations of the suprafacial commissure and commissura basivestibularis, these forming its anterior and posterior walls.

11. The fenestra cochleae and aquaeductus cochleae result from the division of the foramen perilymphaticum by a process extending from the cochlear capsule.

12. The cavum vestibulare of the cartilaginous otic capsule of the cat is comparable with that of the reptile (Lacerta) in possessing two subdivisions, a separating partition and similar relations to parts of the membranous labyrinth.

13. The lamina parietalis seems to be derived from two independently arising centers of chondrification, an anterior one, which also constitutes the orbito-parietal commissure and unites with the otic capsule in the parietocapsular commissure; and a posterior center which unites, first, with the summit of the lateral occipital arch and, next, with the pars canalicularis. From the posterior center (called parietal plate in the descrip- 
tion) the tectum posterius apparently arises as a process. The definitive parietal plate sems to be the result of the fusion of the anterior and posterior elements.

14. The facial nerve makes its exit from the chondrocranium by the primary facial foramen, at which spot is located the geniculate ganglion and the origin of the great superficial petrosal nerve. The primary facial foramen is to be regarded as comparable with the foramen faciale of Lacerta.

15. The floor of the hypophyseal fossa is formed from a single crescentric cartilage arising independently.

16. In the cat a small space, filled with mesenchyma, existing for a brief period, between the anterior end of the basal plate and the hypophyseal cartilage, is identified as a fenestra basicranialis posterior.

17. The dorsum sellae in cat is formed from the crista transversa and, in addition, by chondrification of the mesenchyma dorsad of it, probably by a separate center. There is evidence in the literature that the dorsum sellae of the lower mammals is a derivative of the crista transversa alone, while that of the higher mammals includes an additional element.

18. The development of the ala temporalis of the cat, representing the type of discontinuous ala, is comparable with that of mole, representing the type of ala temporalis continuous with the sella turcica. The difference between these forms of ala is an apparent one, resulting from failure of the root of the temporal wing of the cat to form in cartilage. The synchondrosis between the ala temporalis and alicochlear commissure and the incisura lacera of cat, the foramen or fissure between ala and commissure in other forms, indicate the plane of junction between these originally independent and different parts. The ala temporalis of cat is comparable with the ala temporalis of Echidna.

19. A pterygoid element appears in the cat as a condensation of mesenchyma, in which ossification is occurring at the stage of the $23.1 \mathrm{~mm}$. embryo. Cartilage is subsequently developed, in which ossification proceeds. There is evidence of two ossific centers, and from these the medial pterygoid lamella and hamular process are formed. 
20. A cavum epiptericum and cavum supracochleare are recognized in the chondrocranium of cat. The names 'membrana limitans' and 'septum transversum' are proposed for the mesenchymal sheets connected with the walls of the orbito-temporal region. In the cat the internal carotid artery enters the membrana limitans, by the carotid foramen, and secondarily into the primitive cranial cavity. A bar of cartilage in the septum transversum, lying upon the semilunar ganglion, is probably a vestige of the primitive chondrocranial wall.

21. The ala orbitalis arises independently in the cat and unites secondarily with the paranasal cartilage, orbitoparietal commissure, and trabecular plate. It is apparently primarily adapted to the cyeball and its adnexa.

22. $\Lambda$ region, extracranial in reptiles, is represented within the chondrocranium of cat as the supracribrous region of the ethmoidal skeleton.

23. 'The structure of the anterior part of the floor of the nose is in agreement with the descriptions of Broom and Zuckerkandl. The nasopalatine cartilage of mammals is interpreted as a structure originally distinct from the lateral posterior cartilage of the nasal floor, and its connection with the latter secondary.

24. Jacobson's cartilage in the cat is the anterior, well developed, portion of a paraseptal cartilage, connected posteriorly with the lamina transversalis posterior.

25. The cartilaginous ethmoidal skeleton of the cat is separated on developmental grounds and physiological relations, into a small ventral part and a large dorsal part. The former presents incomplete walls about the inferior meatus; the latter rather continuous walls about the paranasal sinuses and olfactory region of the nose.

26. The dorsal part of the ethmoidal skeleton in embryos to the stage of $30 \mathrm{~mm}$. is formed from the septal cartilage, parieto-tectal cartilages, paranasal cartilages and the laminae antorbitales.

27. The parieto-tectal cartilages, paired, spring from the septal cartilage. They contribute the roof of the precerebral division of the ethmoidal skeleton, the side wall of the atrial region, 
participate in forming the crista semicircularis and probably, to some extent, give origin to the alar cartilages.

28. The paranasal cartilages, paired, arise independently and are primarily adapted to the diverticula of the recessus laterales. They participate with the parieto-tectal cartilages in the formation of the semicircular crests and in the origin of the maxilloturbinal processes. From this cartilage the inferior oblique muscle of the eye arises.

29. The foramen epiphaniale is the vestige of the original space between the parieto-tectal and paranasal cartilages.

30. The lamina antorbitalis, paired, arises independently, and unites secondarily with the paranasal and septal cartilages. From it are formed the posterior cupola and the bases of the ethmo-turbinals I and II.

31. The ethmoidal skeleton of cat may be compared with that of Lacerta as follows: the region of alar cartilages in the cat and the anterior zone of the lizard; tectum nasi and lamina transversalis anterior of the cat with the zona annularis of the lizard; the combined paranasal and antorbital parts of the eat with the posterior zone of the saurian. 


\section{LITERATLRE CI'TED}

ArAI, H. 1907 Der Inhalt des Canalis craniopharyngeus. Anat. Hefte, vol. 33 .

BARDEEN, C. R. 1908 Early development of the cervical vertebrae and the base of the occipital bone in man. Am. Jour. Anat., vol. 8.

Baur, G. 1894 Ueber den Proatlas einer Schildkröte (Platypeltis spinifer Les.). Anat. Anz., vol. 10.

Bezcker, A. 1903 Vergleichende Stilistik der Nasenregion bei den Sauriern, Vögeln und süugethieren. Morphol. Jahrb., vol. 31.

Blendinger, W. 1904 Das Cribrum der Säugetiere. Morphol. Jahrb., vol. 32.

BoLx, L. 1899 De Variaties het grensgebied tusschen hoofd en halwervelkolom. Neder. 'lijdschr. voor Geneeskunds, vol. 1.

1904 Entwicklungsvorgange in der occipital Region des Primordialcraniums beim Menschen. Petrus Camper, vol. 2.

Bondy, G. 1907 Beitrüge zur vergleichenden Anatomie des Cehörorgans der Säuger. Anat. Hefte, vol. 35 .

Broman;, I. 1899 Die Entwickelungsgeschichte der Gehörknöchelchen beim Menschen. Anat. Hefte, Abt. 1, H. 37.

Broom, R. 1896 On the comparative anatomy of the organ of Jacobson in Marsupials. Proc. Linnean Soc: of N. S. W., Pt. 4.

Canuveati. 1905 Comparative anatomy of the domesticated animals. New York.

Conning, H. K. 1902 Uber die vergleichende Anatomie der Augenmuskulatur. Morph. Jahrb., vol. 29.

De Burlet, H. M. 1914 Zur Entwicklungsgeschichte des Walschadels. III. Das Primordialcranium eines Embryo von Balaenoptera rostrata. Morph. Jahrb., vol. 49.

DECKkR, F. 18*3 Ueber den Primordialschädel einiger Säugetiere. Zeitschr. f. d. wissensch. Zoologic, vol. 38.

Denker, A. 1899 Vergleichend-anatomische Untersuchungen über dus Cehörorgan der Säugetiere. Leipzig.

Dixon 1906 Some specimens showing indications of the presence of an occipital vertebra. Trans. R. Acad. of Med. in Ireland, vol. 24.

FAwCETT, F. 1905 On the early stages in the ossification of the pterygoid plates of the sphenoid bone of man. Anat. Anz., vol. 26.

1906 On the development, ossification and growth of the palate bone of man. Jour. of Anst. and Physiol., vol. 40.

Fischer, 1:. 1901 Das Primordialcranium von Talpa europaca. Ein Beitrag

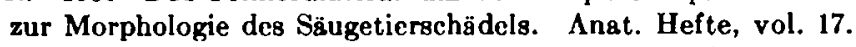

1902 Zur Kenntniss des Primordialeraniums der Affen. Anat. Anz., vol. 20.

1903 Zur Entwickelungsgeschichte des Affenschädels. Zeitschr. f. Morphol. u. Anthropol., Bd. V.

1905 Das P'rimordialcranium von Tursius spectrum. Vorläuf. Mitteilung, Abhandl. d. kgl. Akad. der Wissensch. Amsterdam.

Fuxischman, A. 1904 Das Kopfskelet der Amnioten. II. Morphol. Jahrb., vol. 32 . 
Froriep, A. 1882 Ueber ein Ganglion des Hypoglossus und Wirbelanlagen in der Occipitalregion. Beitrag zur Ehtwickelungsgeschichte des Säugetierkopfes. Arch. f. Anat. u. Physiol., Anat. Abt.

1886 Zur Entwickelungsgeschichte der Wirbclsäule, insbesondere des Atlas und Epistropheus und der Occipitalregion. II. Beobachtung an Säugethiercmbryonen. Arch. f. Anat. u. Physiol., Anat. Abt.

1902 Zur Fntwickelungsgeschichte des Wirbeltierkopfes. Verh. d. Anat. Gesclsch. auf der 16 Vers. in Halle a. S.

1902 Einige Bemerkungen zur Kopfirage. Anat. Anz., vol. 21.

Fuchs, H. 1910 Ueber das Pterygoid, Palatiuum und Parasphenoid der Quadrupeden, insbesondere der Reptilien und Säugetiere. Anat. Anz., vol. 36.

Gaupp, E. 1898 Die Metameric des Schädels. Merkel u. Bonnet, Ergebn. der Anat. u. Entwickelungsgesch, vol. 7, 1897.

1900 Das Chondrocranium von Lacerta agilis. Ein Beitrag zum Verständnis des Amniotenschödels. Anat. Hefte, vol. 15.

1901 Alte Probleme und neuere Arbeiten über den Wirbeltierschädel. Ergebn. d. Anat. u. Entwickelungsgesch., vol. 10.

1902 Ueber die Ala temporalis des Säugerschädels und die Regio orbitalis einiger anderer Wirbelticrschädel. Anat. Hefte, vol. 19.

1905 Teue Deutungen auf dem Gehiete der Lchre vorn Säugetierschädel. Anat. Anz., vol. 27.

1905 Die Entwickelung des Kopfskeletes. Hertwigs Handb. d. vergl. u. exper. Entwickelungslehre d. Wirbelticre, vol. 3.

1906 Ueber allgemeine und spezielle Fragen aus der I,chre vom Kopfskelet der Wirbeltiere. Verhandl. d. Anat. Gesellsch. auf. d. 20. Vers̊mml. in Rostock.

1908 A Ucher Entwickelung und Bau der beiden ersten Wirbel und der Kopfgelenke von Lichidna aculeata, nebst allgemeinen Bemerkungen über die Kopfgelenke der Amnioten. Jen. Denkschr., vol. 6. $1908 \mathrm{~B}$ Zur Entwicklungsgeschichtc und vergleichenden Morphologie des Schädels von Echidna aculeata, var. typica. Semons zool. Forschungsreisen, vol. 3. (Jen. Denkschr., vol. 6.)

1910 Säugerpterygoid und Echidnapterygoid, nebst l3ernerkungen über dus Säuger-palatinum und den Processus basipterygoideus. Anat. Hefte, 127 Heft.

Glaesmer, E. 1910 Die Atlanto-Occipital-Synostuse. Ueber ihre pathologischen oder morphologischen Ursachen auf Grund eines Weichteilpräparates. Anat. $\Lambda$ nz., vol. 36 .

Grosser, O. 1902 Zur Anatomie der Nasenhöhle und des Rachens der einheimischen Chiropteren. Morphol. Jahrb., vol. 29.

HARVEY, R. 1882 Note on the organ of Jacobson. Quart. Jour. micr. Seience.

$\mathrm{J}_{\triangle \mathrm{COB}} \mathbf{Y}, \mathbf{M} .1895$ Lin Beitrag zur Kenntnis des menschlichen Primordialcraniums. Arch. f. mikros. Anat., vol. 44.

JAYNE, H. 1898 Mammalian Anatomy. The skeleton of the cat. Philadelphia.

Kernan, J. D., Jr. 1915 The development of the occipital region of the domestic cat with an interpretation of the paracondyloid process. 
Kollmani, J. 1904 Der Canalis cranio-pharyngeus. Verh. d. Anat. Ges. Jena, 1904. Anat. Anz., vol. 25.

Kunkfl. 1912 The development of the skull of Emys lutaria. Jour. Morph., vol. 23.

Legal, E. 1883 Die Nasenhöhle und der Thränennasengang der Amnioten Wirbeltiere (Schwein). Morphol. Jahrb., vol. 8.

Levi, G. 1900 Beitrag zum Studium der Entwickelung des knorpeligen Primordialcraniums des Menschen. Arch. f. mikros. Anat., vol. 55. 1908 Studi anatomici ed embriologici sull' osso occipitale. Arch. Ital. d. Anat. e di Embr., vol. 7.

Macalister, A. 1893 Notes on the development and variations of the atlas. Jour. Anat. and Physiol., vol. 32.

Mackirn, C. C. 1914 Skull of a human fetus of $40 \mathrm{~mm}$. Am. Jour. Anat., vol. 16 .

Mead, C. S. 1909 The chondrocranium of an embryo pig, Sus scrofa. Am: Jour. Anat., vol. 9.

Nicola, B. 1906 Sullo svelluppo, sui canali perforanti e sulle fessure della porzione laterale dell' ala magna dell' os sfenoidale nella specie imana. Mem. Accad. Sc. Torino. ser. 2, vol. 56.

Noordexbos, W. Ueber die Entwickelung des Chondrocraniums der Säugetiere. Petrus Camper, vol. 3.

Olmstead, M. 1911 Das Primordialcranium eines Hundeembryo. Anat. Hefte, vol. 43.

OsBonN, H. F. $1900 \mathrm{~A}$ Intercentra and hypophyses in the cervical region of Mosasaurs, lizards and Sphenodon. Am. Nat., vol. 34.

$1900 \mathrm{~B}$ Origin of the mammalia. III. Occipital condyles of reptilian tripartite type. Ain. Nat., vol. 34.

Parker, W. K. 1875 On the structure and development of the skull in the pig. Philos. Trans. Roy. Soc. of London, vol. 164.

1885 On the structure and development of the skull in Urodeles. Trans. Zool. Soc. of London, vol. 11.

Parkir and Bettany, G. T. 1877 The morphology of the skull. Isondon.

Peter, K. 1902 Anlage und Homologie der Muscheln des Menschen und der Sãugetiere. Arch. f. mikr. Anat. u. Entw.-Gesch., vol. 60.

Pohlmans, E. H. 1910 Die embryonale Metamorphose der Physiognomie und der Mundhöhle des Katzenkopfes. Morphol. Jahrb., vol. 41.

Reighard, J. AND J. 1902 Anatomy of the cat. New York.

Retzirs, G. 1884 Das Gehörorgan der Wirbelthiere. II. Das Gehörorgan der Reptilien, der Vögel und der Säugethiere. Stockholm.

Serdel, O. 1891 Iéber die Nasenhöhle der höheren Säugethiere und des Menschen. Morphol. Jahrb., vol. 17.

Srino, K. 1914 Studien zur Kenntnis des Wirbeltierkopfes. Anat. Hefte, vol. 50.

Spence, L. 1890 A comparison of the external and middle ear of man and the cat. Proc. Am. Soc. of Microse., vol. 14.

Spurgat, F. 1896 Beiträge zur verglcichenden Anatomie der Nasen- und Schnauzenknorpel des Menschen und der Tiere. Morphol. Arbeiten, vol. 5 . 
Strauss-Durczheim, H. 1845 Anatomie descriptive et comparative du chat, type des mammifères én general, et des carnivores en particular. Paris.

Suschkis, P. 1895-96 Zur Anatomie und Entwickelungsgeschichte des Schädels der Raubvögel. Anat. Anz., vol. 11.

Swjetschnikow, W. A. 1906 Ueber die Assimilation des Atlas und die Manifestation des Occipitalwirbels beim Menschen. Arch. f. Aart. u. Physiol. Anat. Abt.

Terhy, R. J. 1913 Development of cranium in mammals. Science, vol. 37, (N. S.), p. 994.

Tonxorr, W. 1900 Zur Entwickelungsgeschichte des Hühnerschädels. Anat. Anz., vol. 18.

Troland, P. 1892 Note sur la présance d'un arc osseux dans l'epaiscur du ligament atlanto-occipital posterieur. Comp. rendus, vol. 44.

VaN BrmmelN, J. F. 1900 Monotreme skull. Proc. kon. Akad. Wetensch. Amsterdam.

Van Kampen, N. 1905 Die Tympanalgegend des Säugetierschädels. Morphol. Jahrb., vol. 34 .

VoIt, M. 1907 Zur Frage der Verästelung des Nervus acusticus bei den Säugetieren. Anat. Anz., vol. 31.

1909 Das Primordialcranium des Kaninchens unter Berücksichtigung der Deckknochen. Anat. Hefte, vol. 38.

Von Noorden, W. 1887 Beitrag zur Anatomie der knorpeligen Schə̈delbasis menschlicher Embryonen. Arch. f. Anat. u. Physiol. Anat. Abt.

Vrolik, A. J. 1875 Studien über die Verknöcherung und die Knochen deg Schädels der Teleostier. Niederland. Arch. f. Zool., vol. 1.

VUlpian, A. 1862 Racine postérieur ou ganglionnaire du nerf hypoglosse. Jour. de la Physiologie, vol. 5.

Webrr, Max 1903 Die Säugetiere. Einführung in dic Anatomie und Systematik der recenten und fossilen Mammalia. Jena.

Weigner, K. 1911 Ueber die Assimilation des Atlas und über die Variationen am $\mathrm{O}_{8}$ occipitale beim Menschen. Anat. Hefte, vol. 45.

WEISs, A. 1901 Die Entwickelung der Wirbelsäule der weissen Ratte, besonders der vordersten Halswirbel. Zeitschr. f. wissensch. Zool, vol. 69 .

Wijhe, J. W. van 1902 Eene niewe methode ter demonstratie van kraakbeenige mikroskeletten. Kon. Akad. van Wettenschappen, Amsterdam, 30 April.

Wilder and GAGF 1882 Anatomical technology as applied to the domestic cat. New York.

Williams, L. W. 1908 The later development of the notochord in mammals. Am. Jour. Anat., vol. 8.

WivczA, H. 1896 Ueber einige Fntwickelungsveränderungen in der Gegend des Schädelgrundes bei den Säugethieren. Anz. d. Akad. d. Wissensch. in Krakau.

ZuCKenkandL, C. 1908 Ueber den Jacobson'schen Knorpel und die Ossification des Pflugscharbeines. Sitzungsb. d. Wiener Akad. Wiss., math.naturw. Kl., vol. 117. 


\section{EXPLANATION OF FIGURES}

All figures are from preparations of embryos of the cat, the lengths of which are indicated. With the exception of figures 17 and 18, the drawings are the work of Mr. C. D. Jarrett.

In the model from which figures 1 to $5,12,13$ have been made, cartilaginous parts only are represented on the left side; on the right side, in addition, are shown vessels, nerves and bones. In figures 1 and 2 , the right otic capsule is represented as partly opened. In figure 3 , the incudal cartilage and part of Meckel's cartilage have been omitted. Figures 15 to 30 are camera lucida drawings of the sections represented. Figures 19 to 30 are from sections of the 23.1 $\mathrm{mm}$. embryo (H. E. C. Series 466); the number of the section is indicated in each fiqure.

Fig. 1 From a model of the cranium of an embryo $23.1 \mathrm{~mm}$. long (II. E. C. Series 466) Dorsal aspect, $\times 2_{1}^{3}$.

Fig. 2 The same; ventral aspect.

Fig. 3 The same; left lateral aspect.

Fig. 4 The same; right lateral aspect.

Fig. 5 Frow a van Wijhe preparation of the head of an embryo $10.5 \mathrm{~mm}$. long (W. A. C. No. 310). Dorsal aspect, $\times{ }_{1}^{21}$.

Fig 6 From a van Wijhe preparation of the head of an embryo $12 \mathrm{~mm}$. long (W. A. C. No. 311). Left side and base seen from the right, $\times 13$.

Fig. 7 From a van Wijhe preparation of the head of an embryo $15 \mathrm{~mm}$. long (W. A. C. No. 312). Dorsal aspect, $\times{ }^{13}$. The breadth of this is somewhat exaggerated, the ala temporalis being ton far toward the side.

Fig. 8 From van Wijhe preparations of the heads of embryos $18-20 \mathrm{~mm}$. long (W. A. C. Nos. 313, 314). Dorsal aspect, $X{ }_{1}{ }_{1}^{1}$.

Fig. 9 From a van Wijhe preparation of the head of an embryo $24 \mathrm{~mm}$. long (W1. A. C. No. 315). Right occipital and otic regions seen from the left. In this, as in all the van Wijhe preparations, the cochlear capsule is for the most part only lightly stained. $\times 1_{1}^{2}$.

Fig. 10 From a model of the left otic capsule of an embryo $23.1 \mathrm{~mm}$. long (H. E. C. Series 466). The large, cut surface is in a frontal plane through the middle of the vestibule. Dorsal and medial aspect, $\times \frac{2 k}{1}$.

Fig. 11 The same as figure 10, excepting the level of the cut surface, which is at the ventral part of the vestibule.

Fig. 12 Region of the foramen rotundum as it appears in the model of the $23.1 \mathrm{~mm}$. embryo. Ventral and caudal aspect, $\times{ }_{1}^{20}$.

Fig. 13 Ethmoidal skeleton; from the model of the $23.1 \mathrm{~mm}$. embryo. Represents the left half from its medial aspect, the septal cartilage being omitted and the nasal tectum, laminae transversales and lamina infracribrosa sectioned just to the left of and parallel with the median plane. $\times{ }_{1}^{23}$.

Fig. 14 From a model of the basal plate and epistropheus in median section showing the course of the notochord. Embryo $23.1 \mathrm{~mm}$. long. $\times \frac{20}{\mathrm{~T}}$.

Fig. 15 Transverse section through the occipital region. Embryo $10.6 \mathrm{~mm}$. long (H. F. C. Series 476, sect. 300). $\times \frac{17}{1}$. 
Fig. 16 Frontal section through base of orbito-temporal region. Embryo $12 \mathrm{~mm}$. long (H. E. C. Series 403, sect's. 200-207). $\times{ }^{15}$.

Fig. 17 Median sagittal section through base of cranium. Embryo $12 \mathrm{~mm}$. long (H. E. C. Series 400). $\times{ }_{i}^{29}$.

Fig. 18 Median sagittal section through base of cranium. Embryo $15 \mathrm{~mm}$. long (H. E. C. Series 437, sect's. 158, 161, 169). $\times \frac{29}{1}$.

Fig. 19 Frontal section through occipital and otic regions. (Sect. 246). $\times$. $\times \frac{13}{1}$.

Fig. 20 Frontal section through occipital and otic regions. (Sect. 253).

Fig. 21 Frontal section through the otic region. (Sect. 256). $\times 23$.

Fig. 22 Frontal section through the otic region. (Sect. 273), $\times 11^{2}$.

Fig. 23 Transverse section through the orbito-temporal region. (Sect. 300). $\times 1 x^{3}$.

Fig. 24 Transverse section through the orbito-temporal region. (Sect. 339). $\times$ s.

Fig. 25 Transverse section through the orbito-temporal and ethmoidal regions. (Sect. 385). $\times 2{ }^{5}$.

Fig. 26. The same as in figure 25 but further forward. (Sect. 404). $\times{ }_{1}^{15}$.

Fig. 27 Transverse section through the ethmoidal region. (Sect. 457). $\times \frac{1}{1}$.

Fig. 28 Transverse section through the ethmoidal region. (Sect. 489). $\times 13$. $\times \frac{23}{13}$.

Fig. 29 Transverse section through the ethmoidal region. (Sect. 492).

Fig. 30 Transverse section through the ethmoidal region. (Sect. 513). $\times \frac{13}{1}$.

\section{ABBREVIATIONS}

$V I$, abducent nerve

$X I$, accessory nerve

Ac.fis., acustic fissure

VIII, acustic nerve

Al.orb., ala orbitalis

Al.temp., ala temporalis

Alar., alar element

Amp.a., ampulla anterior

Amp.l., ampulla lateralis

Amp.p., ampulla posterior

Ant.pl., antorbital plane

Aq.coc., aquaeductus cochleae

Pr.at., atlantal process

At., atlas

Atrt., atrioturbinale

Bas.pl., basal plate

Can.sem.ant., canalis semicircularis

anterior

Can.sem.lat., canalis semicircularis

lateralis
Can.sem.post., canalis semicircularis posterior

Car.for., carotid foramen

Cavepipt., cavum epiptericum

Cav.coc., cavum cochleae

Cav.nas., cavum nasi

Cav.vest.ant., cavum vestibulare anterius

Cav.vest.post, cavum vestibulare posterius

Cent.at., centrum of atlas

Cent.ep., centrum of epistropheus

Ch.tym., chorda tympani

Co.cap., cochlear capsule

Co.d., cochlear duct

Com.alic., commissura alicochlearis

Com.bas., commissura basicochlearis

Com.basiv., commissura basivestibularis

Com.el., commissural element 
Com.orb.-par., commissura orbito-parietalis

Com.p.-cap., commissura parieto-capsularis

Com.sph.eth., commissura spheno-ethmoidalis

Com.supr.f., commissura suprafacialis

Cr.int.orb., crista interorbitalis

Cr.intervest., crista intervestibularis

Cr.par., crista parotica

Cr.sem., crista semicircularis

Cr.trans., crista transversa

Den., dens epistrophei

Dent., dentale

Dor.se., dorsum sellae

D.co., ductus cochlearis

D.sem.a., ductus semicircularis anterior

D.sem.l., ductus semicircularis lateralis

D.sem.p., ductus semicircularis posterior

Endl.d., endolymphatic duct

$E p$., epist ropheus

Eth. I, ethmoturbinal I

Eth. $I I$, ethmoturbinal II

Ext.meat., external auditory meatus

Oc., eyeball

VII, facial nerve

Fen.acust., fenestra acustica

Fen.bas., fenestra basalis

Fen.bas,post., fenestra basicranialis posterior

Fen.nar., fenestra narina

Fen.olf., fenestra olfactoria

Fen.sphen.-par., fenestrs spheno-parietalis

Fen.vest., fenestra vestibuli

Fis.alicoch., fissura alicochlearis

Fis.bas.post., fissura basicochlearis posterior

Fis.orb.-eth., fissura orbito-ethmoidalis

For.co., foramen cochlese

For.endl., foramen endolymphaticum

For.epiph., foramen epiphaniale

For.fac., foramen faciale

For.hyp., foramen hypophyseos

For.jug., foramen jugulare

For.jug.sp., foramen jugulare spurium

For.mag., foramen occipitale magnum

For.peril., foramen perilymphaticum

For.rot., foramen rotundum
Fos.inc., fossa incudis

Fos.oc-can., fossa occipito-canalicularis

Front., frontal bone

Gen.gang., geniculate ganglion

$I X$, glossopharyngeal nerve

Gr.sup., great superficial petrosal nerve

Hi.sem., hiatus semilunaris

Hyp.ar.at., hypochordal arch of atlas

Hyp.can., hypoglossal canal

$X I I$, hypoglossal nerve

Hyph.can., hypophyseal canal

Hyph.cart., hypophyseal cartilage

Hyph., hypophysis

Inciv., incisive bone

Inciv.d., incisive duct

Inc.lac., incisura lacera

Inc.lacr., incisura lacrimalis

Inc.max.atr., incisura maxillo-atrioturbinalis

Inc.occ.ant., incisura occipitalis anterior

Inc.occ.post., incisure occipitalis posterior

Inc.oval., incisura ovalis

Inc.posttr., incisura postransversalis.

Inc.sing., incisura singularis

Inc.cart., incudal cartilage

Inf.ac.for., inferior acustic foramen

Inf.obl.m., inferior oblique muscle

Infr.n., infraorbital nerve

Int.car.art., internal carotid artery

$J . O$., Jacobson's organ

Jug.v., jugular vein

Lam.ant., lamina antorbitalis

Lam.asc., lamina ascendens

Lam.infracr., lamina infracribrosa

Lam.par., lamina parietalis

Lam.suprch., lamina supraconchalis

Lam.trans.ant., lamina transversalis anterior

Lam.trans.post., lamina transversalia posterior

Lat.m.at., lateral mass of atlas

Lat nas.gl., lateral nasal glands

Lat.nas.n., lateral nasal nerve

Lat.occ., Iateral occipital arch

Mand.cond., mandibular condensation of ala temporalis

Mand..n, mandibular nerve 
$M$, massa angularis

Mast., masseter muscle

Max., maxillary bone

Max.cond., maxillary condensation of ala temporalis

Max.n., maxillary nerve

Maxturb., maxilloturbinal

Meat.ac.int., meatus acusticus internus

Meat.inf., meatus inferior of the nose

Meat.s., meatus supraconchalis

Meck., Meckel's cartilage

Memb.lim., membrana limitans

Met.opt., metoptic root

Mo., mouth

N.L.D., naso-lacrimal duct

Nas.ph.d., nasopharyngeal duct

Nasturb., nasoturbinal

Neu.ar.al., neural arch of atlas

Neu.ar.ep.. neural arch of epistropheus

Noto., notochord

Cond.occ., occipital condyles

III, oculo-motor nerve

Olf., olfactory nerve

Oph., ophthalmic nerve

Op.for., optic foramen

$I I$, optic nerve

$P a l$, palate bone

Pal.max., palate process of maxilla

Para.pl., parachordal plate

Parna.cart., paranasal cartilage

Para.cart., paraseptal cartilage

Par.nas., paries nasi

Par.-tect., parieto-tectal cartilage

Pa.atr., pars atrialis

Pa.can., pars canalicularis

Pa.co., pars cochlearis

Pa.lac., pars lacrimalis

Phary.pch., pharyngeal pouch I

Pl.suprch.. planum supracochleare

Post.cup., posterior cupola

P.opt., preoptic root

Prc.al., processus alaris

Prc.max.ant., processus maxillaris anterior

Prc.orb., processus orbitalis

Prc.para., processus paracondyloideus

Prc.pty., processus pterygoideus

P'rm.lat., prominentia lateralis

Prm.utr., prominentia utricularis
Prm.ut.inf., prominentia utriculo-ampullaris inferior

Prm.ut.sup., prominentia utriculo-ampullaris superior

Pty.cart., pterygoid cartilage

Pty.n., pterygoid nerve

Pty.m., pterygoid muscle

Rec.amp.ant., recessus ampullaris anterior

Rec.amp.post., recessus ampullaris posterior

Rec.lat., recessus lateralis

Rec.lat.inf., recessus lateralis inferior

Rec.lat.sup., recessus lateralis superior

Reich., Reichert's cartilage

Sac., sacculus

Sel.tur., sella turcica

Sem.gang., semilunar ganglion

Sept., septal cartilage

Sep.sp., septum spirale

Sept.tr., septum transversum

Sph.-orb.fis., spheno-orbital fissure

Sph.p.gang., sphenopalatine ganglion

Sp.N.I, Spinal Nerve I

Sp.N.II, Spinal Nerve II

Sq., squamosal

St., stapedial cartilage

Stp.m., stapedius muscle

Sulc.ch., sulcus chiasmaticus

Sulc.fac., sulcus facialis

Sulc.lat.ant., sulcus lateralis anterior

Sulc.lat.post., sulcus lateralis posterior

Sulc.sig., sulcus sigmoideus

Sulc.sp., sulcus spiralis

Sulc.suprach., sulcus supraconchalis

Sulc.supr.: sulcus supraseptalis

Sup.ac.for., superior acustic foramen

Tect.nas., tectum nasi

Tect.post., tectum posterius

Temp.m., temporal muscle

Trab., trabecular platc

$V$, trigeminal nerve

$I V$, trochlear nerve

Tub.eph., tuberculum ephippii

Tub.jug., tuberculum jugulare

$X$, vagus

Vert.a., vertebral artery

Vo., vomer

$U t r .$, utriculus

$Z y g .$, zygomatic bone 


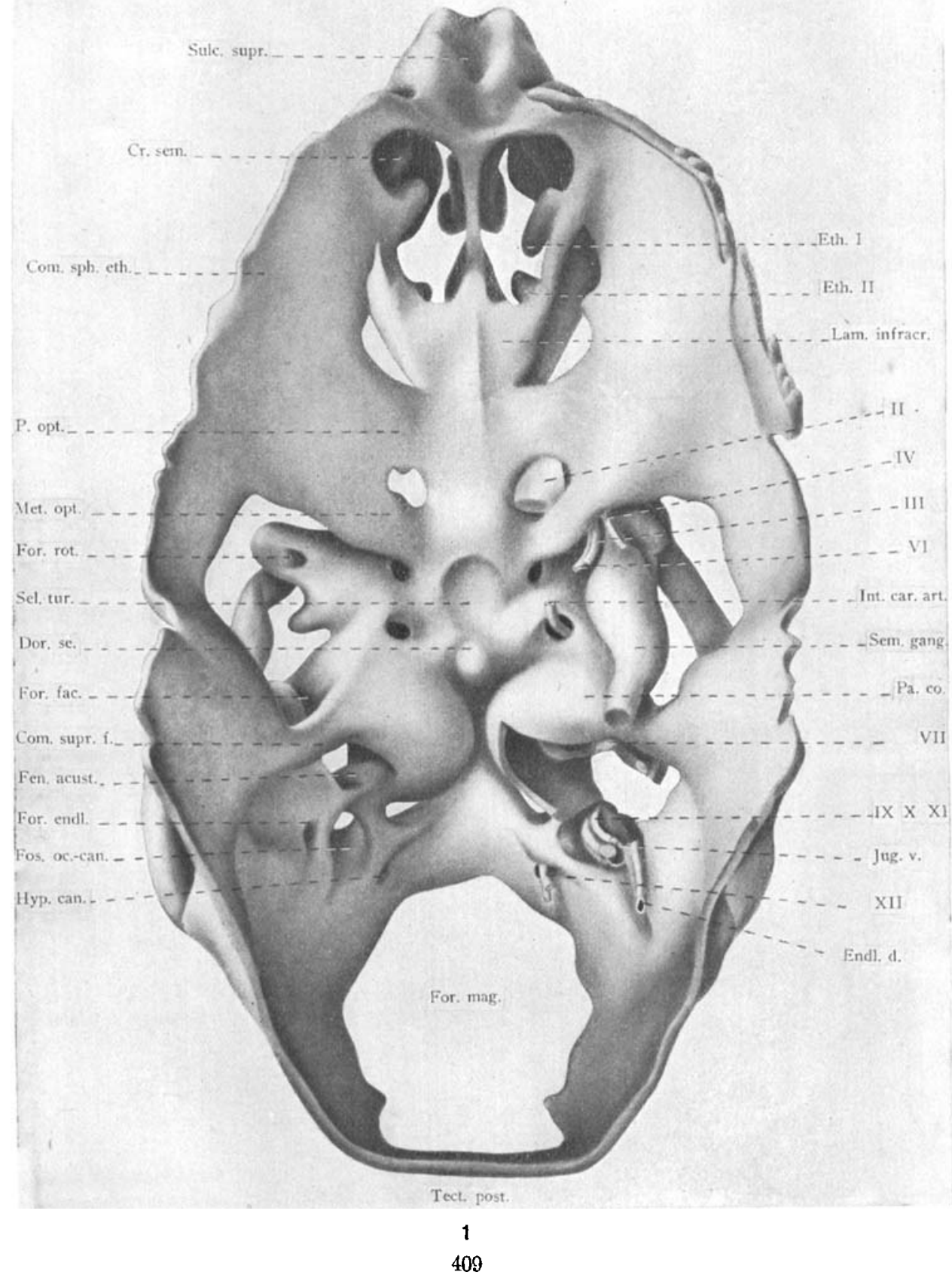

JOURNAL OF MORPHOLOGY, VOL. 29, NO.'2 


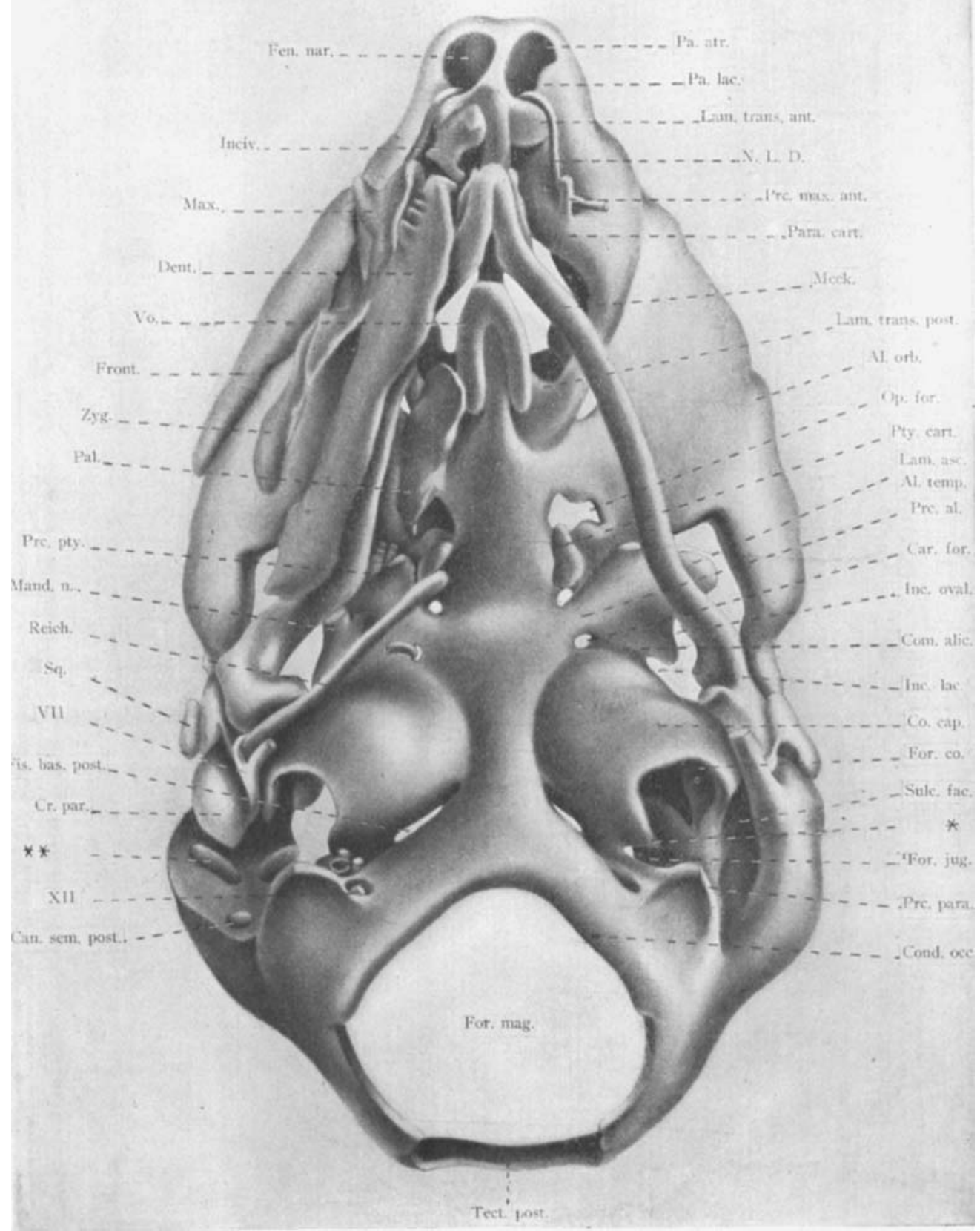



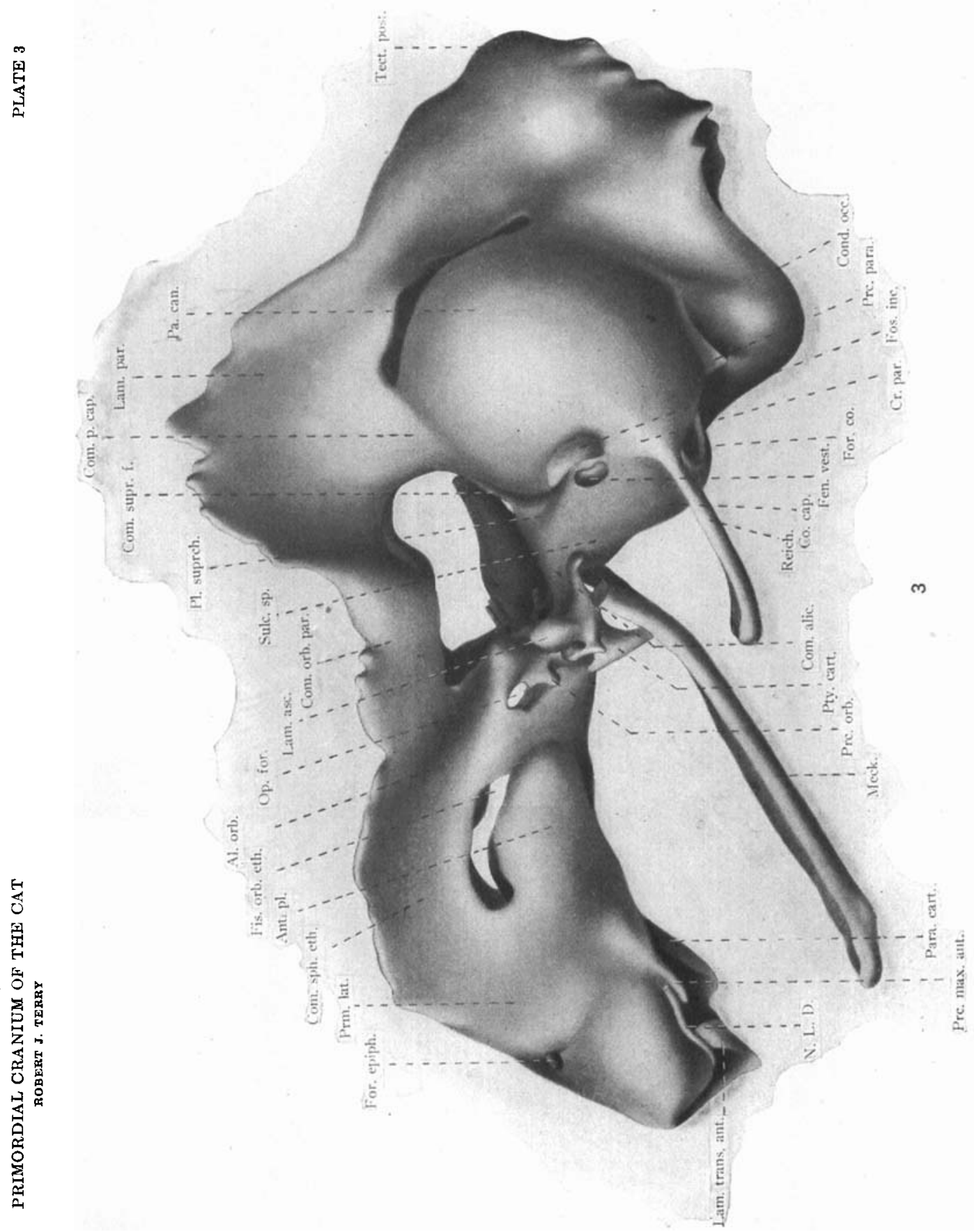
皇

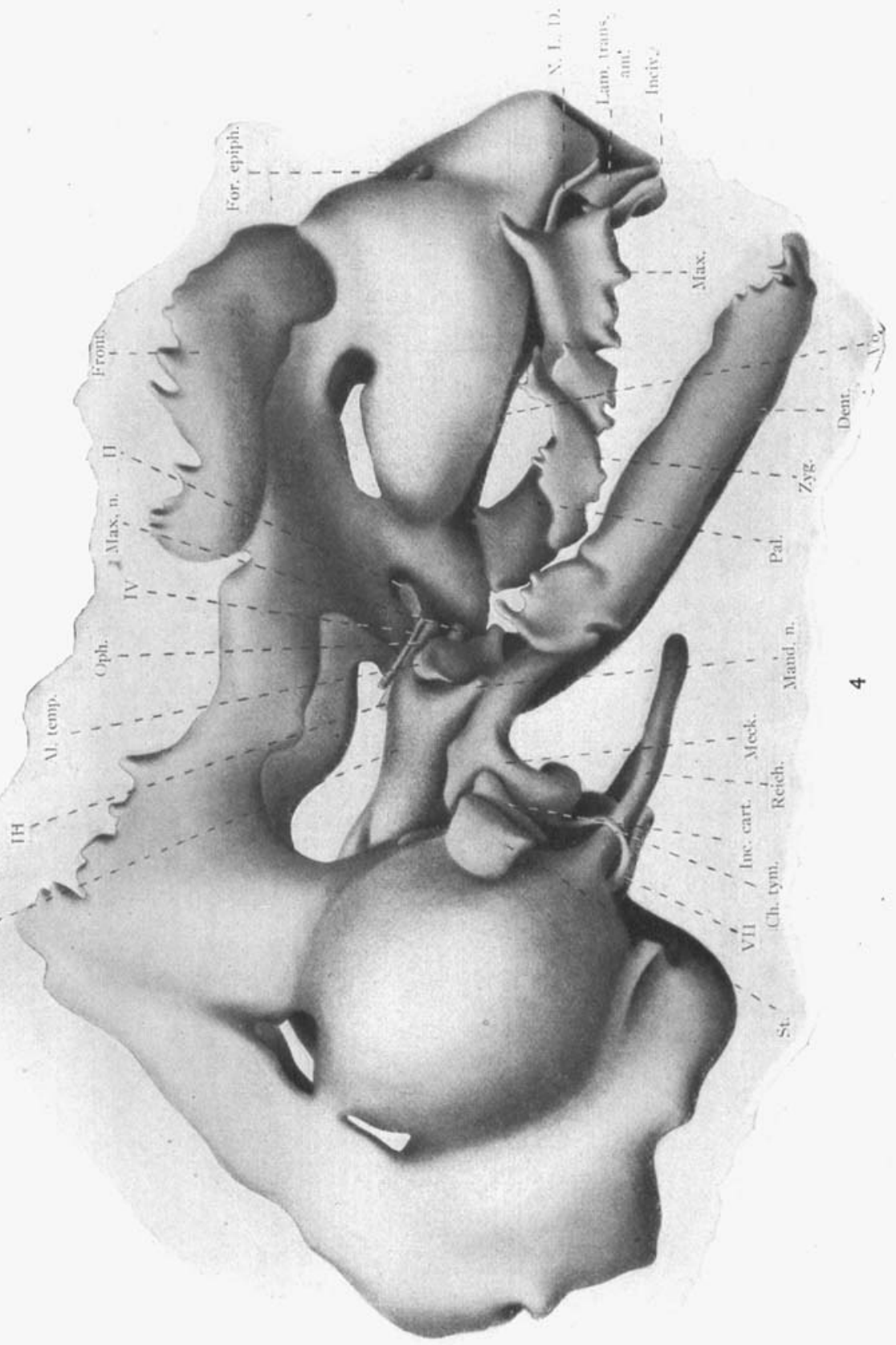

415 


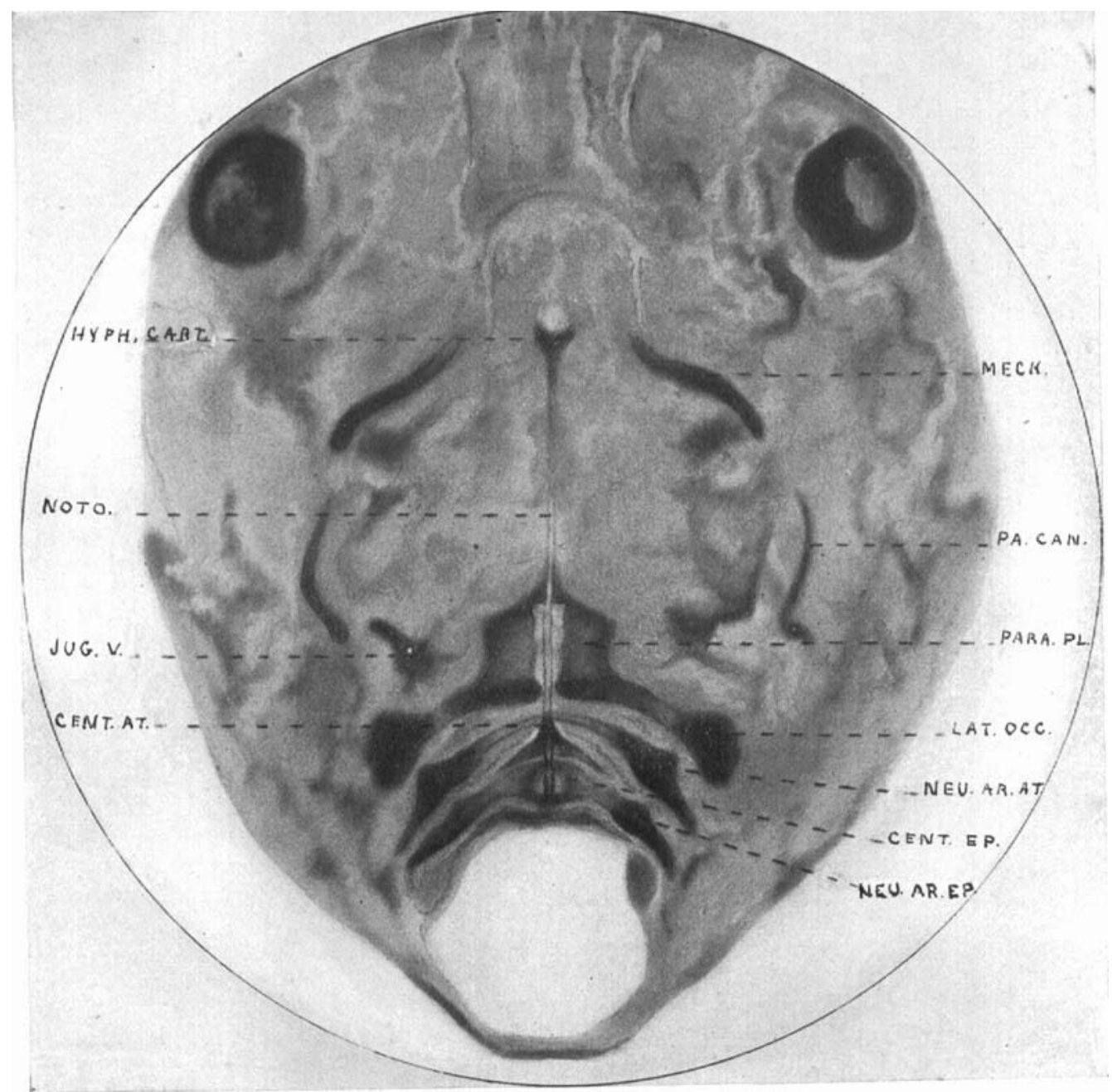



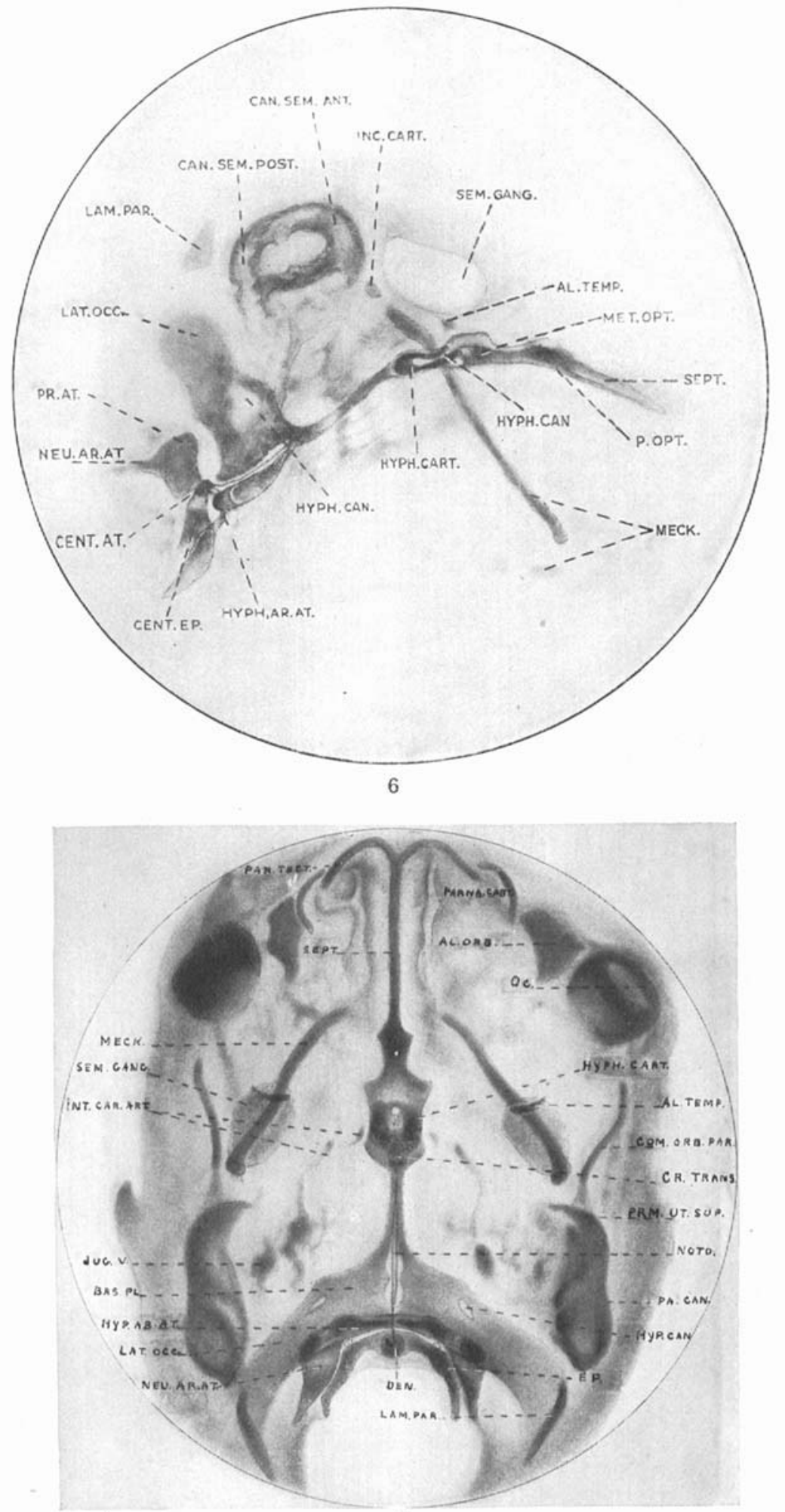
ROBERT J. TERRY
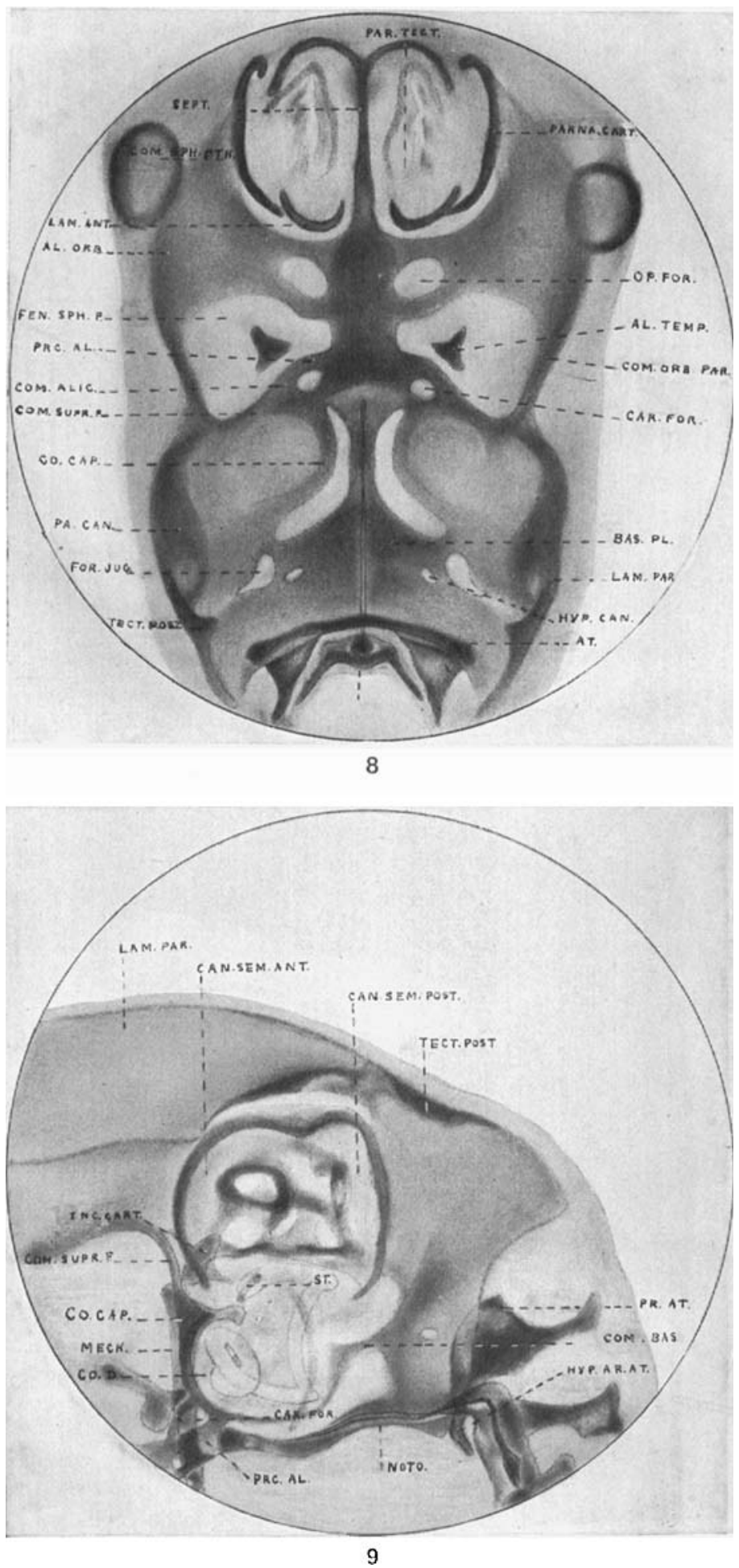
PRIMORDIAI, CRANILM OF THE CAT

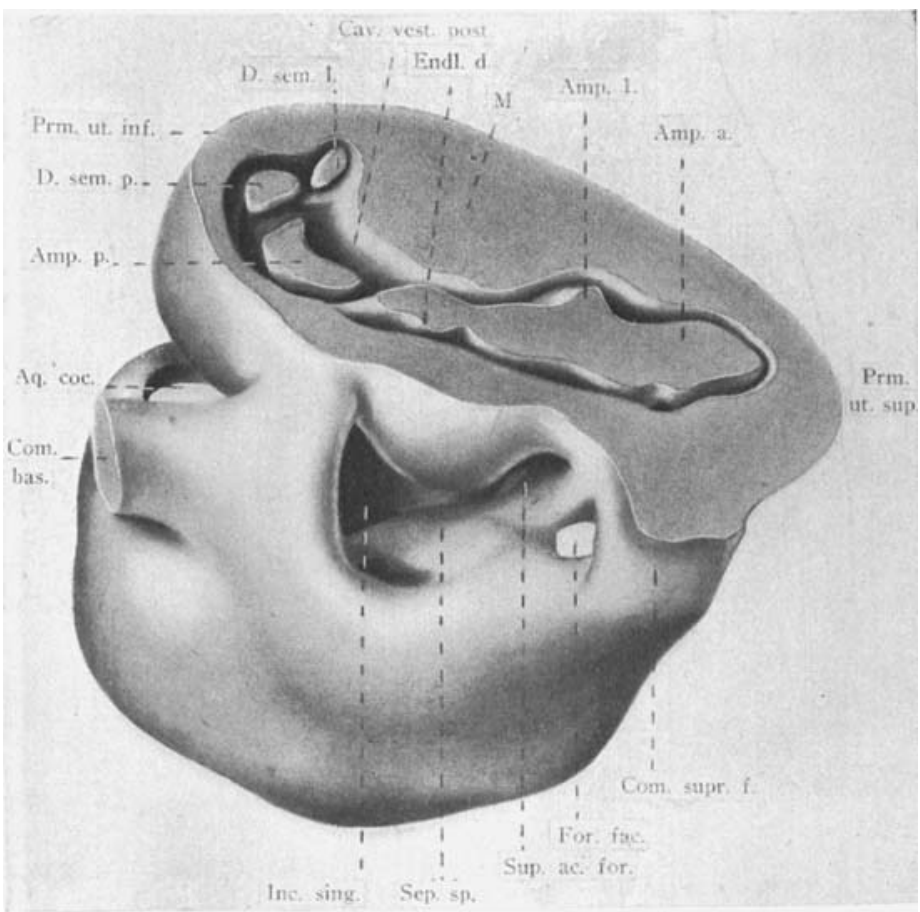

10

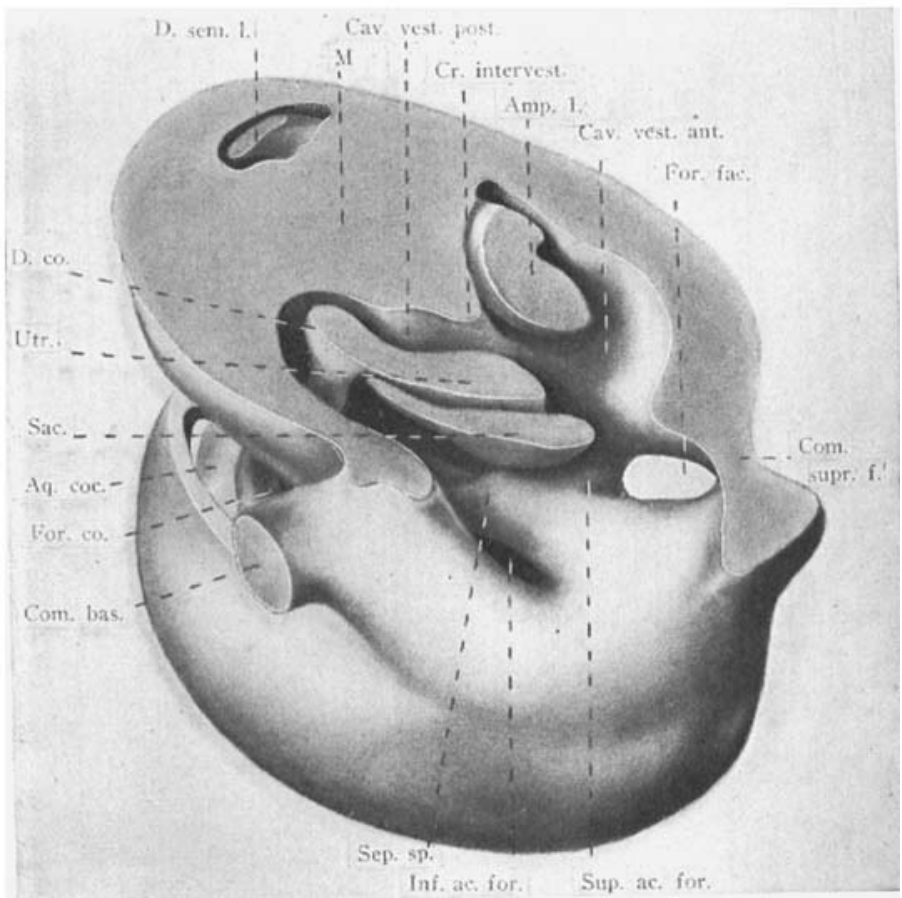




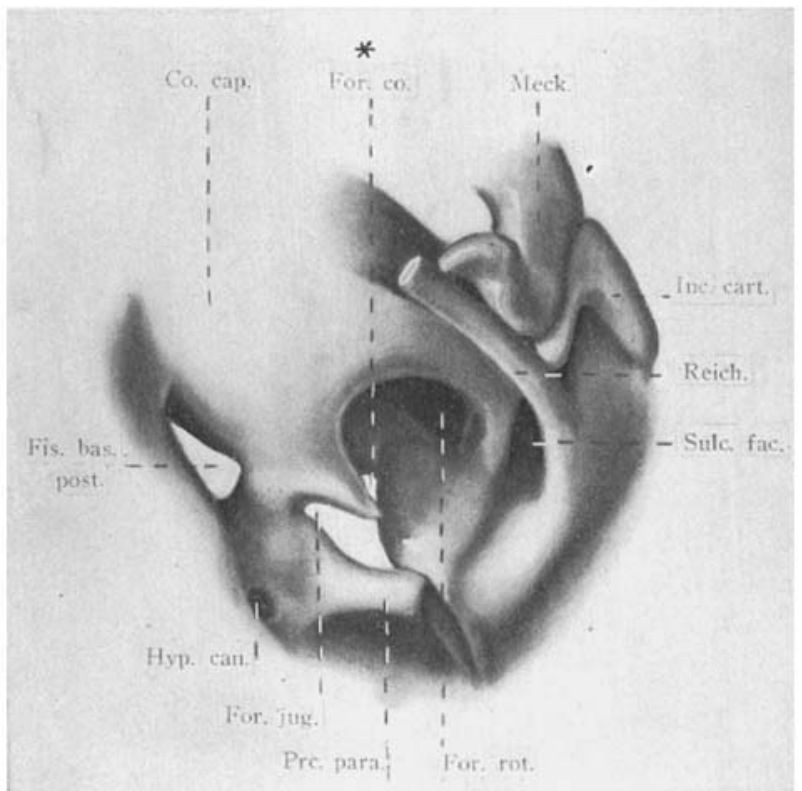

12

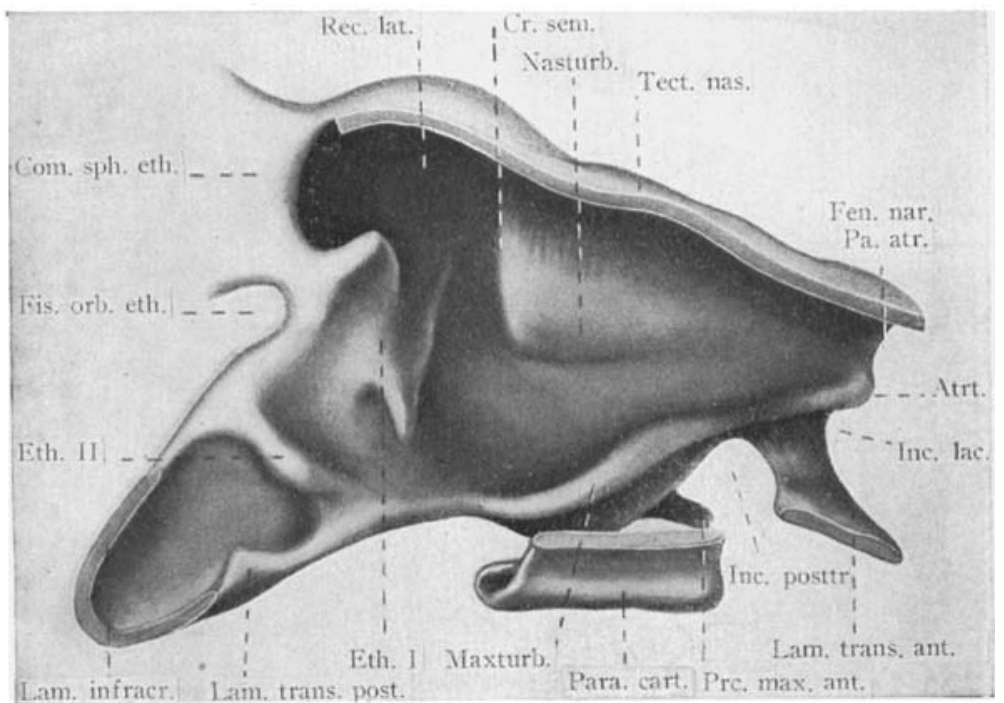

JOURNAL OF MORPHOTOKY, VOI.. 29, NO, 2 

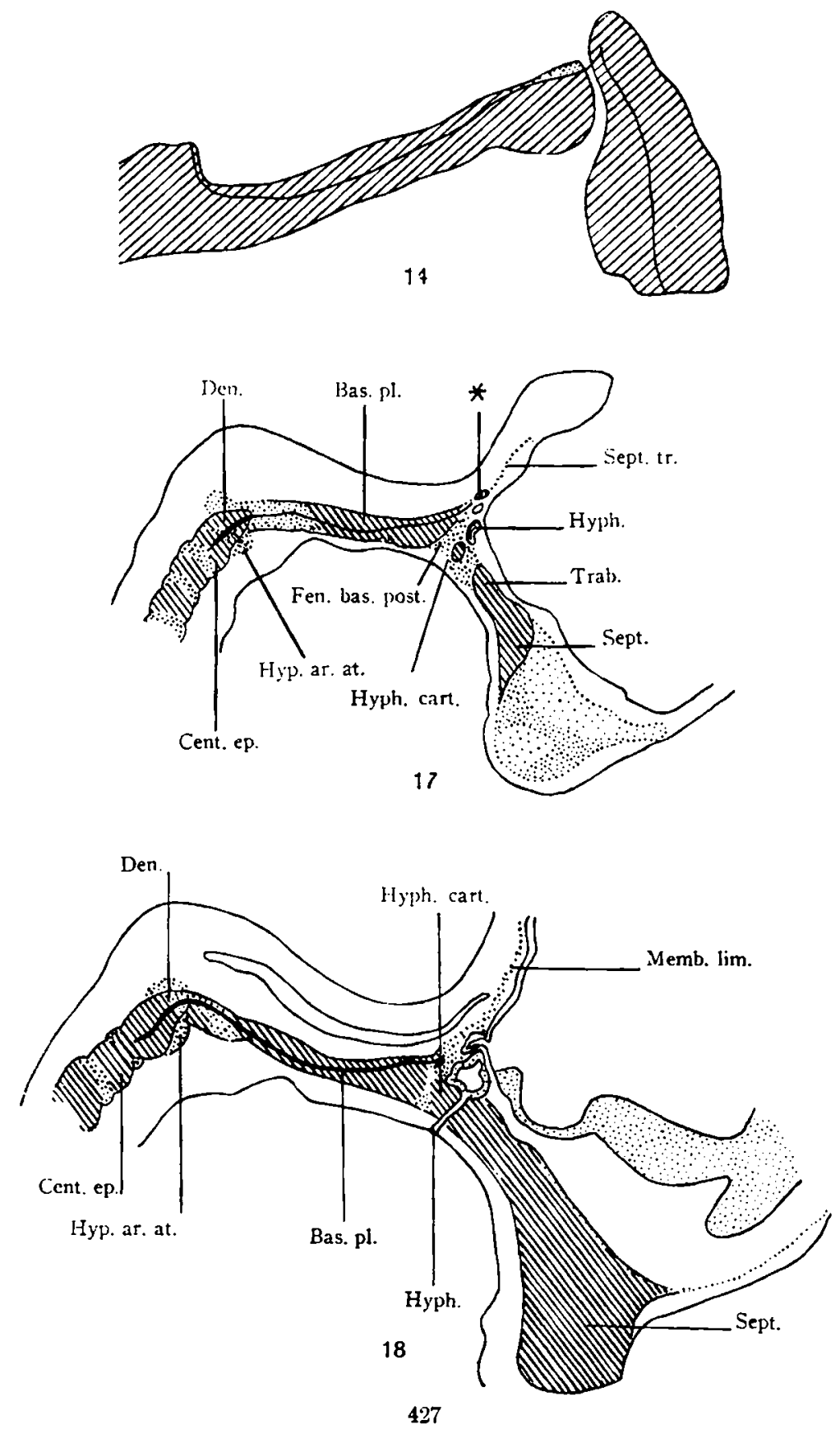

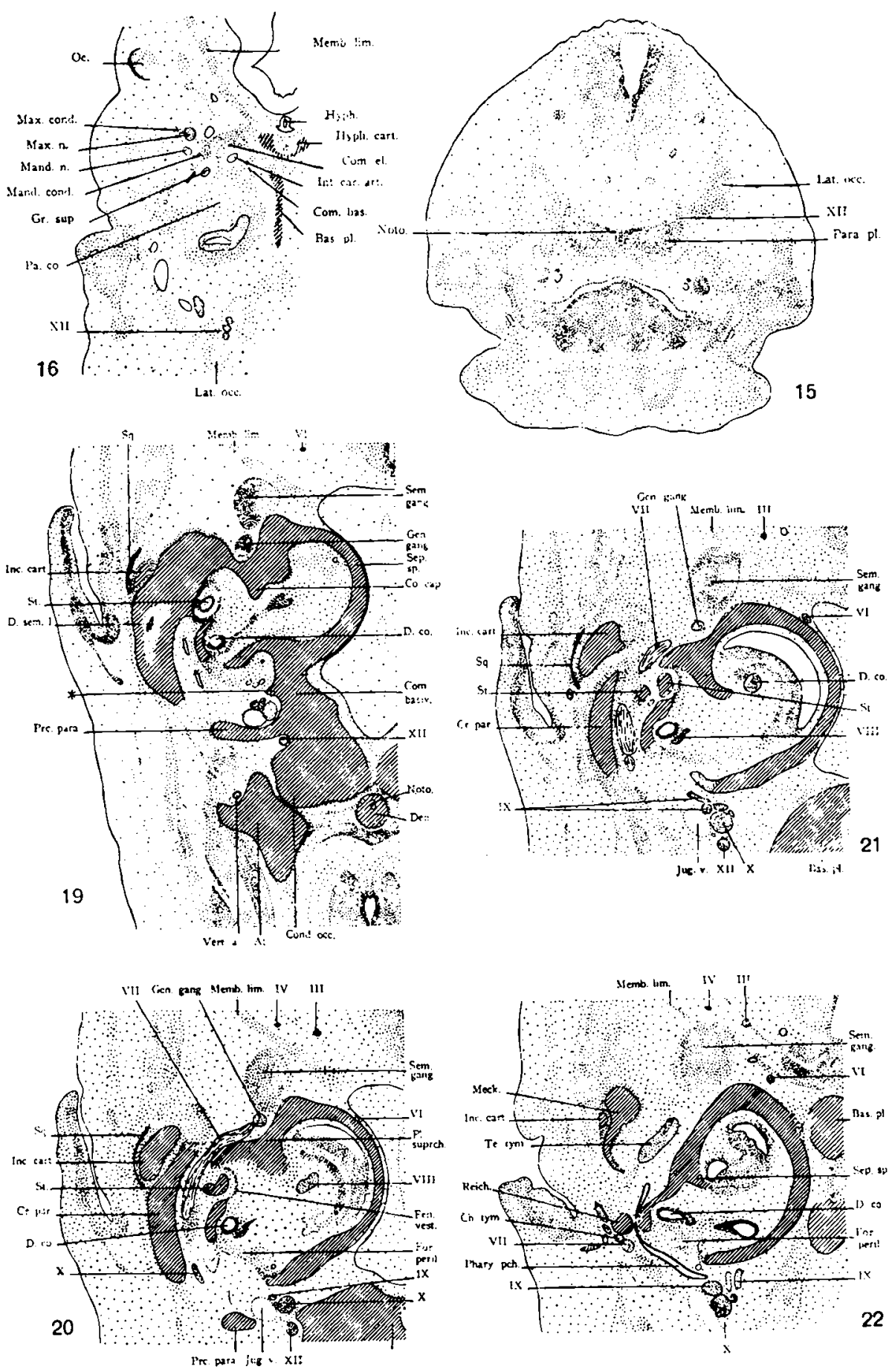
ROFERT J. TEKKY
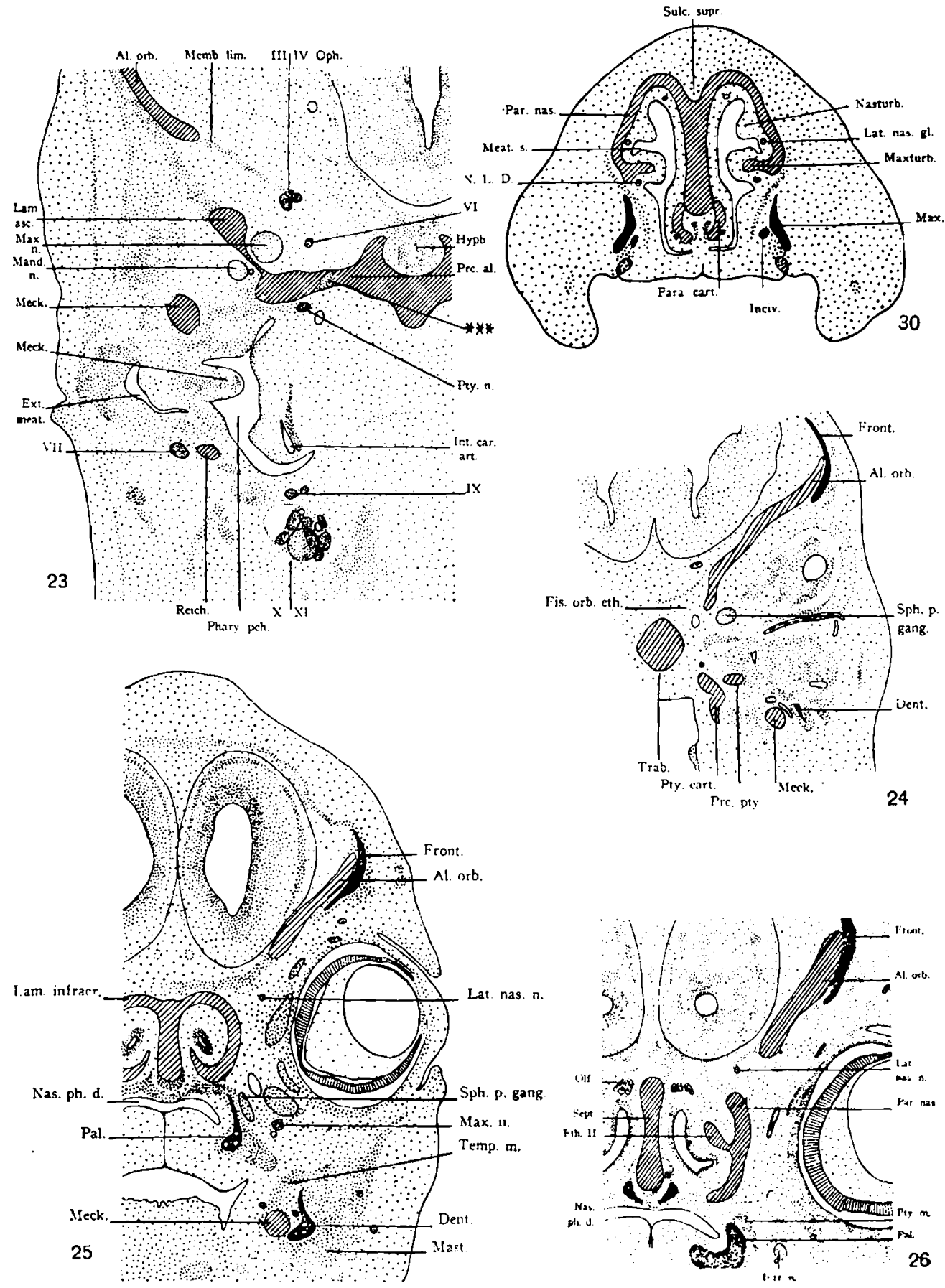
PRIMURDIAL CRANILM OF THL CIT
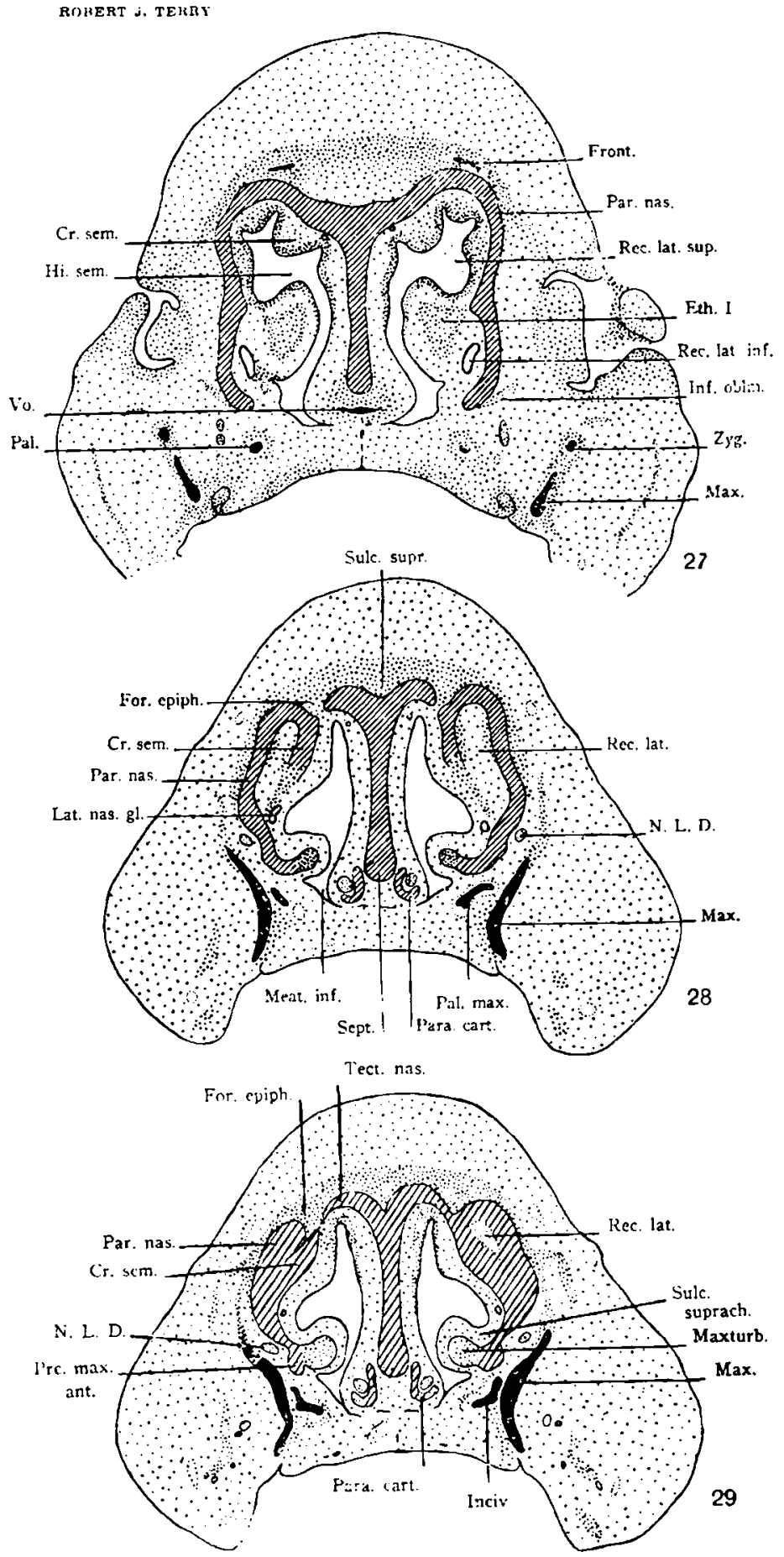